REVISTA DE PSICOLOGÍA

VOLUMEN 9, NÚMERO 3, NÚMERO SUPLEMENTARIO 2019 



\section{REVISTA DE PSICOLOGÍA VOLUMEN 9, NÚMERO 3 SUPLEMENTARIO}

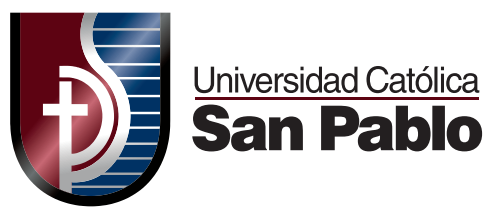

AREQUIPA, 2019 


\section{DIRECTOR EDITOR}

Walter L. Arias Gallegos. Universidad Católica San Pablo (Perú)

COMITÉ EDITORIAL

Lorena Diez Canseco Briceño. Universidad Católica San Pablo (Perú)

Marcio Soto Añari. Universidad Católica San Pablo (Perú)

Jorge Olaechea Catter. Pontificia Universidad Gregoriana (Italia)

Jean-Paul Swinnen. Pontificia Universidad Católica Argentina (Argentina)

Ermanno Pavesi. Gustav-Siewerth-Akademie di Weilheim-Bierbronnen (Suiza)

Mitchell Clark. Mount Royal University (Canadá)

COMITÉ DE REVISORES NACIONALES:

Ramón León Donayre. Universidad de Lima (Lima)

Santiago Cueto Caballero. Pontificia Universidad Católica del Perú (Lima)

Federico León. Universidad del Pacífico (Lima)

Charles Portilla Revollar. Universidad Católica de Santa María (Arequipa)

Aymé Barreda Parra. Universidad Nacional de San Agustín (Arequipa)

Edwin Salas Blas. Universidad San Martín de Porres (Lima)

Ricardo Canales. Universidad Nacional Mayor de San Marcos (Lima)

Flor Vilches Velásquez. Universidad Católica de Santa María (Arequipa)

Carlos Ponce Díaz. Universidad Inca Garcilaso de la Vega (Lima)

Aníbal Meza. Universidad San Ignacio de Loyola (Lima)

Jenny Quezada. Universidad Femenina del Sagrado Corazón (Lima)

Gina Chávez Ventura. Universidad Privada del Norte (Trujillo)

Paula Delgado Cuzzi. Universidad Católica San Pablo (Arequipa)

César Merino Soto. Universidad San Martín de Porres (Lima)

Gabriela Cáceres Luna. Universidad Católica San Pablo (Perú)

Juan Carlos Rios Toce. Aurea Consulting (Perú)

COMItÉ DE REVISORES INTERNACIONALES:

Sara Fernández Guinea. Universidad Complutense de Madrid (España)

Ana María Jacó-Vilela. Universidade do Estado do Rio de Janeiro (Brasil)

Marcos Ríos Lago. Universidad nacional de Educación a Distancia (España)

Hugo Klappenbach. Universidad Nacional de San Luis (Argentina)

María Regina Maluf. Universidade de São Paulo (Brasil)

Norman López Velásquez. Universidad de Los Lagos (Chile)

David de Noreña Martínez. Universidad Nacional de Educación a Distancia (España)

Manolete Moscoso. University of South Florida (Estados Unidos)

María Cristina Richaud. CIIPME (Argentina)

Oscar Veliz García. Universidad Católica del Norte (Chile)

Jorge Valencia Ríos. Universidad de Antioquia (Colombia)

María Andrea Piñeda. Universidad Nacional de San Luis (Argentina)

Gilberto Oviedo. Universidad de los Andes (Colombia)

María Gracia Murillo Deglane. Glendale Community College (Estados Unidos)

José Emilio García. Universidad Católica de Asunción (Paraguay)

Juan Carlos Tuppia. Pontificia Universidad Gregoriana (Italia)

\section{Universidad Católica}

San Pablo

TRADUCCIÓN

Mitchell Clark

DISEÑO Y DIAGRAMACIÓN

José Luis Vizcarra Ojeda

(C) Departamento de Psicología

Facultad de Ciencias Económico Empresariales y Humanas

Universidad Católica San Pablo

Campus Campiña Paisajista s/n. Quinta Vivanco. Arequipa (Perú).

Teléfono (+51 54) 605630, anexo 362 / warias@ucsp.edu.pe

Hecho el depósito legal en la Biblioteca Nacional del Perú $\mathrm{N}^{\circ}$ 2011-11207

Impreso en Joshua V\&E S.A.C. Calle Angamos $N^{\circ} 118$ Urb. María Isabel Cercado - Arequipa.

No está permitida la reproducción parcial o total de esta obra a excepción de lo contemplado en el decreto legislativo 822 . 


\section{ÍNDICE}

\section{PRESENTACIÓN}

Walter L. Arias Gallegos

\section{INVESTIGACIONES}

CALIDAD DE VIDA PROFESIONAL Y APRENDIZAJE ORGANIZACIONAL EN TRABAJADORES

DE UN RESTAURANTE DE LIMA

Katerine Santiago Aranda y Mario Reyes Bossio

CLIMA ORGANIZACIONAL Y RENDIMIENTO LABORAL EN SERVIDORES ADMINISTRATIVOS DE UNA UNIVERSIDAD PÚBLICA DE LA CIUDAD DE AREQUIPA

José Miguel Calizaya López y Rildo Santos Bellido Medina

HACIA DESCRIPCIONES NÍTIDAS DE LA CULTURA ORGANIZACIONAL

Federico R. León, Oswaldo Morales, Oswaldo Otoya, Antonio Romero, Ángela de la Cruz y Fiorella Sarria

Clima afectivo para el trabajo COOPERATIVO DE DOCENTES DE LIMA

Doris Elida Fuster Guillén, Liliana Aldazábal Melgar,

Sara Tello Cabello, Patricia Guillén Aparicio

y Ronald M. Hernández 


\section{ARTÍCULOS}

CONSTRUCCIÓN DEL SENTIDO DESDE LAS NARRATIVAS

DE LOS MIEMBROS DE UNA ORGANIZACIÓN

Eduardo Escalante, Ignacio Fernández y Pía Cordero

¿QUÉ HACE A UNA DECISIÓN BUENA? CRITERIOS

DE TOMA DE DECISIONES EN EL MANAGEMENT CIBERNÉTICO

Gonzalo Flores-Castro Lingán

\section{RESEÑAS}

¿QUÉ SABEMOS ACERCA DE LA INVESTIGACIÓN

LATINOAMERICANA EN PSICOLOGIIA ORGANIZACIONAL?

Tomás Caycho Rodríguez

HISTORIAS DE LA PSICOLOGÍA

COMENTARIO:

SiNTÉTICA HISTORIA DE LA PSICOLOGÍA

organizacional en el Perú

135

Arturo Orbegoso Galarza 


\section{PRESENTACIÓN}

En esta oportunidad la Revista de Psicología de la Universidad Católica San Pablo, presenta un tercer número del noveno volumen del año 2019, que tiene como primera particularidad, que es un número monográfico dedicado a la psicología organizacional. Esta es la tercera vez que se publica un número monográfico, siendo la primera en el primer número del año 2015 cuando se editó un monográfico en historia de la psicología, y la segunda en el primer número del año 2016 sobre la temática de emociones positivas y virtudes humanas. Una segunda particularidad es que, se trata de un ejemplar suplementario y el tercero del año, pues de aquí en adelante se tiene previsto que los números monográficos se publiquen como ediciones suplementarias de la revista.

El hecho de haber escogido una temática organizacional, se debe a la cantidad de trabajos en esta rama de la psicología que han llegado a nuestra redacción, ello como respuesta a una convocatoria lanzada previamente. Pero, por otro lado, también se debe a la relevancia de esta temática y a la creciente difusión de que goza hoy en día en el Perú. Solo la revista Liberabit publicó el año 2002 un monográfico sobre esta temática en nuestro país. Por otro lado, en la Universidad Nacional Mayor de San Marcos se ofrece desde el año 2014 la carrera de Psicología Organizacional y de la Gestión Humana, además se publican cada vez más en el Perú, artículos de investigación en riesgo psicosocial en el trabajo y comportamiento organizacional. Arequipa no es ajena a esta realidad, ya que la psicología organizacional es una de las líneas de investigación más fortalecida gracias al aporte de diversos colegas regionales que trabajan estos temas.

Pues bien, en este número tenemos cuatro investigaciones empíricas y dos artículos de revisión, además de las secciones de reseñas e historias de la psicología, también dedicadas a la psicología organizacional. De este modo, un primer artículo es presentado por Katerine Santiago Aranda y Mario Reyes Bossio, quienes analizan la relación entre la calidad de vida profesional y el aprendizaje organizacional en una muestra de trabajadores de un restaurante de la ciudad de Lima. En segundo lugar, José Calizaya López y Rildo Bellido Medina nos presentan un estudio comparativo y correlacional, en el que analizan las manifestaciones del clima organizacional y el rendimiento laboral en el personal administrativo de una universidad de Arequipa, según el sexo, cargo y condición laboral de los trabajadores; y luego correlacionan ambas variables. 
Un tercer trabajo presentado por Federico León, uno de los más importantes psicólogos organizacionales de Perú, quien junto a sus colaboradores describen a través de dos estudios empíricos, las dimensiones de la cultura organizacional según el modelo de Cameron y Quinn. En cuarto lugar, Doris Fuster Guillén y sus colaboradores presentan un estudio correlacional sobre el clima afectivo y el trabajo cooperativo en una muestra de docentes peruanos.

Como parte de los estudios teóricos, Eduardo Escalante, Ignacio Fernández y Pía Cordero nos presentan un análisis de la construcción del sentido desde las narrativas de los miembros de una organización sobre la base del modelo teórico de Snowden. Un sexto artículo, de autoría de Gonzalo Flores Castro, se dedica al análisis de la toma de decisiones desde el marketing cibernético, tomando como referente las aplicaciones de la antropología cristiana en la empresa, en la teoría de Antonio Pérez López.

En la sección de reseñas de libros, Tomás Caycho nos entrega la recensión del libro Psicología Organizacional en Latinoamérica, que ha sido recientemente editado por Littlewood y Uribe. Finalmente, como comentario, tenemos un breve análisis histórico de la psicología organizacional en el Perú, que escribió Arturo Orbegoso, conocido historiador de la psicología peruana.

Este número monográfico, ha sido preparado con mucho esmero por el equipo editorial de la Revista de Psicología de la Universidad Católica San Pablo, y está dedicado a los psicólogos laborales, así como a todos los interesados en esta rama de la psicología, que parece desarrollarse de forma renovada en nuestro país. Asimismo, queremos agradecer, como siempre, a nuestros revisores nacionales e internacionales; a nuestros colaboradores, ya que sin ellos no sería posible animar esta publicación; y a nuestros colegas y lectores, que cada día motivan nuestro trabajo. Esperamos que la comunidad académica, y especialmente, aquella dedicada a la psicología organizacional, reciba este número con el mismo entusiasmo con el que ha sido preparado.

Dr. Walter L. Arias Gallegos

Director de la Revista de Psicología

Universidad Católica San Pablo 


\section{ARTÍCULOS DE INVESTIGACIÓN}

CALIDAD DE VIDA PROFESIONAL Y APRENDIZAJE ORGANIZACIONAL EN TRABAJADORES DE UN RESTAURANTE DE LIMA

Katerine Santiago Aranda y Mario Reyes Bossio

CLIMA ORGANIZACIONAL Y RENDIMIENTO LABORAL EN SERVIDORES ADMINISTRATIVOS DE UNA UNIVERSIDAD PÚBLICA DE LA CIUDAD DE AREQUIPA José Miguel Calizaya López y Rildo Santos Bellido Medina

HACIA DESCRIPCIONES NÍTIDAS DE LA CULTURA ORGANIZACIONAL

Federico R. León, Oswaldo Morales, Oswaldo Otoya, Antonio Romero y Ángela de la Cruz

Clima Afectivo para el trabajo cooperativo de DOCEnTES DE Lima

Doris Elida Fuster Guillén, Liliana Aldazábal Melgar, Sara Tello Cabello Patricia Guillén Aparicio y Ronald M. Hernández 



\title{
CALIDAD DE VIDA PROFESIONAL Y APRENDIZAJE ORGANIZACIONAL EN TRABAJADORES DE UN RESTAURANTE DE LIMA
}

\author{
QUALITY OF PROFESSIONAL LIFE AND ORGANIZATIONAL \\ LEARNING AMONG WORKERS FROM A RESTAURANT IN LIMA
}

\section{Katerine Santiago Aranda}

Licenciada en Psicología por la Universidad Peruana de Ciencias Aplicadas. Tiene una especialización en Dirección de Empresas por la Universidad ESAN. Dedicada al reclutamiento y desarrollo del personal.

\section{Mario Reyes-Bossio}

Licenciado en psicología y Magíster en Psicología por la Universidad San Martín de Porres. Premio Nacional de Psicología en la categoría de psicología Deportiva (2015). Psicólogo deportivo en varias instituciones deportivas de alto rendimiento.

Profesor en la Universidad Peruana de Ciencias Aplicadas, Lima, Perú.

(iD https://orcid.org/oooo-0oo3-4655-1927

Correspondencia: Mario Reyes Bossio

Facultad de Psicología

Universidad Peruana de Ciencias Aplicadas

Prolongación Primavera 2390

Lima 15023, Lima, Perú.

Correo electrónico: mario.reyes@upc.pe 

Rev. Psicol. (Arequipa. Univ. Catól. San Pablo) / Año 2019 / Vol 9 / N 3 / pp. 13-33

ISSN 2306-0565 versión impresa / ISSN 2311-7397 versión on line

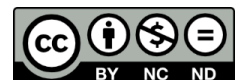

Esta obra está bajo una Licencia Creative Commons

Atribución 4.o Internacional (BY-NC-ND)

\title{
CALIDAD DE VIDA PROFESIONAL Y APRENDIZAJE ORGANIZACIONAL EN TRABAJADORES DE UN RESTAURANTE DE LIMA
}

\section{QUALITY OF PROFESSIONAL LIFE AND ORGANIZATIONAL LEARNING AMONG WORKERS FROM A RESTAURANT IN LIMA}

\author{
Katerine Santiago Aranda y Mario Reyes-Bossio \\ Universidad Peruana de Ciencias Aplicadas, Lima, Perú
}

\begin{abstract}
Resumen
Se estudió la relación existente entre la calidad de vida profesional (apoyo directivo, carga en el trabajo y motivación intrínseca) y el aprendizaje organizacional (aprendizaje individual y grupal, y aprendizaje organizacional). La muestra (189 participantes $(M=26.78$ años; $D E=5.86 ; 79 \%$ hombres $)$, trabajadores de un restaurante de Lima (Perú). Los participantes respondieron a los siguientes cuestionarios: Escala de Calidad de Vida Profesional (CVP; Grimaldo E Reyes, 2014) y Cuestionario sobre las Dimensiones del Aprendizaje Organizacional (CDAO; Mayorca, Ramírez, Viloria \& Campos, 2007). Los resultados demostraron una correlación positiva y significativa entre la subescala apoyo directivo del CDAO y las subescalas de la CVP-35: aprendizaje individual y grupal ( $r=.67 ; p<.001)$ y aprendizaje organizacional $(r=.71 ; p<.001)$. La subescala motivación intrínseca del CDAO se correlacionó positiva y significativamente con el aprendizaje individual y grupal ( $r$ $=.58 ; p<.001)$ y el aprendizaje organizacional $(r=.61 ; p<.001)$ de la escala CVP-35. La subescala carga en el trabajo del CDAO se correlacionó significativamente con el aprendizaje individual y grupal $(r=.34 ; p<.001)$ y el aprendizaje organizacional $(r=.34 ; p<.001)$ de la escala CVP-35. En conclusión, en la presente investigación se ha encontrado que tanto la variable calidad de vida profesional y aprendizaje organizacional correlacionan positiva y significativamente.
\end{abstract}

Palabras clave: Calidad de vida profesional, aprendizaje organizacional, apoyo directivo, carga en el trabajo, motivación intrínseca, aprendizaje grupal. 


\begin{abstract}
The relationship between professional quality of life (managerial support, workload and intrinsic motivation) and organizational learning (individual and group learning, and organizational learning) were studied. The sample (189 participants $(M=26.78$ years old, $S D=5.86,79 \%$ men) consisted of workers from a restaurant in Lima (Perú). Participants answered the following questionnaires: Professional Life Quality Scale (CVP, Grimaldo \& Reyes, 2014) and Organizational Learning Dimensional Questionnaire (CDAO, Mayorca, Ramírez, Viloria \& Campos, 2007).The results indicated a positive and significant correlation between the CDAO management support subscale and the CVP-35 subscales: learning $(r=.67 ; p<.001)$ and organizational learning $(r=$ $.71 ; p<.001)$. The CDAO intrinsic motivation subscale correlated positively and significantly with individual and group learning $(r=.58 ; p<.001)$ and organizational learning $(r=.61 ; p<.001)$ of the CVP-35 scale. The work load subscale of $C D A O$ was significantly correlated with individual and group learning $(r=.34$; $p<.001)$ and organizational learning $(r=.34 ; P<.001)$ of the CVP-35 scale. In conclusion, the present research found that the variables professional quality of life and organizational learning correlate positively and significantly.
\end{abstract}

Key words: Professional quality of life, organizational learning, management support, work load, intrinsic motivation, group learning.

\section{Introducción}

Para las organizaciones es importante promover una óptima calidad de vida profesional, pues esta conllevaría al incremento en la producción, buen desempeño, mayor satisfacción y motivación por parte de los trabajadores (Gómez, 2010). De no efectuarse, la posibilidad de concretarse el aprendizaje organizacional se verá interrumpida (Malvezzi, 2012). Por tal motivo, si las empresas buscan desarrollar un continuo progreso y evolución, deben promover en sus trabajadores, la capacidad de aprender con mayor rapidez (Natividad, Espinoza, Cruz \& Guivar, 2010). Para ello buscan nuevas y mejores estrategias, siendo una de ellas, el aprendizaje organizacional (Sandoval, 2004).
En el contexto peruano, Fontes (2002) señala que la participación del trabajador en una organización incluye el tiempo que permanece en el trabajo (más de un tercio del día), hecho que afecta directamente en la salud y bienestar de los trabajadores y sus correspondientes familias en materia de calidad de vida. A esta problemática se suma la dificultad existente en la economía peruana para poder propiciar empleos de calidad, lo cual se evidencia en los bajos niveles de productividad que manifiesta (Chacaltana \& Yamada, 2009). En ese sentido, es esencial que en toda organización exista una buena interacción en los grupos de trabajo, ya sea a través de dinámicas interpersonales, búsqueda de solución de problemas, compromiso en equipo y una eficiente comunicación, 
donde se involucre la participación individual, grupal y organizacional (Marchand, 2006). Por ello, se debe considerar importante tanto la calidad de vida profesional como el aprendizaje organizacional. Aquello, permitiría que los trabajadores se sientan satisfechos y cómodos en su ambiente laboral, generando así, mayor apertura a nuevos conocimientos en su campo laboral (Marchand, 2006).

En referencia al aprendizaje organizacional en el contexto peruano, éste se centra en la participación mayoritaria de los líderes, tales como gerentes y empresarios. En tal sentido, el aprendizaje organizacional tiene como tarea generary desarrollar una cultura empresarial peruana con ambición y éxito, que va de la mano con las habilidades y los conocimientos ejercidos y transferidos desde la cadena de mando hacia sus subordinados (Castellano, 2007).

En suma, es importante explorar el aprendizaje organizacional y la calidad de vida profesional en el contexto peruano. Por una parte, el aprendizaje organizacional le brinda la mayor relevancia al conocimiento y como éste permite que una organización no desaparezca en el camino y que por el contrario se convierta en su mayor fuente de riqueza en las organizaciones (Angulo, 2017). Por otra parte, la calidad de vida profesional es considerada como una variable importante debido a que influye y se relaciona directamente con el desarrollo de las actividades que desempeña el ser humano y que termina repercutiendo en un mayor o menor nivel de productividad (Gonzales \& Sandoval, 2016).

\section{Calidad de vida profesional}

La calidad de vida profesional es definida como la percepción de bienestar que la persona experimenta, que proviene del equilibrio entre las demandas o la carga en el trabajo y los recursos (psicológicos, organizacionales y relacionales) que emplea para afrontarlas (García, 1993). Se trata de un proceso complejo, dinámico y multidimensional (Grimaldo, 2011), y es el resultado de lo que una organización provee a sus miembros, el cual genera un impacto en la salud física, psicológica y emocional del individuo (Da Silva, 2006; Harter, Schimidt \& Keyes, 2002).

Las dimensiones que componen la calidad de vida profesional son tres (Fernández, Santa \& Casado, 2007; Grimaldo \& Reyes, 2014). La primera, (a) apoyo directivo, está relacionada al soporte emocional por parte de los directivos hacia el personal a su cargo. Este apoyo directivo le permite al trabajador poder desarrollar sus tareas de una manera eficiente y así recibir una retroalimentación directa entre el jefe y el trabajador (Albanesi, 2013; Quezada, Sanhueza \& Silva, 2010). La segunda dimensión, (b) demandas de trabajo, es la percepción que tiene el trabajador sobre su propio puesto laboral. Los trabajadores pueden percibir cuan seguros o inseguros se sienten dentro de la organización a la que pertenecen, e incluso autoevaluarse, todo esto siempre ligado a las funciones que les corresponda desempeñar (Alonso, Iglesias \& Franco, 2002). Finalmente, la tercera dimensión es la (c) motivación intrínseca, la cual se manifiesta al realizar el trabajo 
encomendado, y que guarda relación con las características del puesto y las del trabajador (Zárate, 2006). Así también, la motivación intrínseca involucra el sentir placer con lo que se desempeña, de esta forma, la persona siente gratificación y autorrealización consigo mismo (Catalá, Peñacoba, Velasco, Jareño \& Fernández, 2016). Se han hallado investigaciones respecto a la calidad de vida profesional relacionada con otras variables. Así, se encuentra que si la importancia y el valor del sueño en la calidad de vida profesional no es el adecuado de acuerdo a su ritmo biológico, podría influir negativamente en el desempeño laboral (Grimaldo \& Reyes, 2014). De manera similar, una baja calidad de vida ha sido relacionada con niveles altos o muy altos de síntomas de estrés (García, Gonzáles, Aldrete, Acosta $\&$ León, 2014). Por último, un estudio experimental encontró una mayor satisfacción en la calidad de vida laboral al implementarse diversas estrategias en cada una de las dimensiones compuestas (Argüelles, Quijano, Sahuí, Fajardo \& Magaña, 2015). Esto se debió a que estas estrategias lograron eliminar las áreas de insatisfacción, infiriendo que conforme se les brinde a los colaboradores lo que ellos necesitan, mejoraría su calidad de vida (Argüelles, Quijano, Sahuí, Fajardo \& Magaña, 2015).

\section{Aprendizaje organizacional}

El aprendizaje organizacional es un proceso dinámico y definido mediante la interacción social que abarca a individuos, grupos y a la misma organización (Cardona \& Calderón, 2006).
El aprendizaje organizacional brinda conocimientos y capacidades, posibilitando nuevos productos y servicios, desarrollando y mejorando así los procesos encaminados en una búsqueda de su perdurabilidad (Garzón \& Fisher, 2008). Para una mayor comprensión de la variable aprendizaje organizacional, Örtenblad (2015) plantea una definición que corresponde a un análisis de investigaciones previas (Caldwell, 2012; Örtenblad, 2007), en la cual expresa la existencia de cuatro conceptos que abarcan el aprendizaje organizacional. El primero se centra en almacenar el conocimiento en la mente organizacional. En el segundo, la organización como generador de aprendizaje a la par con lo que el trabajador aprende en él. El tercero proporciona el aprendizaje a través de un clima organizacional apropiado. Por último, busca que la organización brinde el aprendizaje de forma estructurada.

Éste tiene como objetivo generar un cambio en la mentalidad de todos los miembros involucrados, transfiriendo el conocimiento adquirido en la organización, recabando información interna y externa permitiéndole a la organización generar cambios en sus conductas para mejorar e incrementar en innovación (Natividad et al., 2010; Reynolds \& White, 2000 como se citó en Mayorca, 2010). En consecuencia, mientras una organización, gane mayor experiencia a través del aprendizaje, será menos resistente al cambio, y, además, con el aprendizaje adquirido, logrará optimizar el modo de vida y las cualidades que poseen los miembros de la organización (Mayorca \& Mayorca, 
2010). Por ello, el aprendizaje organizacional es necesario en las organizaciones porque considera al conocimiento como una capacidad para poder establecer un acercamiento con los clientes y asi poder brindar mejores servicios para las empresas de manera mas rápida y eficiente (Garzón \& Fischer, 2010).

En línea con Yang, Watkins y Marsick (2004), el aprendizaje organizacional abarca seis dimensiones: aprendizaje en equipo, empowerment, dirección estratégica, sistema integrado, investigación y diálogo, y aprendizaje continuo. Estas dimensiones se agrupan a su vez en tres bloques importantes: (a) aprendizaje individual, (b) en equipo y (c) organizacional (Garzón \& Fisher, 2008). El aprendizaje individual, está orientado a la adquisición de nuevas experiencias de conocimiento. Por su parte, el aprendizaje en equipo, se dirige a una necesidad de establecer condiciones y mecanismos para elaborar equipos que logren aprender a través de la práctica y el desempeño continuo (Senge, 2012), desarrollando equipos eficaces o de alto rendimiento. Por último, el aprendizaje organizacional es la consecuencia del aprendizaje individual, en la que se considera que una organización que se encuentra orientada al aprendizaje, logra facilitar el desarrollo permanente de sus miembros y atraviesa una transformación continua. El aprendizaje organizacional constituye un factor clave para el desempeño eficiente de las empresas. Por tal motivo, es importante conocer su funcionamiento y así poder emplearlo acorde a los intereses generales de la organización (Barrera, 2011). El aprendizaje organizacional se convierte en una importante herramienta de participación activa por parte de sus miembros, ya que permite que desarrollen sus capacidades para crear nuevas ideas, y generar diferentes cambios, con el fin de optimizar el desempeño de los trabajadores, formando un progreso organizacional (Mayorca, 2010). En la misma línea, generar y desarrollar la calidad de vida profesional dentro de una organización es importante, ya que esta busca incrementar la satisfacción y autorrealización de los trabajadores. También, el aprendizaje organizacional es significativo para las organizaciones que buscan proteger sus recursos humanos, por lo que debe ofrecer al colaborador un entorno que genere su desarrollo como ser humano (Salvatierra, 2013).

Por otro lado, estudios previos han hallado que la implementación de herramientas de gestión no beneficia la doble vía en la comunicación, autonomía y participación de los miembros, que se necesitan para desarrollar el aprendizaje organizacional (Pujol \& Navarra, 2001). Además, la factibilidad y la rapidez con que se produzca el aprendizaje, dependerá de la cultura organizacional, ya que, la información en sí misma, no asegura el aprendizaje de las personas (Castañeda \& Fernández, 2007). Referente a ello, una investigación señala que el aprendizaje organizacional es lento si la cultura en la que se desarrolla es fuerte y tradicional, porque ésta presenta dificultades para adaptarse con facilidad a cambios tanto sociales como económicos (Pirela de Faria \& Sánchez, 2009). Por otra parte, se ha encontrado que, la capacidad del aprendizaje organizacional, 
no genera un impacto directo en relación al desempeño organizacional (Gálviz \& Rojas, 2013).

\section{El presente estudio}

La presente investigación tiene como objetivo examinar la relación entre las variables aprendizaje organizacional y calidad de vida profesional en una muestra de colaboradores del área de producción y servicio al cliente en un restaurante de Lima (Perú). Se espera encontrar que, a mayor calidad de vida profesional, mayor aprendizaje organizacional. Además, se identifica una necesidad por conocer a profundidad esta relación, ya que se han encontrado investigaciones que abordan ambas variables de manera independiente o en relación con otras. Es importante tomar en cuenta el contexto en el que se desarrolla un restaurante, ya que los trabajadores se ven expuestos a sentir presión en caso que no haya mucha variedad en la oferta gastronómica, que no exista una buena relación entre los precios y la calidad de los platos, lo que en suma afecta anímicamente al trabajador e influye en su nivel de productividad (Ramos, Segura, Gonzáles \& Alonso, 2012). Por tal motivo, el aprendizaje organizacional permitiría el desarrollo de nuevas ideas, realizar innovaciones y métodos de dirección que permitan mejorar la forma en la que los colaboradores se desempeñan en su centro laboral (Passaillague \& Estrada, 2016). La aplicación de la presente investigación es relevante, ya que permite el estudio de ambas variables en el contexto de producción y servicio al cliente, aportando información y evidencia que permita contribuir y promover nuevas áreas de investigación en un campo con poca exploración, como lo es el contexto peruano.

\section{Método}

\section{Participantes}

Para esta investigación se utilizó un muestreo no probabilístico intencional, puesto que la elección del personal a los que se les aplicó la prueba fue elegida por pertenecer al área de producción y servicio (Hernández, Fernández \& Baptista, 2010). Para el cálculo del tamaño de la muestra, se empleó el programa $G^{*}$ Power versión 3.1.9.2, en el cual se estableció un mínimo de 153 participantes, asumiendo una prueba de hipótesis de una cola, un poder estadístico de .8 , el cual determinará la probabilidad de aceptar la hipótesis de investigación planteada (Cárdenas \& Arancibia, 2014). Asimismo, se tomó un margen de error de .05 y un tamaño de efecto de o.2. En la presente investigación la muestra fue de 189 participantes (ver Tabla 1). 
Tabla 1. Características demográficas de la muestra

\begin{tabular}{|llc|}
\hline \multicolumn{1}{|c}{ Características } & & n (\%) \\
\hline \multirow{2}{*}{ Sexo } & Masculino & $150(79 \%)$ \\
\multirow{2}{*}{ Edad (años) } & Femenino & $39(21 \%)$ \\
Grado de Instrucción & & $26.78 \pm 5.86$ \\
& Secundaria & $78(41 \%)$ \\
& Técnica & $75(40 \%)$ \\
Área & Universitaria & $36(19 \%)$ \\
& Producción & $87(46 \%)$ \\
Lugar de Origen & Servicio al cliente & $102(54 \%)$ \\
& Lima & $102(54 \%)$ \\
Condición Laboral & Provincia & $86(46 \%)$ \\
& Full Time & $184(97 \%)$ \\
Reciben Capacitaciones & Part Time & $5(3 \%)$ \\
& Sí & $143(76 \%)$ \\
& No & $45(24 \%)$ \\
Tipo de Capacitación & Para crecimiento personal & $56(40 \%)$ \\
& Para crecimiento profesional & $77(54 \%)$ \\
& Para otro tipo de crecimiento & $9(6 \%)$ \\
\hline
\end{tabular}

\section{Instrumentos}

Cuestionario sociodemográfico

Se utilizó una ficha sociodemográfica para obtener datos de edad, género, grado de instrucción, estado civil, número de hijos, lugar de origen, área de trabajo, tiempo laborando en la organización y condición laboral.

Cuestionario sobre las dimensiones del aprendizaje organizacional (CDAO)

El instrumento (originalmente llamado Dimensions of the Learning Organization
Questionnaire; DLOQ; Watkins y Marsick, 1997, como se citó en Marsick, 2013), tiene como objetivo evaluar las actividades de aprendizaje en una organización, las cuales corresponden a la forma de actuar ante los cambios continuos del entorno mediante la adquisición, y desarrollo del conocimiento para el logro de los objetivos organizacionales. Los 43 ítems que componen la prueba se dividen en 3 dimensiones: aprendizaje individual (13 reactivos), aprendizaje grupal (6 reactivos) y aprendizaje de la organización (24 reactivos). El formato de respuesta es de tipo Likert de 1 (nunca) a 6 (siempre). 
Este instrumento ha sido traducido y adaptado en Venezuela por Mayorca, Ramírez, Viloria y Campos (2007). Tal estudio evaluó la validez de contenido a través de una traducción al español. Asimismo, la confiabilidad del instrumento fue evaluada mediante el método de consistencia interna con la prueba alfa de Cronbach, siendo el coeficiente obtenido de 0.97 para el total y entre 0.65 y 0.93 para cada dimensión.

En el presente estudio, para la dimensión de aprendizaje organizacional se obtuvo un coeficiente alfa de Cronbach de .96, y un rango de correlación ítem-test corregida de .62 a .81. Para la dimensión aprendizaje individual/grupal, tal coeficiente fue de .92 y con un rango de correlación ítem-test corregida de .34 a .74 .

Escala de Calidad de Vida Profesional (CVP-35; Cabezas, 1998)

Para la presente investigación se usó la adaptación de Grimaldo y Reyes (2014). Este instrumento tiene como objetivo identificar los niveles de calidad de vida profesional. Las dimensiones que mide son: cargas de trabajo, motivación intrínseca y apoyo directivo. Cuenta con 35 preguntas con un formato de respuesta del 1 al to que se agrupan en las siguientes categorías: nada (valores 1 y 2), algo (valores 3, 4 Y 5), bastante (valores 6, 7 y 8) y mucho (valores 9 y 10).

Respecto a la validez del instrumento los autores utilizaron el método de criterio de jueces, en el que se halló una validez significativa de $p<0.05$ en todos los ítems.
Respecto a la validez de constructo, los autores reportan el análisis factorial exploratorio a través del método de extracción de ejes principales y el método de rotación oblicua. Finalmente los autores reportan la confiabilidad medida con el coeficiente alfa de Cronbach: .9o para carga en el trabajo, .91 para motivación intrínseca y .95 para apoyo directivo.

En el presente estudio el análisis de consistencia interna reveló índices alfa de Cronbach altos: .95 para la dimensión apoyo directivo con un rango de correlación ítem-test corregida de .58 a .83. Para la dimensión carga en el trabajo, el índice fue de 88 con un rango de correlación ítemtest corregida de .5o a .72. Finalmente, la dimensión motivación intrínseca obtuvo un índice alfa de Cronbach de .91 con un rango de correlación ítem-test corregida de .60 a .79 .

\section{Procedimiento}

Los instrumentos utilizados fueron revisados por un jurado experto en el tema. Luego de verificar la pertinencia de los ítems, se procedió a realizar un piloto para ver la claridad y comprensión de los ítems. Por tal motivo, el piloto fue aplicado a una muestra $(N=20)$ con características similares a la muestra original, con el fin de identificar que todas las preguntas sean totalmente claras; esto se llevó a cabo mientras los colaboradores se encontraban trabajando. Posterior a ello, se decidió modificar el ítem 8 ("Las personas están dispuestas a una retroalimentación honesta entre unos y otros") del instrumento Cuestionario sobre las dimensiones 
del aprendizaje organizacional (CDAO). Así, se cambió la palabra realimentación, por retroalimentación. Esto debido a que en el estudio piloto se encontró que era una pregunta que no quedaba del todo clara para la muestra. Asimismo, en el instrumento Escala de Calidad de Vida Profesional CVP-35 se agregó la palabra "de" al enunciado del ítem 6 ("La falta de tiempo para mi vida personal") con la finalidad de que quede más claro.

Posterior a ello, se realizó el contacto con el jefe de operaciones, responsable de las sedes seleccionadas y se le consultó si estarían dispuestos a ser parte de una encuesta académica para una investigación que se estaba llevando a cabo en la institución. Este consultó con el gerente y las responsables del área de recursos humanos, quienes finalmente dieron la autorización. Una vez informado al personal del área de producción y servicio y haber aceptado voluntariamente, se procedió a entregar el consentimiento informado para que lo firmaran, medio por el cual se les indicó la confidencialidad de la información y los participantes autorizaron su participación voluntaria. Luego, se les brindó las instrucciones necesarias para que llenen la ficha sociodemográfica y para la aplicación de los instrumentos.

La aplicación de ambas encuestas fue realizada de forma colectiva, es decir, se entregó la encuesta a pequeños grupos de tres trabajadores, y se les indicó que la realización de las encuestas era de manera anónima e individual y tenían 20 minutos para poder desarrollarla. Asimismo, ésta se llevó a cabo en un horario en el que los trabajadores tuvieron un receso, de tal manera que el tiempo no era un limitante, como también, el ambiente en el que se encontraban era cómodo y estaba dentro del mismo centro laboral que en ese momento no contaba con la presencia de comensales.

Para los análisis de datos, primero se utilizó la prueba Kolmogorov-Smirnov para examinar la distribución de los datos de las variables. Para los datos con una distribución normal se emplearon pruebas paramétricas ( $t$ de Student y correlación de Pearson), mientras que para las variables que no presentaron distribución normal se utilizaron pruebas no paramétricas (prueba U-Mann Whitney y Spearman).

\section{Resultados}

\section{Análisis de correlación}

En base a los resultados de los análisis de normalidad, se empleó la prueba de correlación Pearson para aprendizaje organizacional y carga en el trabajo y para las otras tres dimensiones, aprendizaje individual y grupal, apoyo directivo, y motivación intrínseca se empleó Spearman (ver Tabla 2). 
Tabla 2. Correlaciones de Spearman (S) y Pearson (P) entre las subescalas de calidad de vida profesional y aprendizaje organizacional $(\mathrm{N}=189)$

\begin{tabular}{|lcccccc|}
\hline & Media & DE & 2 & 3 & 4 & 5 \\
\hline 1. Aprendizaje organizacional & 4.30 & 1.00 & $.84^{* * * \mathrm{~S}}$ & $.71^{* * * \mathrm{~S}}$ & $.34^{* * * \mathrm{~S}}$ & $.61^{* * * \mathrm{~S}}$ \\
2. Aprendizaje individual y grupal & 4.34 & .85 & - & $.67^{* * * \mathrm{~S}}$ & $.34^{* * * \mathrm{P}}$ & $.58^{* * *}$ \\
3. Apoyo directivo & 7.15 & 1.87 & & - & $.54^{* * * \mathrm{P}}$ & $.82^{* * *}$ \\
4. Carga en el trabajo & 6.05 & 1.87 & & & - & $.54^{* * *}$ \\
5. Motivación intrínseca & 7.97 & 1.52 & & & & - \\
\hline
\end{tabular}

Nota: las correlaciones con las variables demográficas son bilaterales ${ }^{*} p<.05,{ }^{* *} p<.01,{ }^{* * *} p<.001$

Adicionalmente, también se ha observado que en las variables sociodemográficas tales como, edad, grado de instrucción, número de hijos y tiempo en la empresa, no se presenta una distribución normal $(p<.05)$, por lo que también fueron correlacionadas por la prueba de Spearman. Se calcularon las correlaciones entre las variables de estudio y las variables demográficas con la prueba de correlación de Spearman (los coeficientes de correlación pueden verse en la Tabla 2). Con respecto a las variables demográficas, se puede apreciar que ninguna correlaciona significativamente con algunas de las variables psicológicas estudiadas.

Se puede apreciar que los dos tipos de aprendizaje se relacionan de manera significativa y positiva con las dimensiones de calidad de vida profesional. El aprendizaje organizacional se correlaciona de forma débil con la carga en el trabajo $(r=.34)$ mientras que la correlación con el apoyo directivo $(r=.71)$ y la motivación intrínseca es de tipo moderada $(r=.61)$. De igual manera ocurre en la correlación entre el aprendizaje individual y grupal con las subdimensiones de la calidad de vida profesional (Tabla 2).

\section{Análisis comparativo}

No se encontraron diferencias significativas con las variables sexo, condición laboral, área y estudios, sólo se encontraron diferencias significativas con respecto a la variable recibes capacitaciones con las cinco variables analizadas: Aprendizaje Organizacional, Aprendizaje Individual/ grupal, Carga en el Trabajo, Apoyo directivo y Motivación Intrínseca. En los cinco casos se observa que los que tienen mayores puntajes son los que sí reciben capacitaciones (Tabla 3 ). 
Tabla 3. Análisis comparativo de las dimensiones de CVP y AO según si reciben capacitaciones

\begin{tabular}{|lccc|}
\hline & \multicolumn{1}{c}{ Sí } & No & \\
& M(DE) & M(DE) & Prueba estadística \\
\hline 1. Aprendizaje organizacional & $4.48(.93)$ & $3.78(1.00)$ & $1947^{* \mathrm{~b}}$ \\
2. Aprendizaje individual/grupal & $4.49(.80)$ & $3.89(.81)$ & $4.34^{* \mathrm{a}}$ \\
3. Carga en el trabajo & $6.24(1.91)$ & $5.49(1.65)$ & $2.37^{* \mathrm{a}}$ \\
4. Apoyo directivo & $7.47(1.76)$ & $6.23(1.80)$ & $1979.5^{* \mathrm{~b}}$ \\
5. Motivación intrínseca & $8.20(1.36)$ & $7.19(1.74)$ & $2115^{* \mathrm{~b}}$ \\
\hline
\end{tabular}

Nota: * $p<.05$, las comparaciones de medias son bilaterales

a. t de student; b. U de Mann - Whitney

\section{Discusión}

El objetivo de la presente investigación fue estudiar la relación existente entre la calidad de vida profesional y el aprendizaje organizacional en una muestra de trabajadores de un restaurante de Lima. Se hipotetizó que a mayor calidad de vida profesional mayor aprendizaje organizacional en los trabajadores. Esto sugeriría que el aprendizaje organizacional depende de cuan satisfechos se sienten los colaboradores con la calidad de vida profesional que tienen en la empresa. El resultado encontrado fue el esperado debido a que ambas variables correlacionaron de manera significativa y positiva, es decir, los participantes que refirieron una buena calidad de vida profesional, se sienten satisfechos con la empresa y con la labor que desempeñan en ella.

En primer lugar, se encontró una correlación positiva significativa entre la variable apoyo directivo con las variables aprendizaje organizacional y aprendizaje individual/grupal. Para el caso de la relación entre apoyo directivo y aprendizaje organizacional, estudios previos con empleados de banco sugieren que la cercanía con una figura directiva, como sucede con el mentoring, favorece el aprendizaje organizacional (Hussaian \& Ishak, 2017). De manera similar, en el estudio de Romero y Lassmann (2016) con trabajadores del bienestar infantil, los autores encontraron que los programas de mentoring generan beneficios tanto personales como profesionales para estos trabajadores, lo que sería significativo para aquellos jefes que estén interesados en retener a los buenos empleados a través de intervenciones efectivas. En conjunto, estos resultados sugieren que estas personas recurren al soporte emocional que sus jefes o líderes les puedan proveer, ya que esto influiría positivamente en el proceso de adquisición del aprendizaje tanto organizacional, como individual/grupal. Asimismo, Fernández (2014) señala que el aprendizaje organizacional permitiría generar una alta rentabilidad y actitudes positivas, como también, mejoraría la relación entre los jefes y sus subordinados, aumentando así la productividad y la calidad del trabajo en la organización. Así por 
ejemplo, en una cadena de restaurantes en Ecuador, se implementó un modelo de gestión basado en el liderazgo centrado en principios, encontrando al aprendizaje continuo como un factor de mayor crecimiento (Quiroz, 2016). En suma, esto sugeriría, como de manera similar lo hacen los resultados de la presente investigación, que es importante promover el apoyo directivo para fortalecer el aprendizaje organizacional, especialmente si se realiza enfatizando el liderazgo.

En segundo lugar, se encontró una correlación positiva y significativa entre la motivación intrínseca y el aprendizaje tanto organizacional como individual/ grupal. Esto sugiere que a mayor motivación intrínseca por parte de los colaboradores, esto les permitiría adquirir un mayor aprendizaje. De hecho, Martín, Trevilla y Martín (2009) señalan que la motivación intrínseca influye de manera positiva y significativa en la transferencia de conocimiento. Esto se evidencia cuando los trabajadores desempeñan tareas en las que ponen en práctica sus capacidades, logrando así sentirse satisfechos y competentes, lo que finalmente influye en su disposición para compartir el conocimiento con los demás trabajadores. Además, Noe, Tews y Dachner (2010) refieren que la eficacia de cómo se lleven a cabo los programas de aprendizaje en la organización, estaría directamente relacionada a la motivación de la persona, lo que guarda una estrecha relación con los resultados encontrados en la presente investigación. Al respecto, en el estudio con trabajadores de la construcción en Tailandia, Navarro, Linares y Montaña (2010), observaron que la posibilidad de crecimiento profesional promueve la motivación, por ello los trabajadores se muestran alegres al adquirir nuevos aprendizajes y experiencias, considerando al aprendizaje como un factor que les permite desarrollarse personalmente. Estos resultados sugieren que el aprendizaje organizacional permitiría que una organización afronte ágilmente los cambios constantes por los que atraviesa una empresa. A través del uso de soluciones innovadoras, tal afrontamiento llevaría a mantener actualizada a la organización y a sus trabajadores, y a evolucionar en un entorno tan cambiante (Gómez, 2015).

En tercer lugar, se encontró una correlación positiva y significativa entre la carga en el trabajo y el aprendizaje tanto organizacional como individual/grupal. Ello sugiere que, a mayor carga en el trabajo, se producirá un mejor aprendizaje tanto organizacional como individual/grupal. En relación a ello, en un estudio previo con una muestra de enfermeros, se encontró que la carga en el trabajo es una dimensión que presenta diferencias ya que ésta podría depender del tipo de servicio al que está ligado, como también de la cantidad de personas atendidas (Fernández, Cuairan \& Curbelo, 2016). El presente estudio, al encontrarse en el rubro de la hostelería se sugiere que la carga en el trabajo podría ser una de las variables que tiene mayor peso al momento de poder predecir el nivel de energía del trabajador, ya que una carga de trabajo que no es manejable, influiría en el descenso de la eficacia y productividad del trabajador, lo que finalmente 
afectaría en el índice de producción de la organización (Gascón, s/f).

En cuarto lugar, se encontró que aquellas personas que sí reciben capacitaciones, presentan mayor predisposición a la adquisición del aprendizaje. En ese sentido, Pardo y Díaz (2014) señalan que tanto los procesos de capacitación, como también el desarrollo de las competencias en el personal, son elementos clave que permiten que se lleve a cabo una transformación organizacional. De esta manera, se genera la mejora del rendimiento de los trabajadores, se reduce la incertidumbre y se promueve la participación de los equipos que favorecen la adaptación al cambio en la organización (Pardo \& Díaz, 2014). En la misma línea, Fernández (2014) señala que con el aprendizaje organizacional no sólo se desarrollarían nuevos conocimientos sino que éstos permitirían aumentar la capacidad de los trabajadores para mejorar los resultados de la empresa, centrándose en la importancia de la inversión en políticas de capacitación y desarrollo de acuerdo a las necesidades de la empresa, lo que permitirá que a largo plazo seagranden los conocimientos de los trabajadores y sea una guía permanente en su vida profesional. En consecuencia, la capacitación del personal en restaurantes debe considerarse cuando se desea promover el aprendizaje organizacional. Así, como bien refiere Sánchez (2014), un plan de capacitación impactaría no sólo en el aspecto económico sino que mejoraría la fidelización y satisfacción por parte de los clientes hacia la empresa. Con ello se logra un cambio en el desarrollo personal de cada trabajador, tal como brindar una solución rápida a los problemas, mejor ejecución de su trabajo y la mejora en su relación en la atención al cliente.

\section{Limitaciones}

Aunque el presente estudio arroja resultados interesantes con implicaciones importantes, debe notarse que también posee algunas limitaciones. En primer lugar, en este estudio el número de mujeres fue reducido, aunque debe notarse que la cadena de producción en restaurantes está generalmente compuesta por hombres. En todo caso, futuros estudios pueden comparar el aprendizaje organizacional y la calidad de vida profesional desde una perspectiva de género. Por otro lado, investigaciones similares al presente estudio son muy escazas tanto en el contexto peruano como en otros países. En tal sentido, este estudio sentará las bases para futuros estudios en poblaciones peruanas.

Finalmente, a manera de recomendación se sugiere que empresas tipo restaurante utilicen métodos reconocidos para propiciar la motivación intrínseca de sus trabajadores, debido a la relación significativa que mantiene con el aprendizaje organizacional. Además, dado que los participantes le dan mayor importancia al apoyo directivo que reciben por parte de su jefe, es decir, por el soporte emocional que reciben de ellos, se recomienda que se refuerce la comunicación entre los jefes y trabajadores. Esto podría favorecer a que los empleados se sientan escuchados y valorados por la organización, lo cual influiría positivamente desde las capacitaciones que les brindan, hasta en la forma 
en cómo un líder se dirige hacia ellos para enseñarles un aprendizaje nuevo.

En conclusión, en la presente investigación se ha encontrado que tanto la variable calidad de vida profesional y aprendizaje organizacional correlacionan positiva y significativamente. En ese sentido, se hallaron las correlaciones entre apoyo directivo, motivación intrínseca, carga en el trabajoy capacitaciones, en relación con el aprendizaje tanto organizacional como individual/grupal. La primera muestra que la relación cercana entre el jefe y el trabajador influiría positivamente en la adquisición y desarrollo del aprendizaje organizacional. La segunda evidencia, es que se generaría un mejor nivel de aprendizaje, si los colaboradores se encuentran motivados laboralmente. La tercera, manifiesta que la carga en el trabajo afectaría directamente en el desempeño laboral del trabajador, si este no es manejado adecuadamente. Finalmente, la cuarta señala que el recibir capacitaciones, permitiría que el trabajador desarrolle sus habilidades personales y profesionales en función al aprendizaje adquirido. 


\section{Referencias}

Alcid, J., \& Lugo, D., (2008). Estado del arte del aprendizaje organizacional con relación al aprendizaje individual y la cultura. (Tesis de Licenciatura). Pontificia Universidad Javeriana, Bogotá, Colombia.

Albanesi, S. (2013). Percepción de calidad de vida profesional en trabajadores de la salud. Alternativas en Psicología, 17, 8-19.

Alonso, M., Iglesias, A.I., \& Franco, A. (2002) Percepción de la calidad de vida profesional en un área sanitaria de Asturias. Atención Primaria, 30(8), 483-489.

Angulo, R. (2017). Gestión del conocimiento y aprendizaje organizacional: Una visión integral. Informes Psicológicos, 17(1), 53-70.

Argüelles, L., Quijano, R., Sahuí, J., Fajardo, M., \& Magaña, D. (2015). Estudio experimental de la calidad de vida laboral en MIPYMES turísticas. Revista Global de Negocios, 3(1), 1-16.

Barrera, G. (2011). Aprendizaje organizacional: transferencia del conocimiento. Bogotá: Universidad Nacional de Colombia.

Bracho, O., \& García, J. (2013). Algunas consideraciones teóricas sobre el liderazgo transformacional. Revista de Estudios Interdisciplinarios en Ciencias Sociales, 15(2), 165-177.

Caldwell, R. (2012). Systems thinking, organizational change and agency: A practice theory

critique of Senge’s learning organization. Journal of Change Management, 12(2), 145-164.

Castañeda, D., \& Fernández, M. (2007). Validación de una escala de niveles y condiciones de aprendizaje organizacional. Universitas Psychologica, 6(2), 245-254

Castellano, P. (2007). Aprendizaje organizacional: Creación o destrucción de valor. Cuadernos de Investigación, 1, 1-26.

Cárdenas, M., \& Arancibia, H. (2014). Potencia estadística y cálculo de tamaño del efecto en $G^{*}$ Power: Complementos a las pruebas de significación estadística y su aplicación en psicología. Salud \& Sociedad, 5(2), 210-224. 
Cardona, J., \& Calderón, G. (2006) El impacto del aprendizaje en el rendimiento de las organizaciones. Cuadernos de Administración, 19(32), 11-43.

Catalá, P., Peñacoba, C., Velasco, L., Jareño, N., \& Fernández, A. (2016) La motivación como variable influyente en la ansiedad y autoconfianza de los deportistas. Información Psicológica, 112, 14-28.

Chacaltana, J., \& Yamada, G. (2009). Calidad del empleo y productividad laboral en el Perú. Washington, DC: Banco Interamericano de Desarrollo.

Conde, Y., Correa, Z., \& Delgado, C. (2010). Aprendizaje organizacional, una capacidad de los grupos de investigación en la universidad pública. Cuadernos de Administración, 44, 25-39.

Contreras, F., Espinoza, J., Hernández, F., \& Acosta, N. (2013). Calidad de vida laboral y liderazgo en trabajadores asistenciales y administrativos en un centro oncológico de Bogotá (Colombia). Psicología desde El Caribe, 30(3), 569-59o.

Da Silva, M. (2006). Nuevas perspectivas de la calidad de vida laboral y sus relaciones con la eficacia organizacional. (Tesis Doctoral). Universidad de Barcelona, Barcelona, España.

Durán, M. (2010). Bienestar Psicológico: el estrés y la calidad de vida en el contexto laboral. Revista Nacional de Administración, 1(1), 71-84.

Fernández, A., Santa, E., \& Casado, M. (2007). Calidad de vida profesional de los profesionales de enfermería en atención primaria de Soria. Biblioteca Las casas, 3(1). Recuperado de: http://www.index-f.com/lascasas/documentos/lco213.pdf

Fernández, A., Cuairan, M., \& Curbelo, R. (2016). Calidad de vida profesional de enfermería en urgencias de un hospital de referencia. Revista Enfermería Global, 15(2), 376-385.

Fernández, J. (2014). "La orientación al aprendizaje organizacional y su impacto en el desempeño de una empresa del sector financiero" (Tesis de doctorado). Universidad de Murcia, Murcia, España.

Fontes, R. (2002). Salud y seguridad en el trabajo en América Latina y el Caribe: Análisis, temas y recomendaciones de política. Banco Interamericano de Desarrollo. 
Garcés, A. (2014). Calidad de vida en el trabajo del profesional médico y de enfermería en una empresa social del estado (E.S.E) III nivel, Bogotá. (Tesis de maestría). Universidad Nacional de Colombia, Bogotá, Colombia.

García, S. (1993). La qualitat de vida profesional coma avantatge competitiu. Revista de Qualitat, 11, 4-9.

Gálviz, V., \& Rojas, M. (2013). Flexibilidad del individuo, el aprendizaje organizacional y el desempeño individual. (Tesis de Grado). Universidad Icesi, Cali, Colombia.

García, M., Gonzáles, R., Aldrete, M., Acosta, M., \& León, S. (2014). Relación entre calidad de vida en el trabajo y síntomas de estrés en el personal administrativo universitario. Ciencia \& Trabajo, 50, 97-102.

Garmendia, M. (2007). Análisis factorial: una aplicación en el cuestionario de salud general de Goldberg, versión de 12 preguntas. Revista Chilena de Salud Pública, 11(2), 57-65.

Garzón, M., \& Fisher, A. (2008). Modelo teórico de aprendizaje organizacional. Pensamiento y Gestión, 24, 195-224.

Garzón, M., \& Fischer, A. (2010). El aprendizaje organizacional, prueba piloto de instrumentos tipo Likert. Forum Empresarial, 15(1), 65-101.

Gascón, S. (s/f). Evaluación y prevención de riesgos psicosociales en hostelería. Aragón. Informe. Universidad de Zaragoza, Zaragoza, España.

Gómez, M. (2010). Calidad de vida laboral en empleados temporales del Valle de Aburrá Colombia. Revista Ciencias Estratégicas, 18(24), 225-236.

Gómez, M. (2015). El aprendizaje organizacional y su influencia en la innovación dentro de la organización. Revista Ingeniería, Matemáticas y Ciencias de la Información, 2(4), 59-65.

Gonzales, M. \& Sandoval, M. (2016). Calidad de vida profesional y síndrome de burnout en enfermeras del hospital María Auxiliadora. Revista de Ciencia y Arte de Enfermería, 2(1), 15-21.

Grimaldo, M. (2011). Calidad de vida en profesionales de la salud en la ciudad de Lima. Liberabit, $17(2), 173-185$. 
Grimaldo, M., \& Reyes, M. (2014). Calidad de vida profesional y sueño en profesionales de Lima. Revista Latinoamericana de Psicología, 47(1), 50-57.

Harter, J. K., Schimidt, F. L., \& Keyes, C. L. (2002). Well-Being in the Workplace and its relationship to business outcomes: A review of the gallup studies. En C. L. Keyes \& J. Haidt (Eds.), Flourishing: The Positive Person and the Good Life (pp. 205-224). Washington D.C.: American Psychological Association.

Hernández, R., Fernández, C., \& Baptista, M. (2010). Metodología de la investigación. México, D.F.: McGraw-Hill.

Hussaian, I., \& Ishak, N. (2017) The relationship between organizational learning and employee engagement in the perspective of young employees from commercial banks in Malaysia. Journal of Business and Economic Development, 2(1), 57-62.

Malvezzi, S. (2012). La gestión de conocimiento y el aprendizaje organizacional para crear competitividad. Material de Formación. Federación Colombiana de Gestión Humana-ACRIP. Recuperado de: http://www.acripnacional.org/ memoria_bog_25octubre.pdf

Marsick, V. (2013). The Dimensions of a Learning Organization Questionnaire (DLOQ): Introduction to the Special Issue Examining DLOQ Use Over a Decade. Advances in Developing Human Resources, 15(2), 127-132.

Martín, J., Cortéz, J., Morente, M., Caboblanco, M., Garijo, J., \& Rodriguez, A. (2003). Características métricas del Cuestionario de Calidad de Vida Profesional (CVP35). Gac Sanit, 18(2), 129-136.

Martín, N., Trevilla, C., \& Martín, V. (2009) Influencia de la motivación intrínseca y extrínseca sobre la transmisión de conocimiento. El caso de una organización sin fines de lucro. CIRIEC-España, Revista de Economía Pública, Social y Cooperativa, 66, 187-211.

Mayorca, E., \& Mayorca, D. (2010) El aprendizaje organizacional una estrategia de cambio en la administración hoy. Revista Panorama Económico, 18, 203-213.

Mayorca, E. (2010). Aprendizaje organizacional como factor de cambio caso: Facultad de Ciencias Económicas Universidad de Cartagena. (Tesis de maestría). Universidad Nacional de Colombia, Bogotá, Colombia. 
Mayorca, R., Ramírez, J., Viloria, O., \& Campos, J. (2007). Evaluación de un cuestionario sobre organizaciones que aprenden: adaptación, validez y confiabilidad. Revista Venezolana de Análisis de Coyuntura, 13(2), 149-164.

Marchand, L. (2006) Actualizaciones para el management y el desarrollo organizacional. Libro electrónico. Recuperado de: http://www.eumed.net/libros-gratis/2007a/223/mpvo.htm

Navarro, E., Llinares, C., \& Montañana, A. (2010) Factores de satisfacción laboral evocados por profesionales de la construcción en la comunidad valenciana (España). Revista de la Construcción, 9(1), 4-16.

Natividad, J., Espinoza, E., Cruz, M., \& Guivar, V. (2010). Relación entre el aprendizaje organizacional y el desempeño laboral de los docentes de la Facultad de Agropecuaria y Nutrición de la Universidad Nacional de Educación Enrique Guzmán y Valle, Lima, Perú.

Noe, R., Tews, M., \& Dachner, A. (2010) Learner engagement: A new perspective for enhancing our understanding of learner motivation and workplace learning. The Academy of Management Annals, 4(1), 279-375.

Örtenblad, A. (2002). A typology of the idea of learning organization. Management Learning, 33(2), 213-230.

Örtenblad, A. (2007). Senge's many faces: problem or opportunity? The Learning Organization, 14(2), 108-122.

Örtenblad, A. (2015). Towards increased relevance: context-adapted models of the learning organization. The Learning Organization, 22(3), 163-181.

Pardo, C., \& Díaz, O., (2014) Desarrollo del talento humano como factor clave para el desarrollo organizacional, una visión desde los líderes de gestión humana para empresas de Bogotá D.C. Revista Suma de Negocios, 5(11) 39-48.

Passaillague, R., \& Estrada, V. (2016). La gestión del conocimiento y el aprendizaje organizacional en instituciones de educación superior. Revista Internacional de Gestión del Conocimiento y la Tecnología, 4(2) 34-43.

Pirela de Faria, L., \& Sánchez, M. (2009) Cultura y aprendizaje organizacional en instituciones de educación básica. Revista de Ciencias Sociales, 15(1), 175-188. 
Pujol, A., \& Navarra, J. (2001). Tecnologías de gestión y aprendizaje organizacional. Reflexiones desde un estudio de caso. Conference Paper. Recuperado de http:// www.webcitation.org/6qXQLXMkn

Quezada, F., Sanhueza, A., \& Silva, F. (2010). Diagnóstico de la calidad de vida laboral percibida por los trabajadores de cuatro servicios clínicos del complejo asistencial “Dr. Víctor Ríos Ruiz" de Los ángeles (CAVRR). Horizontes Empresariales, 9(1), 55-68.

Quiróz, J. (2016). Implementación de un modelo de gestión basado en el liderazgo centrado en principios y su impacto en la rentabilidad de los restaurantes de la cadena Menestras del Negro de la ciudad de Quito en el año 2015. (Tesis de Magíster) Universidad Católica del Ecuador, Quito, Ecuador.

Ramos, L., Segura, A., Gonzáles, Y., \& Alonso, A. (2012). Evaluación y análisis de eficacia y eficiencia en restaurantes. Caso: Restaurante especializado en comida internacional. Revista Ingeniería Industrial, 1, 51-67.

Riquelme, A., Cravero, A., \& Saavedra, R. (2008). Gestión del conocimiento y aprendizaje organizacional: Modelo adaptado para la administración pública chilena. Chile: Universidad Autónoma de Chile.

Romero, A., \& Lassmann, H. (2016). Benefits of mentoring programs for child welfare workers: A systematic review. Human Service Organizations: Management, Leadership \& Governance. doi:10.1080/23303131.2016.1267055

Salazar, M. (2006). El liderazgo transformacional ¿modelo para organizaciones educativas que aprenden? UNI Revista, 1(3), 1-12.

Salvatierra, L. (2013). La percepción del talento humano de una empresa del sector financiero en Monterrey, sobre la calidad de vida en el trabajo. (Tesis de maestría). Universidad Autónoma de Nuevo León, Monterrey, México.

Sánchez, M. (2014). Capacitación en habilidades de atención al cliente para mejorar la calidad del servicio brindado en "El restaurant Mar Picante" de la ciudad de Trujillo. (Tesis de licenciatura). Universidad Privada Antenor Orrego, Trujillo, Perú.

Sandoval, M. (2004). El Aprendizaje Organizacional como respuesta al cambio. Su relación con el desarrollo,comportamiento y la comunicación organizacional: una visión general de las empresas de comercio y servicio en la ciudad de Puebla. (Tesis de licenciatura). Universidad de las Américas, Puebla, México. 
Segurado, A., \& Agulló, E. (2002). Calidad de vida laboral: hacia un enfoque integrador desde la psicología social. Psicothema, 14(4), 828-836.

Senge, P. (2012). La quinta disciplina: el arte y la práctica de la organización abierta al aprendizaje. Buenos Aires, Granica.

Solf, A. (2006). Motivación intrínseca laboral y su relación con las variables de personalidad orientación a la meta y tesón. Persona, 9, 111-126.

Yang, B., Watkins, K. E., \& Marsick, V. J. (2004). The construct of the learning organization: Dimensions, measurement, and validation. Human Resource Development Quarterly, 15(1), 31-55.

Zárate, A. S. (2006). Motivación Intrínseca Laboral y su relación con las variables de personalidad Orientación a la Meta y Tesón. Persona, 9, 111-126.

Recibido: 9 de mayo de 2018

Aceptado: 10 de abril de 2019 



\title{
CLIMA ORGANIZACIONAL Y RENDIMIENTO LABORAL EN SERVIDORES ADMINISTRATIVOS DE UNA UNIVERSIDAD
}

\author{
PÚBLICA DE LA CIUDAD DE AREQUIPA*
}

\author{
ORGANIZATIONAL CLIMATE AND LABOUR PERFORMANCE AMONG \\ ADMINISTRATIVE PERSONNEL FROM A PUBLIC UNIVERSITY IN AREQUIPA
}

José Manuel Calizaya López

Licenciado en Trabajo Social. Doctor en Ciencias de la Educación y Magíster en Ciencias con Mención en Gestión Social y Desarrollo Sostenible.

Docente principal, director del Departamento Académico de Trabajo Social y miembro del Instituto de Investigaciones Sociales de la Universidad Nacional de San Agustín, Arequipa, Perú.

(iD) https://orcid.org/oooo-0oo1-6221-0909

\section{Rildo Santos Bellido Medina}

Doctor en Psicología y Magíster en Gerencia Estratégica de Recursos Humanos por la Universidad nacional de San Agustín. Docente auxiliar en la Escuela Profesional de Relaciones Industriales y miembro del Instituto de Investigaciones Sociales de la Universidad Nacional de San Agustín, Arequipa, Perú.

(iD https://orcid.org/oooo-0oo2-8699-3490

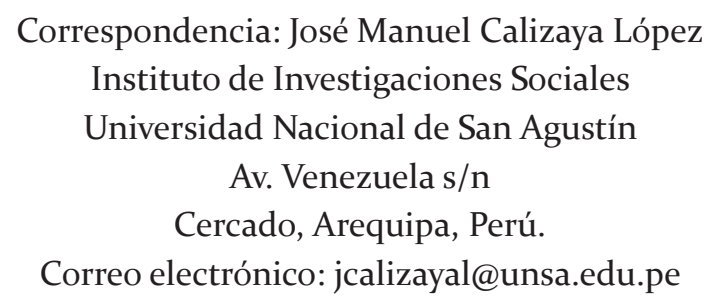

\footnotetext{
* La presente investigación es uno de los resultados esperados del proyecto de investigación seleccionado por UNSA Investiga financiado por la Universidad Nacional de San Agustín de Arequipa, contrato Nºo9-2016-UNSA.
} 

Rev. Psicol. (Arequipa. Univ. Catól. San Pablo) / Año 2019 / Vol 9 / N 3 / pp. 37-55

ISSN 2306-0565 versión impresa / ISSN 2311-7397 versión on line

(c) $(\$) \begin{aligned} & \text { Esta obra está bajo una Licencia Creative Commons } \\ & \text { Atribución 4.o Internacional (BY-NC-ND) }\end{aligned}$

\title{
CLIMA ORGANIZACIONAL Y RENDIMIENTO LABORAL EN SERVIDORES ADMINISTRATIVOS DE UNA UNIVERSIDAD PÚBLICA DE LA CIUDAD DE AREQUIPA
}

\author{
ORGANIZATIONAL CLIMATE AND LABOUR PERFORMANCE AMONG \\ ADMINISTRATIVE PERSONNEL FROM A PUBLIC UNIVERSITY IN AREQUIPA
}

\author{
José Manuel Calizaya López y Rildo Santos Bellido Medina \\ Universidad Nacional de San Agustín, Arequipa, Perú
}

\begin{abstract}
Resumen
El presente estudio pretende valorar el clima organizacional y el rendimiento laboral entre los trabajadores administrativos de una universidad pública de Arequipa. Se evaluó a 339 trabajadores de entre 20 y 70 años, siendo el 43.4\% mujeres y el 56.6\% varones. Se aplicó la Escala de Clima Organizacional y el Cuestionario de Rendimiento Laboral. El análisis estadístico reveló que ni el sexo y ni la edad, se asocian con el clima organizacional o el rendimiento laboral. Sin embargo, el clima organizacional y el rendimiento laboral mostraron diferencias significativas en función del cargo. Finalmente, el clima organizacional y el rendimiento laboral solo obtuvieron correlaciones nulas.
\end{abstract}

Palabras claves: Clima organizacional, rendimiento laboral, psicología organizacional.

\begin{abstract}
This study was designed to assess the organizational climate and job performance among administrative workers at a public university in Arequipa. . We tested 339 workers between 20 and 70 years of age (43.4\% female and 56.6\% male). We administered the Organizational Climate Scale and the Labour Performance Questionnaire. The statistical analysis revealed that neither gender nor age, were associated with organizational climate or labour performance,
\end{abstract}


although, the organizational climate and labour performance showed significant differences according to the participants' positions in the University. Finally, the association between organizational climate and labour performance only obtained null correlations.

Keywords: Organizational climate, labour performance, organizational psychology.

\section{Introducción}

Según Ivancevich (2006), el clima organizacional estudia los comportamientos, actitudes y desempeño humano en una empresa; basándose en teorías, métodos y principios de la psicología, la sociología y la antropología cultural; para entender la manera en cómo se percibe, se valora las capacidades de aprendizaje y las acciones individuales del trabajador. Luthans (2008) por otra parte, manifiesta que el clima organizacional es la aplicación de las fortalezas y las capacidades psicológicas del área de recursos humanos, que se miden, sedesarrollany seadministran eficazmente para el mejoramiento del desempeño en el lugar del trabajo actual. Sin embargo, hay un consenso entre las interpretaciones más conocidas sobre el clima organizacional (Arias, 2013), que lo refiere a la manera cómo perciben los trabajadores de una organización el trabajo, el ambiente, el ambiente físico en que éste se da, las relaciones interpersonales que tienen lugar en torno a él y las diversas regulaciones formales que afectan a dicho trabajo.

Por otro lado, los factores que determinan en el clima laboral son los siguientes:

a. Factores externos. Los factores externos de la organización como los clientes, proveedores, presiones sindicales y los medios de comunicación.

b. Factores psicológicos. Los factores psicológicosqueestán presentes comolasactitudes, las opiniones, las percepciones, las motivaciones y las expectativas de las personas durante sus interacciones.

c. Factores individuales, grupales y estructurales. Las características de cada individuo, comprende sus actitudes, percepciones, personalidad, valores, motivaciones y el nivel de estrés que puedan sentir influye sobre su comportamiento y sobre o ambiente al interior de la organización.

El clima organizacional resulta entonces, de la forma cómo las personas establecen procesos de interacción social (Méndez, 2006) y se ve influenciado por un sistema de valores, actitudes y creencias, como también por el ambiente o entorno. De hecho, un estudio local reciente, reveló que el clima organizacional tiene un impacto positivo y significativo en las relaciones interpersonales de los trabajadores de una empresa del sector privado (Arias, Lazo \& Quintana, 2018).

En ese sentido, según Martínez (2003) el clima organizacional determina la forma en que los individuos perciben el ambiente 
de trabajo, su rendimiento personal, su nivel de productividad y el grado de satisfacción que experimentan siendo parte de la organización en la cual labora. Por ello, nos basamos en un modelo desarrollado por Calizaya, Bellido y Huamani (2019) que sugiere que el clima organizacional se compone de tres dimensiones: cultura organizacional, diseño organizacional y potencial humano.

Se entiende como cultura organizacional la forma característica de pensar y hacer las cosas en una organización, producto de las interacciones para adaptarse a circunstancias del entorno y a tensiones internas (Schein, 1996). Existen 10 características primarias que concentran la esencia de la cultura organizacional:

1. La identidad de sus miembros: el grado en que los empleados se identifican con la organización como un todo y no solo con su tipo de trabajo o campo de conocimientos.

2. Énfasis en el grupo: las actividades laborales se organizan en torno a grupos y no a personas.

3. El enfoque hacia las personas: las decisiones de la administración toman en cuenta las repercusiones que los resultados tendrán en los miembros de la organización.

4. La integración de unidades: la forma como se fomenta que las unidades de la organización funcionen de forma coordinada e independiente.
5. El control: el uso de reglamentos procesos y supervisión directa para controlar la conducta de los individuos.

6. Tolerancia al riesgo: el grado en que se fomenta que los empleados sean agresivos, innovadores y arriesgados.

7. Los criterios para recompensar: como se distribuyen las recompensas, como los aumentos de sueldo y los ascensos, de acuerdo con el rendimiento del empleado y por su antigüedad, favoritismo $\mathrm{u}$ otros factores ajenos al rendimiento.

8. El perfil hacia los fines o los medios: de qué manera la administración se perfila hacia los resultados o metas y no hacia las técnicas o procesos usados para alcanzarlos.

9. El enfoque hacia un sistema abierto: el grado en que la organización controla y responde a los cambios externos.

10.Tolerancia al conflicto: grado en que la organización fomenta que los miembros traten abiertamente sus conflictos y críticas (Schein, 1996).

La cultura organizacional es un sistema particular de símbolos, influido por la sociedad circundante, por la historia de la organización y por sus líderes pasados, así como también por diferentes factores de contingencia. Según esta concepción, la cultura no es un elemento estático, sino una materia prima viviente utilizada de manera diferente por cada empleado y 
transformada por ellos durante el proceso de decodificación de los acontecimientos organizacionales. De esta manera, la cultura organizacional es una herramienta eficaz para la interpretación de la vida y del comportamiento organizacionales y para la comprensión de los procesos de decadencia, adaptación y cambio radical en las organizaciones (Allaire y Firsirotu, 1992). Según el modelo que aquí se trabaja, la cultura organizacional se compone de siete indicadores: Motivación, identidad, apoyo, equidad, trabajo en equipo, organización y condiciones de trabajo.

Así tenemos que la motivación es para Robbins (2008) la disposición para hacer algo, en donde la habilidad de la persona para satisfacer alguna necesidad condicionada de ese algo. La identidad organizacional está constituida por valores y creencias, considerándose a las creencias como convicciones compartidas y la idea generalizada de lo que es importante, y los valores son los estándares establecidos y aceptados por el grupo sobre lo que son y sus formas de reaccionar ante los imprevistos (Deal y Kennedy, 1999). El apoyo es una manifestación tanto individual como grupal o institucional que favorece los procesos de afrontamiento en el trabajo (Arias, 2013). La equidad se refiere a la igualdad de oportunidades que tienen los trabajadores de lograr sus metas laborales y de acceder a promociones en el trabajo. El trabajo en equipo es la ejecución de un proyecto a cargo de un grupo de personas, cuyo elemento clave es la capacidad de autogestión, es decir que, el grupo de personas están capacitadas para realizar las acciones que demanda la empresa (Mapcal, 1998). La organización es la coordinación de actividades diferentes, de colaboradores individuales, para llevar a cabo transacciones planeadas con el ambiente (Lawrencey Lorsch, 1973), y las condiciones laborales de un trabajador son los factores de su entorno intrínseco, que determinan la motivación, la satisfacción o insatisfacción laboral; y como menciona Chiavenato (2009), la motivación de las personas para el trabajo depende de dos factores íntimamente relacionados: factores higiénicos y factores motivacionales.

Por otro lado, según Hellrieguel y Slocum (2014), el diseño organizacional es el proceso de elegir una estructura de tareas, responsabilidades y relaciones de autoridad dentro de las organizaciones, que representa las conexiones entre varias divisiones o departamentos de una organización en un organigrama. Según nuestro modelo, esta dimensión se compone de tres componentes: comunicación, reconocimiento y espacio físico.

En cuanto a la primera, Katz y Kahn (1977) definen a la comunicación como el intercambio de información y difusión de significados. La comunicación fluye horizontal (entre posiciones de un mismo rango) o verticalmente (a nivel jerárquico); y se transmite de diversas formas (escritos, verbal, etc.). Su contenido es diverso (ordenes, informes, quejas, etc.) y tiene un costo económico. También se puede diferenciar entre comunicación formal e informal. En la primera incluyen todos los canales y medios de comunicación 
que en la organización se establecen de manera consciente y deliberada. Abarca comunicaciones verbales, memorandas, cartas, actas, informes o manuales oficiales. Por su parte, la comunicación informal comprende aquel conjunto de mensajes no escritos o rumores que se intercambian como resultado de la amistad o compañerismo (Simón, 1988).

Por reconocimiento se entiende la percepción que tienen los trabajadores sobre la retribución que reciben por el esfuerzo realizado, y constituye el primer incentivo en una relación laboral. No solo se refiere al establecimiento de un salario justo, sino de incentivos adicionales (no necesariamente monetarios) que motiven al trabajador a realizar un mejor desempeño (Litwin y Stringer, 1978). La OMS (2010), define como ambiente físico del trabajo a la parte de los recursos del espacio de trabajo que puede detectarse mediante monitoreos humanos o electrónicos e incluyen la estructura, aire, maquinaria, equipo, productos, químicos, materiales y procesos que se realizan o están presentes en el espacio de trabajo; y que pueden afectar la seguridad física o mental, la salud y el bienestar de los trabajadores. En ese sentido, Mejía (2011), refiere que los diversos factores ambientales pueden generar un gran impacto en la vida de los individuos, e incidir en diferentes aspectos, desde el comportamiento general hasta en la salud física, psicológica y social de los individuos.
En cuanto al potencial humano, este constructo abarca una diversidad de variables propias del trabajador que se alinean con la gestión del talento (Chiavenato, 2002). Dentro de estas capacidades tenemos la innovación, que describe el proceso a través del cual las ideas creativas se desarrollan en algo tangible, como por ejemplo un nuevo producto o práctica (Henry, 1991). El liderazgo es la habilidad de influir positivamente en la gente y los sistemas provocando una actitud determinada, bajo la autoridad de una persona a fin de tener un impacto significativo y lograr resultados importantes (Evans y Lindsay, 2008). La autonomía, es entendida como la capacidad que tienen los profesionales de controlar o manejar de una forma eficaz su situación laboral (Ruíz, 2015), y la cohesión, que según Balaguer, Castillo, Moreno, Garrigues y Soriano (2004), es una variable que ayuda a entender la dinámica del grupo y a desarrollar el buen clima en un equipo de trabajo.

Como segunda variable de este estudio tenemos al rendimiento laboral, que es definido por Chiavenato (2000) como las acciones o comportamientos observados en los empleados que son relevantes en el logro de los objetivos de la organización. Bittel (2000) plantea que el desempeño es influenciado en gran parte por las expectativas del empleado sobre el trabajo, sus actitudes hacia los logros y su deseo de armonía. Por tanto, el desempeño se relaciona o vincula con las habilidades y conocimientos que apoyan las acciones del trabajador, en pro de consolidar los objetivos de la empresa. Ghiselli (1998) 
señala como el desempeño está influenciado por cuatro factores: la motivación, habilidades y rasgos personales, claridad y aceptación del rol, y oportunidades para realizarse. La importancia de este enfoque reside en el hecho que el desempeño del trabajador va de la mano con las actitudes y aptitudes que estos tengan en función a los objetivos que se quieran alcanzar, seguidos por políticas normas, visión y misión de la organización.

De acuerdo con nuestro modelo propuesto (Calizaya, Bellido, Arias \& Huamani, 2019) el rendimiento laboral se compone de seis factores: asistencia y puntualidad, actitud hacia el trabajo, desempeño laboral, trabajo en equipo, orientación hacia los resultados y planificación. La puntualidad es una actitud que se adquiere desde los primeros años de vida mediante la formación de hábitos en la familia, donde las normas y costumbres establecen horarios para cada una de nuestras actividades (Orbegoso, 2007). Por lo que, la puntualidad es una disciplina, que se adquiere con la práctica y con el sacrificio según el temperamento de cada persona (Waichman, 2003).

Robbins (2008) define actitud, "como los juicios evaluativos, favorables o desfavorables, sobre objetos, personas o acontecimientos. Manifiestan la opinión de quienes hablan acerca de algo" (p. 235). El autor indica que las actitudes no se asemejan con los valores, pero sí se encuentran relacionadas; así, la actitud se encuentra compuesta por tres componentes: cognición, afecto y comportamiento. Así mismo, Robbins (2008) indica que la persona puede poseer muchas actitudes, pero centrándonos en el comportamiento organizacional son tres: satisfacción con el trabajo, participación en el trabajo y compromiso con la organización.

Robbins y Coulter (2010) entienden que el rendimiento laboral es un proceso para determinar qué tan exitosa ha sido una organización (o un individuo o un proceso) en el logro de sus actividades y objetivos laborales. En general a nivel organizacional la medición del desempeño laboral brinda una evaluación acerca del cumplimento de las metas estratégicas a nivel individual. Así también, Robbins y Judge (2013) explican que, en las organizaciones, solo se evalúan la forma en que los empleados realizan sus actividades y estas incluyen una descripción del puesto de trabajo, sin embargo, las compañías actuales, menos jerárquicas y más orientadas al servicio, requieren de más información. Hoy en día se reconocen tres tipos principales de conductas que constituyen el desempeño laboral, como son el desempeño de las tareas, el civismo y falta de productividad.

En cuanto al trabajo en equipo como dimensión del rendimiento laboral, Posner (200o), lo define como una modalidad de articular las actividades laborales de un grupo humano en torno a un conjunto de fines, de metas y de resultados a alcanzar. El trabajo en equipo implica una interdependencia 
activa entre los integrantes de un grupo que comparten y asumen una misión de trabajo. Para Robbins (2008), la velocidad y la capacidad de reacción ante determinadas circunstancias son los dos elementos principales de la orientación a resultados, una característica que tienen las organizaciones para acercarse a los objetivos propuestos de la forma más eficaz posible. Especialistas de la gestión empresarial como Robbins (2008), creen incluso, que es una competencia estrechamente vinculada a la capacidad de adaptación de las instituciones a su entorno, sobre todo si se tiene en cuenta que el mercado actual cambia continuamente y exige a los profesionales de esta área nuevas competencias y habilidades.

Según Chiavenato (2000), a planificación es la primera función administrativa porque sirve de base para las demás funciones. Esta función determina por anticipado cuáles son los objetivos que deben cumplirse y qué debe hacerse para alcanzarlos; por tanto, es un modelo teórico para actuar en el futuro. La planificación comienza por establecer los objetivos y detallar los planes necesarios para alcanzarlos de la mejor manera posible. La planificación determina donde se pretende llegar, qué debe hacerse, cómo, cuándo y en qué orden.

En vista de estas definiciones conceptuales y operativas, el fin de este estudio es valorar las relaciones entre el clima organizacional y el rendimiento laboral, según los modelos propuestos, analizando también de manera comparativa, cómo se manifiestan estas variables en función del sexo, la condición laboral y el cargo de los trabajadores de una universidad pública de la ciudad de Arequipa.

\section{Método}

\section{Participantes}

El estudio se realizó con servidores administrativos de una universidad pública de la ciudad de Arequipa. La muestra fue aleatoria y estuvo conformada por 339 servidores de una población total de 1479 trabajadores. La edad media de los servidores administrativos fue de 43 años con una desviación estándar de \pm 11.63 , en un rango de 20 a 70 años. El $43.4 \%$ fueron mujeres y el $56.6 \%$ varones. La condición laboral fue del 57.2\% nombrados, el 34.5 CAS (Contrato Administrativo de Servicios) y el 8.3\% con contrato a tiempo fijo; de los cuales el 40,1\% trabajan como secretarias, el $13.9 \%$ conserje, el $11.2 \%$ asistente, el $9.4 \%$ vigilante, el $8.6 \%$ bibliotecario, el $6.8 \%$ técnicos y el restante $10 \%$ trabajan como jardinero, almacenista, cajero, nutricionista, reportero y camarógrafo.

\section{Instrumentos}

Se utilizó la Escala del Clima Organizacional elaborada y validada por Calizaya, Bellido y Huamani (2019), el cual consta de 50 ítems de respuesta tipo Likert ( $1=$ muy en desacuerdo, hasta, $5=$ muy de acuerdo) que evalúa tres dimensiones: La primera dimensión es la Cultura organizacional con siete indicadores, que son Motivación (ítems: 
1, 2, 3, 4), Identidad (Ítems: 5, 6, 7), Apoyo (Îtems: 8, 9, 10), Equidad (Ítems: 11, 12, 13, 14), Trabajo en equipo (Ítems: 15, 16, 17), Organización (Îtems:18, 19, 20) y Condiciones de trabajo (Îtems: 21, 22, 23, 24). La segunda dimensión es el Diseño Organizacional con tres indicadores, que son la Comunicación organizacional (Îtems: 25, 26, 27, 28), Reconocimiento (Îtems: 29, 30, 31, 32) y Espacio físico (Îtems: 33, 34, 35, 36) y la tercera dimensión Potencial Humano con cuatro indicadores que son la Innovación (Îtems: 37, 38, 39, 40), Liderazgo (Ítems: 41, 42, 43), Autonomía $(44,45,46)$ y Cohesión $(47,48,49,50)$. Las mismas que presentan confiabilidad alta (Cultura organizacional $\omega=$ .95; Diseño organizacional $\omega=.86$ y Potencial Humano $\omega=.91$ ).

El otro instrumento utilizado fue el Cuestionario de Rendimiento Laboral, elaborado y validado por Calizaya, Bellido, Arias y Huamani (2019), el mismo que presenta 6 factores y 47 ítems, Asistencia y puntualidad con 4 ítems (1, 2, 3,4); Actitud hacia el trabajo con 11 ítems $(5,6,7,8,9,10,11,12,13,14$, 15); Desempeño laboral con 7 ítems (16, $17,18,19,20,21,22)$; Trabajo en equipo con 11 ítems $(23,24,25,26,27,28,29$, 30, 31, 32, 33); Orientación a resultados con 8 ítems $(34,35,36,37,38,39,40,41)$ y Planificación con 6 ítems (42, 43, 44, 45, 46, 47). Se obtuvieron los niveles de confiabilidad de los 6 factores mediante el método de consistencia interna y con la prueba alfa de Cronbach: .32 para Asistencia y puntualidad, .96 para Actitud hacia el trabajo, .78 para
Desempeño laboral, .8o para Trabajo en equipo, .93 para Orientación a resultados y .92 para el factor Planificación. En los instrumentos se adjuntaron preguntas para medir características sociodemográficas como edad, sexo, condición laboral, cargo y área laboral; y se consignaron los datos propios del consentimiento informado.

\section{Procedimiento}

La Escala de Clima Organizacional fue aplicada a los servidores administrativos en su área de trabajo, y el cuestionario de Rendimiento laboral fue aplicado al jefe inmediato superior de cada uno de los servidores administrativos seleccionados en la muestra. La evaluación fue hecha de acuerdo al cargo laboral y al área de trabajo. Esta evaluación se realizó con la autorización y en coordinación con las autoridades de la universidad, y previo consentimiento informado y reserva total de la información individual. Para el análisis de la información se utilizó el programa estadístico SPSS versión 24. Se exploró la distribución de los datos, y se evidenció que no existe normalidad ( $\mathrm{p}<.05)$, por lo tanto, el análisis estadístico utilizado fue no paramétrico. Se realizó el análisis descriptivo y el comparativo de las variables y sus dimensiones según edad, sexo, condición laboral y cargo. La comparación de dos muestras independientes se utilizó con el estadístico U de MannWhitney, la comparación de más de dos muestras independientes (comparando los puntajes del rango promedio) con la $\mathrm{H}$ de Kruskal-Wallis y las correlaciones 
con la Rho de Spearman. Asimismo, se aplicó el calculó de la probabilidad de superioridad (PSest) como tamaño del efecto para U de Mann-Whitney, las normas interpretativas son: No efecto (PSest $\leq$ o.o); pequeño (PSest $\geq 0,56)$; mediano (PSest $\geq 0.64$ ) y grande (PSest $\geq$ o.71) (Grissom, 1994). Para calcular el tamaño del efecto de Kruskal-Wallis se utilizó el coeficiente épsilon al cuadrado (ER2), (Tomczak \& Tomczak, 2014), las normas interpretativas son: pequeño ( $E R 2 \geq 0.01)$; mediano $(E R 2 \geq 0.06)$ y grande $\left(E R_{2} \geq 0.14\right)$ (Faul, Erdfelder, Lang, \& Buchner, 2007).

\section{Resultados}

En la Tabla 1, se observa con respecto a la cultura organizacional, que el 50\% de los investigados presenta puntajes menores a 80 , de un puntaje máximo de 115 , que indica un puntaje medio con tendencia al puntaje alto. En el diseño organizacional menos del $50 \%$ de participantes presenta 38 puntos de un rango de 12 a 50 puntos, que indica un nivel medio. En la dimensión potencial humano se observa que el $50 \%$ de los participantes, presenta puntajes menores a 45 de un rango de 14 a 70 , que indica un puntaje medio con tendencia al puntaje alto. Finalmente, en la variable clima organizacional el $50 \%$ de participantes presenta puntajes menores a 162 de un rango de 50 a 245 puntos, que indican un nivel medio.

Tabla 1. Valores descriptivos del clima organizacional

\begin{tabular}{|lccccc|}
\hline & $\boldsymbol{M}$ & $\boldsymbol{D E}$ & $\boldsymbol{M d}$ & Min. & Max. \\
\hline Cultura Organizacional & 79.2 & 16.3 & 80.0 & 24 & 115 \\
Diseño organizacional & 37.9 & 9.2 & 38.0 & 12 & 60 \\
Potencial Humano & 45.7 & 10.2 & 45.0 & 14 & 70 \\
Clima organizacional & 162.9 & 33.6 & 162.0 & 50 & 245 \\
\hline
\end{tabular}

Nota: $M=$ media aritmética; $D E=$ desviación estándar; $M d=$ mediana; $M i n=$ puntaje mínimo; Max= puntaje máximo

No existen diferencias estadísticamente es decir, los valores de probabilidad de significativas del clima organizacional y superioridad (tamaño del efecto), se aprosus dimensiones según sexo (Tabla 2), ximan a un efecto pequeño (PSest< $<.43$ ). 
Tabla 2. Análisis comparativo de las dimensiones del clima organizacional según sexo

\begin{tabular}{|c|c|c|c|c|c|}
\hline Dimensiones & $\begin{array}{c}\text { Hombres } \\
(n=192) \\
\operatorname{Mdn}\left(R_{i c}\right)\end{array}$ & $\begin{array}{c}\text { Mujeres } \\
(n=147) \\
\text { Mdn (Ric') }\end{array}$ & $U$ & $p$ & $P S_{\text {est }}$ \\
\hline Cultura Organizacional & $78.0(22.0)$ & $81.0(23.0)$ & $13444 \cdot 5$ & 0.455 & 0.48 \\
\hline Diseño organizacional & $38.0(13.7)$ & $38.0(14.0)$ & 13916.5 & 0.827 & 0.49 \\
\hline Potencial Humano & $45.0(15.0)$ & $45.0(15.0)$ & 13558.5 & 0.536 & 0.48 \\
\hline Clima organizacional & $158.0(50.5)$ & $163.0(47.0)$ & 13538.0 & 0.521 & 0.48 \\
\hline
\end{tabular}

Nota: $n=$ tamaño muestral; $U=U$ de Mann-Whitney; $p=$ p valor; $P S e s t=$ Probabilidad de Superioridad (tamaño del efecto)

En la Tabla 3, se observa que no existen diferencias estadísticamente significativas del clima organizacional y sus dimensiones según condición laboral, es decir, los valores de coeficiente épsilon al cuadrado (tamaño del efecto), se aproximan a un efecto pequeño $(E R 2=0.003)$.

Tabla 3. Análisis comparativo de las dimensiones del clima organizacional según condición laboral

\begin{tabular}{|c|c|c|c|c|c|c|}
\hline Dimensiones & $\begin{array}{l}\text { Nombrado } \\
\text { (n=194) } \\
\text { Mdn (Ric') }\end{array}$ & $\begin{array}{c}\text { Contrato } \\
\text { plazo fijo } \\
(n=28) \\
\text { Mdn (Ric') }\end{array}$ & $\begin{array}{c}\text { CAS } \\
(n=117) \\
\operatorname{Mdn}\left(\text { Ric }^{\prime}\right)\end{array}$ & $\boldsymbol{H}$ & $p$ & $E_{R}^{2}$ \\
\hline Cultura organizacional & $79.5(22.2)$ & $81.5(28.0)$ & $81.0(23.0)$ & 0.4 & 0.823 & 0.001 \\
\hline Diseño organizacional & $37.5(13.0)$ & $37.5(14.2)$ & $39.0(14.0)$ & 1.3 & 0.515 & 0.003 \\
\hline Potencial humano & $45.0(13.2)$ & $46.5(19.7)$ & $45.0(15.0)$ & 0.1 & 0.970 & 0.001 \\
\hline Clima organizacional & $158.5(48.2)$ & $165.0(56.7)$ & $162.0(52.0)$ & 0.3 & 0.851 & 0.001 \\
\hline
\end{tabular}

Nota: $\boldsymbol{n}=$ tamaño muestral; $\boldsymbol{H}=\mathrm{H}$ de Kruskal Wallis; $\boldsymbol{p}=\mathrm{p}$ valor; $E R \mathbf{R}=$ coeficiente épsilon al cuadrado (tamaño del efecto)

En la Tabla 4, se observa que existen diferencias en las dimensiones diseño organizacional, potencial humano y la variable clima organizacional según cargo laboral, donde el coeficiente $(E R 2=.04)$ indica que la proporción de variabilidad de estas dimensiones y de la variable pueden atribuirse al cargo laboral (efecto pequeño). En la dimensión cultura organizacional, no existen diferencias significativas y el coeficiente $(E R 2=0.03)$ indica un efecto pequeño. De modo que, al analizar los rangos promedio, se observa que los participantes con el cargo de conserje, secretaria, asistente, son los que presentan puntajes más altos, a diferencia de los participantes con el cargo de bibliotecario y vigilante que presentan puntajes bajos. 
Tabla 4. Análisis comparativo de las dimensiones y del clima organizacional según cargo

\begin{tabular}{|c|c|c|c|c|c|c|c|c|c|c|}
\hline Dim. & $\begin{array}{c}\text { Bibliotecario } \\
\qquad(n=29) \\
M d n\left(\text { Ric }^{\prime}\right)\end{array}$ & $\begin{array}{c}\text { Conserje } \\
(n=47) \\
\text { Mdn (Ric') }\end{array}$ & $\begin{array}{c}\text { Secretaria } \\
(n=136) \\
\text { Mdn (Ric') }\end{array}$ & $\begin{array}{c}\text { Asistente } \\
(n=38) \\
\text { Mdn (Ric') }\end{array}$ & $\begin{array}{c}\text { Vigilante } \\
(n=32) \\
\text { Mdn (Ric') }\end{array}$ & $\begin{array}{c}\text { Técnico } \\
(n=23) \\
\text { Mdn (Ric') }\end{array}$ & $\begin{array}{c}\text { Otros } \\
(n=34) \\
\text { Mdn (Ric') }\end{array}$ & $H$ & $p$ & $E_{R}^{2}$ \\
\hline 1 & $75.0(27.5)$ & $81.0(23.0)$ & $81.0(22.5)$ & $81.0(22.2)$ & $74.0(33.0)$ & 76.0 (10.0) & $84.5(34.0)$ & 10.8 & 0.09 & 0.03 \\
\hline 2 & $38.0(14.5)$ & $39.0(12.0)$ & $38.0(12.0)$ & $39.5(10.2)$ & $31.5(17.7)$ & $35.0(13.0)$ & $40.5(17.2)$ & 12.8 & 0.04 & 0.04 \\
\hline 3 & $43.0(18.5)$ & $47.0(14.0)$ & $46.0(15.0)$ & $45.0(12.7)$ & $39.5(19.2)$ & $40.0(9.0)$ & $46.0(15.2)$ & 12.3 & 0.05 & 0.04 \\
\hline 4 & $155.0(57.5)$ & $164.0(43.0)$ & $164.5(47.2)$ & $165.5(40.0)$ & $141.0(70.5)$ & 149.0 (30.0) & $170.0(62.0)$ & 13 & 0.04 & 0.04 \\
\hline
\end{tabular}

Nota: $\boldsymbol{n}=$ tamaño muestral; $\boldsymbol{H}=\mathbf{H}$ de Kruskal Wallis; $\boldsymbol{p}=\mathbf{p}$ valor; $\boldsymbol{E R} \mathbf{2}=$ coeficiente épsilon al cuadrado (tamaño del efecto); $1=$ Cultura organizacional; $2=$ Diseño organizacional; $3=$ Potencial humano; $4=$ Clima organizacional.

A nivel correlacional, se observa que no existe relación entre la edad, la variable clima organizacional y sus dimensiones; sin embargo, las tres dimensiones del clima organizacional, cultura organizacional, diseño organizacional y potencial humano están correlacionadas de manera fuertey positiva con la puntuación global del clima organizacional, y de manera moderada entre sí (ver Tabla 5).

Tabla 5. Correlaciones del clima organizacional y sus dimensiones con la edad

\begin{tabular}{|lccccc|}
\hline & 1 & 2 & 3 & 4 & 5 \\
\hline Edad & 1.000 & & & & \\
Cultura Organizacional & 0.031 & 1.000 & & & \\
Diseño organizacional & 0.015 & $.842^{* *}$ & 1.000 & & \\
Potencial Humano & 0.009 & $.804^{* *}$ & $.784^{* *}$ & 1.000 & \\
Clima organizacional & 0.026 & $.960^{* *}$ & $.926^{* *}$ & $.908^{* *}$ & 1.000 \\
\hline
\end{tabular}

En la Tabla 6, se observa con respecto al rendimiento laboral, que el $50 \%$ de los servidores administrativos presenta puntajes menores a 109, de un rango de 58 a 199, que indica un puntaje medio con tendencia baja. Con respecto a las dimensiones: actitud hacia el trabajo $(M d=25)$, desempeño laboral $(M d=$ $15)$, orientación a resultados $(M d=15)$ y planificación $(M d=13)$ indican un puntaje medio con tendencia baja. Sin embargo, la dimensión trabajo en equipo $(M d=28)$ indican un puntaje medio, a diferencia de la dimensión asistencia y puntualidad, donde el 50\% de participantes presenta puntajes menores a 14 de un rango de 5 a 20 puntos, que indica un puntaje medio con tendencia al puntaje alto. 
Tabla 6. Valores descriptivos del rendimiento laboral

\begin{tabular}{|lccccc|}
\hline & $\boldsymbol{M}$ & $\boldsymbol{D E}$ & $\boldsymbol{M d}$ & $\boldsymbol{M i n}$. & Max. \\
\hline Asistencia y puntualidad & 14.2 & 2.4 & 14.0 & 5 & 20 \\
Actitud hacia el trabajo & 25.6 & 10.2 & 25.0 & 12 & 55 \\
Desempeño laboral & 15.4 & 4.6 & 15.0 & 7 & 33 \\
Trabajo en equipo & 27.4 & 6.7 & 28.0 & 11 & 48 \\
Orientación a resultados & 16.0 & 6.2 & 15.0 & 8 & 35 \\
Planificación & 13.3 & 5.1 & 13.0 & 6 & 30 \\
Rendimiento Laboral & 111.9 & 29.5 & 109.0 & 58 & 199 \\
\hline
\end{tabular}

Nota: $M=$ media aritmética; $D E=$ desviación estándar; $M d=$ mediana; $M i n=$ puntaje mínimo; Max= puntaje máximo

No existen diferencias estadísticamente superioridad (tamaño del efecto), se aprosignificativas del rendimiento laboral y ximan a un efecto pequeño (PSest $<0.49$ ), sus dimensiones según sexo (Tabla 7), que indican que el rendimiento laboral es decir, los valores de probabilidad de no diferencia entre hombres y mujeres.

Tabla 7. Análisis de las diferencias de del rendimiento laboral según sexo

\begin{tabular}{|c|c|c|c|c|c|}
\hline Dimensiones & $\begin{array}{c}\text { Hombres } \\
(n=192) \\
\text { Mdn (Ric') }\end{array}$ & $\begin{array}{c}\text { Mujeres } \\
(n=147) \\
\text { Mdn (Ric') }\end{array}$ & $U$ & $p$ & $P S_{e s t}$ \\
\hline Asistencia y puntualidad & $15.0(3.0)$ & $14.0(3.0)$ & 13591.5 & 0.555 & 0.48 \\
\hline Actitud hacia el trabajo & $24.5(20.0)$ & $25.0(13.0)$ & 13995.0 & 0.896 & 0.49 \\
\hline Desempeño laboral & $15.0(6.7)$ & $15.0(6.0)$ & 13731.0 & 0.669 & 0.48 \\
\hline Trabajo en equipo & $27.0(11.0)$ & $28.0(7.0)$ & 12975.0 & 0.203 & 0.45 \\
\hline Orientación a resultados & $15.0(10.0)$ & $16.0(7.0)$ & 13675.5 & 0.625 & 0.48 \\
\hline Planificación & $13.0(9.0)$ & $12.0(6.0)$ & 13505.0 & 0.496 & 0.47 \\
\hline Rendimiento Laboral & $109.0(50.5)$ & $110.0(34.0)$ & 13740.5 & 0.678 & 0.48 \\
\hline
\end{tabular}

Nota: $n=$ tamaño muestral; $U=U$ de Mann-Whitney; $p=$ p valor; $P S e s t=$ Probabilidad de Superioridad (tamaño del efecto)

En la Tabla 8, se observa que existen diferencias en las dimensiones actitud hacia el trabajo, desempeño laboral, trabajo en equipo, orientación a resultados, planificación y la variable rendimiento laboral, donde el coeficiente $\left(E R_{2}<0.04\right)$ indica que la proporción de variabilidad de estas dimensiones y de la variable pueden atribuirse al cargo laboral (efecto pequeño), donde los servidores administrativos nombrados y CAS son los que presentan puntajes más altos que los servidores por contrato a plazo fijo; los mismos que en la dimensión asistencia y puntualidad 
presentan puntajes más altos, con un coeficiente $(E R 2=0.02)$ que indica un efecto pequeño.

Tabla 8. Análisis comparativo de las dimensiones del rendimiento laboral según condición laboral

\begin{tabular}{|c|c|c|c|c|c|c|}
\hline Dimensiones & $\begin{array}{l}\text { Nombrado } \\
(n=194) \\
\operatorname{Mdn}\left(\text { Ric }^{\prime}\right)\end{array}$ & $\begin{array}{c}\text { Contrato } \\
\text { plazo fijo } \\
(n=28) \\
\operatorname{Mdn}\left(\text { Ric }^{\prime}\right)\end{array}$ & $\begin{array}{c}\text { CAS } \\
(n=117) \\
\operatorname{Mdn}\left(\text { Ric }^{\prime}\right)\end{array}$ & $\boldsymbol{H}$ & $p$ & $E_{R}^{2}$ \\
\hline Asistencia y puntualidad & $14.0(3.0)$ & $15.0(2.0)$ & $14.0(3.0)$ & 6.4 & 0.04 & 0.02 \\
\hline Actitud hacia el trabajo & $24.0(17.2)$ & $17.5(12.5)$ & $26.0(12.5)$ & 8.7 & 0.013 & 0.03 \\
\hline Desempeño laboral & $15.0(6.0)$ & $12.5(4.7)$ & $16.0(6.0)$ & 7.2 & 0.028 & 0.02 \\
\hline Trabajo en equipo & $27.0(11.0)$ & $24.5(5.0)$ & $28.0(7 \cdot 5)$ & 6.5 & 0.038 & 0.02 \\
\hline Orientación a resultados & $14.0(8.0)$ & $13.0(8.7)$ & $17.0(7.0)$ & 8.1 & 0.017 & 0.02 \\
\hline Planificación & $12.0(8.0)$ & $11.0(6.0)$ & $14.0(7.0)$ & $7 \cdot 7$ & 0.021 & 0.02 \\
\hline Rendimiento Laboral & $107.5(45.0)$ & $92.5(32.7)$ & $114.0(38.5)$ & 8.5 & 0.014 & 0.03 \\
\hline
\end{tabular}

Nota: $n=$ tamaño muestral; $H=H$ de Kruskal Wallis; $p=$ p valor; $E R 2=$ coeficiente épsilon al cuadrado (tamaño del efecto)

En la Tabla 9, se observa que existen diferencias en las dimensiones, desempeño laboral, trabajo en equipo, orientación a resultados, planificación y la variable rendimiento laboral, donde el coeficiente $(E R 2<0.04)$ indica que la proporción de variabilidad de estas dimensiones y de la variable pueden atribuirse al cargo laboral (efecto pequeño), donde los servidores administrativos con cargo de conserjey secretaria son los que presentan puntajes más altos que los otros servidores. Asimismo, en la dimensión actitud hacia el trabajo, los servidores con cargo de conserje y secretaria presentan puntajes más altos, con un coeficiente $(E R 2=$ o.o6) que indica un efecto mediano. Sin embargo, en la dimensión asistencia y puntualidad los servidores con cargo de vigilante presentan puntajes más altos que los otros servidores con un coeficiente $(E R 2=.06)$ que indica un efecto mediano. 
Tabla 9. Análisis comparativo de las dimensiones del rendimiento laboral según cargo

\begin{tabular}{|c|c|c|c|c|c|c|c|c|c|c|}
\hline Dim. & $\begin{array}{c}\text { Bibliotecario } \\
(n=29) \\
\text { Mdn (Ric') }\end{array}$ & $\begin{array}{c}\text { Conserje } \\
(n=47) \\
\operatorname{Mdn}\left(\text { Ric }^{\prime}\right)\end{array}$ & $\begin{array}{c}\text { Secretaria } \\
(n=136) \\
\text { Mdn (Ric') }\end{array}$ & $\begin{array}{c}\text { Asistente } \\
(n=38) \\
\text { Mdn (Ric') }\end{array}$ & $\begin{array}{c}\text { Vigilante } \\
(n=32) \\
\operatorname{Mdn}\left(\text { Ric }^{\prime}\right)\end{array}$ & $\begin{array}{c}\text { Técnico } \\
(n=23) \\
\operatorname{Mdn}\left(\text { Ric }^{\prime}\right)\end{array}$ & $\begin{array}{c}\text { Otros } \\
(n=34) \\
\operatorname{Mdn}\left(\text { Ric }^{\prime}\right)\end{array}$ & $H$ & $p$ & $E_{R}^{2}$ \\
\hline 1 & $15.0(3.0)$ & $14.0(2.0)$ & $14.0(3.0)$ & $15.0(3.0)$ & $16.0(1.0)$ & $15.0(3.0)$ & $14.0(4.0)$ & $17 \cdot 3$ & 0.008 & 0.06 \\
\hline 3 & $13.0(8.0)$ & $16.0(9.0)$ & $15.5(6.0)$ & $15.0(5.2)$ & $13.5(6.7)$ & $12.0(5.0)$ & $16.5(8.2)$ & 14.8 & 0.022 & 0.04 \\
\hline 4 & $23.0(14.0)$ & $30.0(12.0)$ & $28.0(7.7)$ & $27.0(10.2)$ & $24.0(8.7)$ & $27.0(8.0)$ & $28.0(9.5)$ & 14.3 & 0.027 & 0.04 \\
\hline 5 & $12.0(15.5)$ & $17.0(14.0)$ & $16.0(7.7)$ & $15.5(6.0)$ & $12.0(3.7)$ & $15.0(8.0)$ & $16.0(9.2)$ & 14.4 & 0.025 & 0.04 \\
\hline
\end{tabular}

Nota: $n=$ tamaño muestral; $H=H$ de Kruskal Wallis; $p=p$ valor; $E R 2=$ coeficiente épsilon al cuadrado (tamaño del efecto); 1=Asistencia y puntualidad; $2=$ Actitud hacia el trabajo; $3=$ Desempeño laboral; $4=$ Trabajo en equipo; $5=$ Orientación a resultados; $6=$ Planificación; $7=$ Rendimiento laboral

A nivel correlacional, se observa que existe relación entre la edad y algunas dimensiones del rendimiento laboral, estas relaciones son bajas y negativas, es decir, a mayor edad menor actitud hacia el trabajo, menor desempeño laboral, menos trabajo en equipo, menor orientación a resultados. En general a mayor edad menor rendimiento laboral yviceversa. Sin embargo, las dimensiones que no se relacionan con la edad son la asistenciay puntualidady la planificación. Además, se observa que las dimensiones correlacionan entre sí, donde la dimensión asistencia y puntualidad presenta correlación negativa de nivel medio con todas las otras dimensiones y la variable rendimiento laboral. Las otras dimensiones están correlacionadas de manera fuertey positiva con la puntuación global del rendimiento laboral (ver Tabla 10).

Tabla 10. Correlaciones del rendimiento laboral y sus dimensiones con la edad

\begin{tabular}{|llccccccc|}
\hline & Edad & $\mathbf{1}$ & $\mathbf{2}$ & $\mathbf{3}$ & $\mathbf{4}$ & $\mathbf{5}$ & $\mathbf{6}$ & 7 \\
\hline Edad & 1.000 & & & & & & & \\
1. Asistencia y puntualidad & 0.065 & 1.000 & & & & & & \\
2. Actitud hacia el trabajo &,$- 155^{* *}$ &,$- 484^{* * *}$ & 1.000 & & & & & \\
3. Desempeño laboral &,$- 120^{*}$ &,$- 453^{* *}$ &, $822^{* *}$ & 1.000 & & & & \\
4. Trabajo en equipo &,$- 149^{* *}$ &,$- 481^{* *}$ &, $857^{* *}$ &, $800^{* *}$ & 1.000 & & & \\
5. Orientación a resultados &,$- 143^{* *}$ &,$- 462^{* *}$ &, $791^{* *}$ &, $748^{* *}$ &, $797^{* *}$ & 1.000 & \\
6. Planificación & -0.101 &,$- 458^{* *}$ &, $841^{* *}$ &, $793^{* *}$ &, $821^{* *}$ &, $819^{* *}$ & 1.000 & \\
7. Rendimiento Laboral &,$- 158^{* *}$ &,$- 457^{* *}$ &, $950^{* *}$ &, $886^{* *}$ &, $930^{* *}$ &, $891^{* *}$ &, $918^{* *}$ & 1.000 \\
\hline
\end{tabular}

La Tabla 11, muestra que no existe relación entre el clima organizacional y sus dimensiones con el rendimiento laboral y sus dimensiones, es decir, el rendimiento laboral no es posible explicarlo a través del clima organizacional en los servidores administrativos de la universidad investigada. 
Tabla 11. Correlaciones del clima organizacional y el rendimiento laboral

\begin{tabular}{|lcccc|}
\hline & $\begin{array}{c}\text { Cultura } \\
\text { organizacional }\end{array}$ & $\begin{array}{c}\text { Diseño } \\
\text { organizacional }\end{array}$ & $\begin{array}{c}\text { Potencial } \\
\text { humano }\end{array}$ & $\begin{array}{c}\text { Clima } \\
\text { organizacional }\end{array}$ \\
\hline 1. Asistencia y puntualidad & -0.067 & -0.096 & -0.083 & -0.077 \\
2. Actitud hacia el trabajo & -0.007 & 0.014 & -0.036 & -0.007 \\
3. Desempeño laboral & 0.035 & 0.031 & -0.038 & 0.021 \\
4. Trabajo en equipo & -0.042 & -0.004 & -0.07 & -0.043 \\
5. Orientación a resultados & -0.021 & 0.002 & -0.093 & -0.025 \\
6. Planificación & -0.002 & 0.007 & -0.072 & -0.013 \\
7. Rendimiento Laboral & -0.011 & 0.007 & -0.069 & -0.018 \\
\hline
\end{tabular}

\section{Discusión}

Para Chiavenato (2000) el clima organizacional constituye el medio interno de una organización, donde la atmósfera en la que se constituye es peculiar a cada organización. Asimismo, menciona que el concepto de clima organizacional involucra diferentes aspectos de la situación, que se sobreponen mutuamente en diversos grados, como el tipo de organización, la tecnología, las políticas, las metas operacionales, los reglamentos internos (factores estructurales); además de las actitudes, sistemas de valores y formas de comportamiento social que son impulsadas o castigadas (factores sociales).

Estos indicadores que se mencionan tienen relación con el tipo de organización que hoy en día presenta la Universidad Nacional de San Agustín de Arequipa, y con los cambios que generan en ella, a través de la implementación de la nueva ley universitaria $\left(\mathrm{N}^{\circ}\right.$ 30220), cuya finalidad es mejorar y fortalecer las universidades peruanas. En ese sentido, los resultados de la presente investigación indican que el clima organizacional que perciben los servidores administrativos, evidencian que un $61.4 \%$ consideran que este se encuentra en un nivel medio, con una tendencia a ser alto en un 31.3\% y percibido como bajo en un $7 \cdot 4 \%$.

El análisis inferencial en función de tres variables sociodemográficas revela ciertos aspectos que merecen ser comentados, pues el sexo de los trabajadores no es una variable que evidencie diferencias en el clima organizacional, así como tampoco existe una correlación significativa entre el clima organizacional o sus dimensiones y la edad de los trabajadores evaluados. Tampoco se registraron diferencias significativas entre los trabajadores de esta universidad pública, en función de la condición laboral, sin embargo, el cargo de los trabajadores sí presenta diferencias estadísticamente significativas en las dimensiones de diseño organizacional y potencial humano, así como en el clima organizacional como constructo global. Aunque los tamaños del efecto son bajos, se puede apreciar que los trabajadores en el cargo de conserje, secretaria y asistente, 
son los que presentan puntajes más altos, mientras que los trabajadores con cargo de bibliotecario y vigilante presentan los puntajes más bajos.

Por otro lado, el rendimiento laboral tiene a ser bajo entre los trabajadores de la universidad pública de Arequipa, y tampoco se evidencian diferencias estadísticamente significativas entre los puntajes de los trabajadores en función del sexo, y se registran correlaciones muy bajas entre la edad con el rendimiento laboral y sus respectivas dimensiones. No obstante, la condición laboral y el cargo de los trabajadores sí registra diferencias estadísticamente significativas en los puntajes del rendimiento laboral (y sus dimensiones). Así, se tiene que el personal administrativo nombrado y CAS presentan puntajes más altos aquellos trabajadores que tienen contrato a plazo fijo, los mismos que en la dimensión asistencia y puntualidad presentan puntajes más altos, pero con tamaños del efecto pequeños.
Por otro lado, en cuanto al cargo, los trabajadores administrativos con cargo de conserje y secretaria son los que presentan puntajes más altos que sus compañeros. Asimismo, en la dimensión actitud hacia el trabajo, los servidores con cargo de conserje y secretaria presentan puntajes más altos, con tamaño del efecto mediano. Sin embargo, en la dimensión asistencia y puntualidad los trabajadores con cargo de vigilante presentan puntajes más altos que los otros colaboradores, también con un tamaño del efecto mediano.

Finalmente, las correlaciones entre el clima organizacional y el rendimiento laboral, cada una con sus respectivas dimensiones, arrojó coeficientes de correlación nulos que sugieren que ambas variables se conducen de manera independiente; es decir, que no existe relación entre el rendimiento laboral y el clima organizacional, al menos en los servidores administrativos de esta universidad pública, ubicada en el sur del Perú. 


\section{Referencias}

Allaire, Y., \& Firsirotu, M. (1992). Cultura Organizacional:Aspectos teóricos, prácticos y metodológicos. Bogotá, Colombia: Legis.

Arias, W. L. (2013). Clima organizacional en ocho empresas de Arequipa. Illustro, $4,39-56$.

Arias, W. L., Lazo, J., \& Quintana, S. (2018). ¿Es el clima organizacional determinante de las relaciones interpersonales o son las relaciones interpersonales las que determinan el clima organizacional? Industrial data, 21(2), 81-90.

Balaguer, I., Castillo, I., Moreno, Y., Garrigues, V., \& Soriano, L. (2004). El clima motivacional y la cohesión en equipos de fútbol. Encuentros en Psicología Social, 2(1), 152-156.

Bittel, L. (200o). Administración de Personal. México: Pearson Educación

Calizaya, J., Bellido, R., Arias, W. L., \& Huamani, J. C. (2019). Construcción y validación de una escala de rendimiento laboral en la ciudad de Arequipa. Manuscrito sometido a revisión.

Calizaya, J., Bellido, R., \& Huamani, J. C. (2019). Construcción y validación de la Escala del Clima Organizacional en la ciudad de Arequipa. Manuscrito sometido a revisión.

Chiavenato, I. (2000). Administración de Recursos Humanos. Colombia: McGraw-Hill.

Chiavenato, I. (2002). Gestión del talento humano. Bogotá, Colombia: McGraw-Hill.

Chiavenato, I. (2009). Comportamiento Organizacional. México: McGraw-Hill.

Deal, T., \& Kennedy, A. (1999). The New Corporate Cultures. Massachusetts, USA: Perseus Books Reading.

Evans, J., \& Lindsay, W. (2008). Administración y control de calidad. México, D.F: Cengage Learning.

Faul, F., Erdfelder, E., Lang, A.G., \& Buchner, A. (2007). G*Power 3: A flexible statistical power analysis program for the social, behavioral, and biomedical sciences. Behavior Research Methods, 39(2), 175-191. 
Ghiselli, J. (1998). Administración de personal. Colombia: s/e.

Grissom, R.J. (1994). Probability of the superior outcome of one treatment over another. Journal of Applied Psychology, 79, 314-16.

Hellriegel, D. y Slocum J. (2014). Comportamiento Organizacional. 1oma Edición. México: Thomson.

Henry, J. (1991). Make sense of creativity. En J. Henry (Ed.), Creative Management. Londres: Sage Publications.

Ivancevich, M. (2006). Comportamiento Organizacional. México: McGraw-Hill.

Katz, D., \& Kahn, R. (1977). Psicología Social de las Organizaciones. México, Trillas.

Lawrence, P., \& Lorsch, J. (1973). Desarrollo de organizaciones: diagnóstico y acción. USA: Fondo Educativo Interactivo.

Litwin, G., \& Stringer, R. (1978). Organizational Climate. New York: Simon \& Schuster.

Luthans, F. (2008). Comportamiento organizacional. México: McGraw-Hill.

Mapcal, A. (1998). Gestión eficaz del trabajo en equipo. Madrid: Díaz de Santos

Martínez, M. (2003). La gestión empresarial: equilibrando objetivos y valores. Madrid: Díaz de Santos.

Mejía, A. (2011). Estrés ambiental e impacto de los factores ambientales en la escuela. Pampedia, 7, 3-18.

Organización Mundial de la Salud (OMS). (2010). Entornos laborales saludables. Fundamentos y Modelo de la OMS. Contextualización, Prácticas y Literatura de Soporte. Recuperado de: http://www.istas.ccoo.es/descargas/guia\%2ode\%20 sensibilizacion\%2odef.pdf

Orbegoso, A. (2007). La deshora peruana o la impuntualidad en el Perú. Colección Realidad Nacional, Vol. 7. Lima: Universidad Ricardo Palma.

Posner, P. (200o). Trabajo en equipo. Buenos Aires: IIPE.

Robbins S. (2008). Comportamiento organizacional. México: Pearson educación. 
Robbins, S., \& Coulter, M. (2010). Administración. México, D.F.: Pearson Educación.

Robbins, S., \& Judge, T. (2013). Comportamiento Organizacional. México: Pearson Educación.

Ruíz, A. (2015). Sobrecarga laboral y autonomía en trabajadores sociales en relación con el síndrome de burnout. (Trabajo de grado). Universidad de La Rioja, España.

Simón, H. (1988). El comportamiento administrativo. Argentina: Editorial Aguilar.

Tomczak, M., \& Tomczak, E. (2014). The need to report effect size estimates revisited. An overview of some recommended measures of effect size. Trends Sport Sciences, 1(21), 19-25.

Waichman, P. (2003). Tiempo libre y recreación. un desafío pedagógico. Buenos Aires: Ediciones PW.

Recibido: 2 de abril de 2019

Aceptado: 19 de agosto de 2019 



\title{
HACIA DESCRIPCIONES NÍTIDAS DE LA CULTURA ORGANIZACIONAL
}

\author{
TOWARD SHARP DESCRIPTIONS \\ OF ORGANIZATIONAL CULTURE
}

Federico R. León

Psicólogo por la Pontifica Universidad Católica del Perú. Magíster en Psicología Industrial por la Universidad de Detroit y Doctor en Psicología Organizacional por la Universidad de Maryland. Investigador acreditado por Concytec y profesor en la Escuela de Postgrado de la Universidad San Ignacio de Loyola, Lima, Perú.

(iD) https://orcid.org/oooo-0oo2-2290-6837

Oswaldo Morales

Abogado por la Universidad de Lima. Maestro en Economía y Regulación de los Servicios Públicos por la Universidad de Barcelona. Tiene estudios de Maestría en Derecho Empresarial por la Universidad de Lima. PhD en Estudios Internacionales de Graduate School of Asia Pacific Studies de la Universidad de Waseda, Japón.

Profesor asociado e investigador de la Universidad ESAN, Lima, Perú.

\section{Oswaldo Otoya}

Psicólogo de la Pontificia Universidad Católica del Perú. Ha realizado especializaciones en México, Costa Rica y Chile. Es director de Consultoría de Q-Reps International. Autor de varios ensayos y publicaciones sobre Gestión

Humana y ha recibido diversos premios y reconocimientos por sus aportes académicos y profesionales. Es professor en la Universidad ESAN, Lima, Perú. 


\section{Antonio Romero}

Magíster en Administración de Negocios por la Universidad ESAN. Expositor y consultor de empresas en recursos humanos por competencias, negociacion y gestión de conflictos, liderazgo orientado a resultados y trabajo en equipo.

Consultor externo y profesor contratado en programas de Gerencia de Administración Pública de la Escuela de Administración de Negocios para Graduados de la Universidad ESAN, Lima, Perú.

\section{Ángela de la Cruz}

Estudiante de Economía y Negocios Internacionales en la Universidad San Ignacio de Loyola, Lima, Perú.

\section{Fiorella Sarria}

Licenciada en Psicología de la Universidad San Ignacio de Loyola. Magíster en Cognición, Aprendizaje y Desarrollo por la Pontificia Universidad Católica del Perú. Cuenta con experiencia en investigación y toma de pruebas psicológicas organizacionales y de desarrollo y en procesos de calidad en educación superior. Universidad San Ignacio de Loyola, Lima, Perú.

Correspondencia: Federico R. León

Escuela de Postgrado

Universidad San Ignacio de Loyola

Av. La Fontana 75o, La Molina, Lima, Perú.

Correo electrónico: federicorleone@gmail.com 
Rev. Psicol. (Arequipa. Univ. Catól. San Pablo) / Año 2019 / Vol 9 / N 3 / pp. 59-71

ISSN 2306-0565 versión impresa / ISSN 2311-7397 versión on line

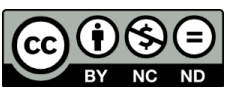

Esta obra está bajo una Licencia Creative Commons

Atribución 4.o Internacional (BY-NC-ND)

\title{
HACIA DESCRIPCIONES NÍTIDAS \\ DE LA CULTURA ORGANIZACIONAL
}

\author{
TOWARD SHARP DESCRIPTIONS \\ OF ORGANIZATIONAL CULTURE
}

\author{
Federico R. León', Oswaldo Morales², Oswaldo Otoya ${ }^{2}$, Antonio Romero², \\ Ángela de la Cruz y Fiorella Sarria \\ 1. Universidad San Ignacio de Loyola, Lima, Perú \\ 2. Universidad ESAN, Lima, Perú
}

\begin{abstract}
Resumen
El Marco de Valores en Competencia es el modelo mejor estudiado de cultura organizacional. Su instrumento de evaluación solicita al informante distribuir 100 puntos entre opciones de respuesta representativas de los cuatro tipos de cultura del marco. Un sesgo en las respuestas ocurre cuando el informante, aplicando el menor esfuerzo o temiendo represalias, distribuye los 100 puntos en montos aproximadamente iguales. Este artículo presenta análisis de datos provenientes de una empresa pública peruana que produjeron descripciones más válidas de la cultura organizacional cuando se convirtió los puntajes a is y os, dependiendo de si el puntaje era o no el mayor de los cuatro. Un estudio que además evaluó liderazgo y bienestar emocional en una empresa privada generó resultados equivalentes.
\end{abstract}

Palabras clave: cultura organizacional, técnica de medición, validez.

\begin{abstract}
The Competing Values Framework is the best studied model of organizational culture. The Assessment of Organizational Culture Instrument asks of the respondent the distribution of 100 points among response options representing the four cultures of the framework. A response bias occurs when the informant, applying least effort or afraid of negative consequences, distributes the 100
\end{abstract}


points approximately equally among the four categories. This article presents analyses of data from a public organization in Peru which produced more valid descriptions of organizational culture when the scores were converted into is and os, depending on whether or not a score was the highest one. A study that in addition evaluated leadership and emotional well-being in a private organization generated equivalent results.

Key words: organizational culture, measurement technique, validity.

\section{Hacia descripciones nítidas de la cultura organizacional}

El volumen 64 del Annual Review of Psychology trae una excelente evaluación del estado del arte en el área de la cultura organizacional (Schneider, Ehrhart, \& Macey, 2013). El concepto se originó en la antropología y desde un principio tuvo foco en lo colectivo. Su principal novedad estuvo en la demostración de cómo las creencias, ideologías, rituales, y mitos ayudan a entender a las organizaciones. En los 1980s emergieron gurús del tema que lograron gran impacto populary también apareció el estudio riguroso de la cultura organizacional, en dos perspectivas. Una, la comparativa, explora los atributos de las organizaciones que diferencian a las más de las menos eficaces. La otra trata de entender cómo los miembros de la organización desarrollan significados y llegan a compartir ciertos supuestos básicos. En esos procesos se ha distinguido la cultura de las sub-culturas, así como de las franjas ambiguas, y se ha identificado niveles, tales como los de los artefactos visibles, los valores abrazados, y los supuestos subyacentes (Schein, 2010). Los principales temas de investigación abarcan el rol del liderazgo, que moldea la cultura cuando los valores y comportamientos del líder llevan al éxito; los vínculos existentes entre cultura nacional, por un lado, y cultura organizacional y tipo de liderazgo, por otro; y la relación entre cultura organizacional y desempeño de la organización (Sackman, 2011), donde destaca el Marco de Valores en Competencia o MVC (Competing Values Framework; Quinn \& Rohrbaugh, 1983; Cameron, Quinn, DeGraff, \&Thakor, 2006). El MVC fue desarrollado en respuesta a la necesidad de un marco teórico de aplicación general que permitiera comparar organizaciones y entender el contexto en el que ciertos valores llevan al éxito. Pese a su antigüedad, el MVC continúa siendo el eje referencial que mejor describe y explica la cultura organizacional en relación al desempeño organizacional. Recientemente, Hartnell, Ou, y Kinicki (2011), en un meta-análisis de 84 estudios que comprendían 94 organizaciones de diversos países, hallaron que los tipos de cultura del MVC se asocian diferentemente a los criterios de desempeño y, pese a que no todos los aspectos de su estructura interna recibieron apoyo empírico, el MVC tiene un importante potencial de utilidad. El MVC es una tipología de organizaciones basada en el cruce ortogonal de una dimensión de estabilidad y control versus flexibilidad y discrecióny una dimensión de orientación 
hacia adentro e integración de las personas versus orientación hacia afuera de la organización y diferenciación de las personas. El cruce origina cuatro tipos de organización: Cooperación, Creación, Competición, y Control.

Los autores del presente artículo creen que una de las áreas donde el MVC necesita perfeccionamiento es la de medición de la cultura, pues el Organizational Culture Assessment Instrument (OCAI) que se usa en el diagnóstico de las cuatro culturas presenta problemas. Una versión preliminar del OCAI definía cuatro tópicos y solicitaba a los informantes valorar cuatro opciones de respuesta para cada uno, correspondientes a los cuatro tipos de cultura del MVC, aplicando una escala Likert de siete puntos (Quinn \& Spreitzer, 1991). Cameron y Quinn (1999) ampliaron los tópicos a seis ítems (rasgo dominante, liderazgo, gestión del personal, énfasis estratégico, factor unificador, y criterio de éxito) y pidieron a los informantes distribuir 100 puntos entre las cuatro opciones de respuesta de cada ítem. Esto se realiza en dos etapas; primero en relación a la organización como es ahora y, luego, a la que le gustaría al informante que fuera. Las estructuras psicométrica y factorial del OCAI han sido estudiadas en los más diversos contextos con resultados positivos (v.g., Choi, Seo, Scott, \& Martin, 2010; Pierce, 2004). Sin embargo, mientras que algunos investigadores emplean la distribución de 100 puntos (v.g., Gálvez Albarracín \& García Pérez de
Lema; 2011; Martínez Ramos, Ollivier Fierro, \& Escobedo Cisneros, 2007), otros continúan usando escalas Likert (Borjas de Xena, 2010; Nummelin, 2007). En cualquier caso, el OCAI no ha sido innovado después del $2006 \mathrm{y}$, así, continúa enfrentando problemas. El mayor consiste en la tendencia del personal a ofrecer respuestas ambiguas, generalmente dadas para salir del paso o, peor aún, dadas con el propósito de evitar opiniones claras por temor a represalias. Después de los escándalos internacionales de los Wikileaks y el espionaje digital norteamericano, el personal de las empresas sospecha que hasta las encuestas on-line vienen con truco y permiten su identificación pese a la usual promesa de anonimato y confidencialidad adelantada por los investigadores o consultores. La manera de no comprometerse es ofrecer respuestas ambiguas. Por ejemplo, distribuir los 100 puntos pedidos en el OCAI en cuatro partes más o menos iguales o asignar puntajes Likert con escasa variación. El principal problema con este tipo de sesgo será que los resultados del estudio emergerán con un alto grado de ambigüedad y pondrán a los consultores en el trance de no poder ofrecer un diagnóstico nítido de la cultura organizacional y a los investigadores en el de quedarse con una hipótesis de sesgo no demostrada. Los estudios presentados en este artículo evaluaron una estrategia original de puntuación en el OCAI, usando como criterio evaluativo su impacto sobre la nitidez de los resultados y la validez del diagnóstico. 


\section{Estudio 1}

\section{Contexto y participantes}

Este estudio se realizó como parte de una consultoría a una organización pública reguladora de la actividad empresarial de un sector de la economía peruana (ORG). Establecida en los 1990s, la ORG ha ganado premios internacionales de excelencia y es considerada un modelo de empresa en el sector público. La totalidad de su personal fue invitado a responder a una encuesta on-line que produjo respuestas de 271 del medio millar de empleados, la mayoría ingenieros. La pérdida de casos se explica por el plazo muy corto para responder - 48 horas - que se dio al personal a causa de las presiones de tiempo ejercidas sobre el estudio.

\section{Instrumento y procedimiento}

Se empleó una traducción castellana de los seis ítems del OCAI. Una tarea del informante fue la de describir a la ORG como un todo; la otra, describir su propia área funcional. En ambos casos se solicitó la distribución de 100 puntos entre las cuatro opciones para cada ítem. Las respuestas para cada ítem fueron convertidas luego a is (para el tipo de cultura indicada como la prevaleciente según el puntaje asignado, aunque la diferencia fuese mínima) y os (para los tipos de cultura con menores puntajes). Los casos donde se producía un empate exacto en el primer puesto fueron descartados del análisis.

\section{Resultados}

Siguiendo el modelo de Cameron y Quinn (1999), mientras más parecida sea la diagramación de la cultura organizacional a un cuadrado con su centro coincidiendo con el cruce de los ejes vertical y horizontal, más ambiguo será el diagnóstico de una cultura, a no ser que la cultura sea realmente equilibrada. Pero ni siquiera una de las docenas de organizaciones representadas en el libro de Cameron et al. (2006) presentó una diagramación tan parecida a un cuadrado al centro de la figura como la resultante de la distribución de 100 puntos ofrecida por el personal de la ORG del presente estudio en referencia a su área de trabajo (Figura 1).

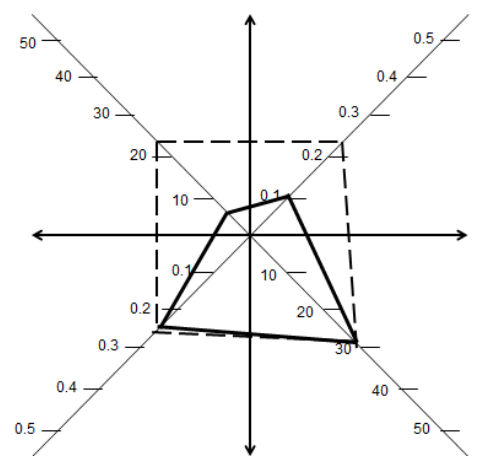

Figura 1. Diagramación de resultados de cultura para la ORG según 1oo puntos distribuidos (línea punteada) y conversión a is y os (línea sólida).

Nota: Las dos modalidades de puntuación representadas en las escalas diagonales - se aplican a cada cuadrante. Las culturas representadas son Cooperación (arriba, izquierda), Creación (arriba, derecha), Control (abajo, izquierda), y Competición (abajo, derecha). 
Lo que está representado allí es una cultura ideal en el sentido de equilibrar las cuatro culturas. En contraste, la conversión a is y os (línea continua) dio lugar a una forma desequilibrada donde la cultura de Cooperación se redujo a un mínimo y la de Creación se le aproximó.

La Figura 2 describe de manera más convencional el promedio de puntajes por ítem del OCAI -también en referencia a la propia área de trabajo- contrastando los resultados obtenidos a partir de la distribución de 100 puntos entre las opciones de respuesta y a partir de su transformación a 1s y os. Los resultados para la ORG como un todo fueron parecidos y no se reportan aquí. Se puede notar que, en todos los casos, la variación de puntajes es mayor cuando se usa los is y os.
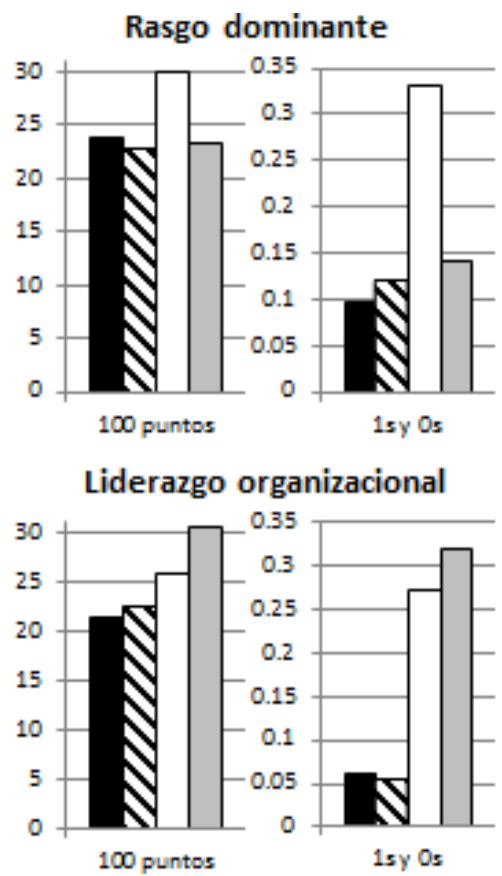

Gestión de personal
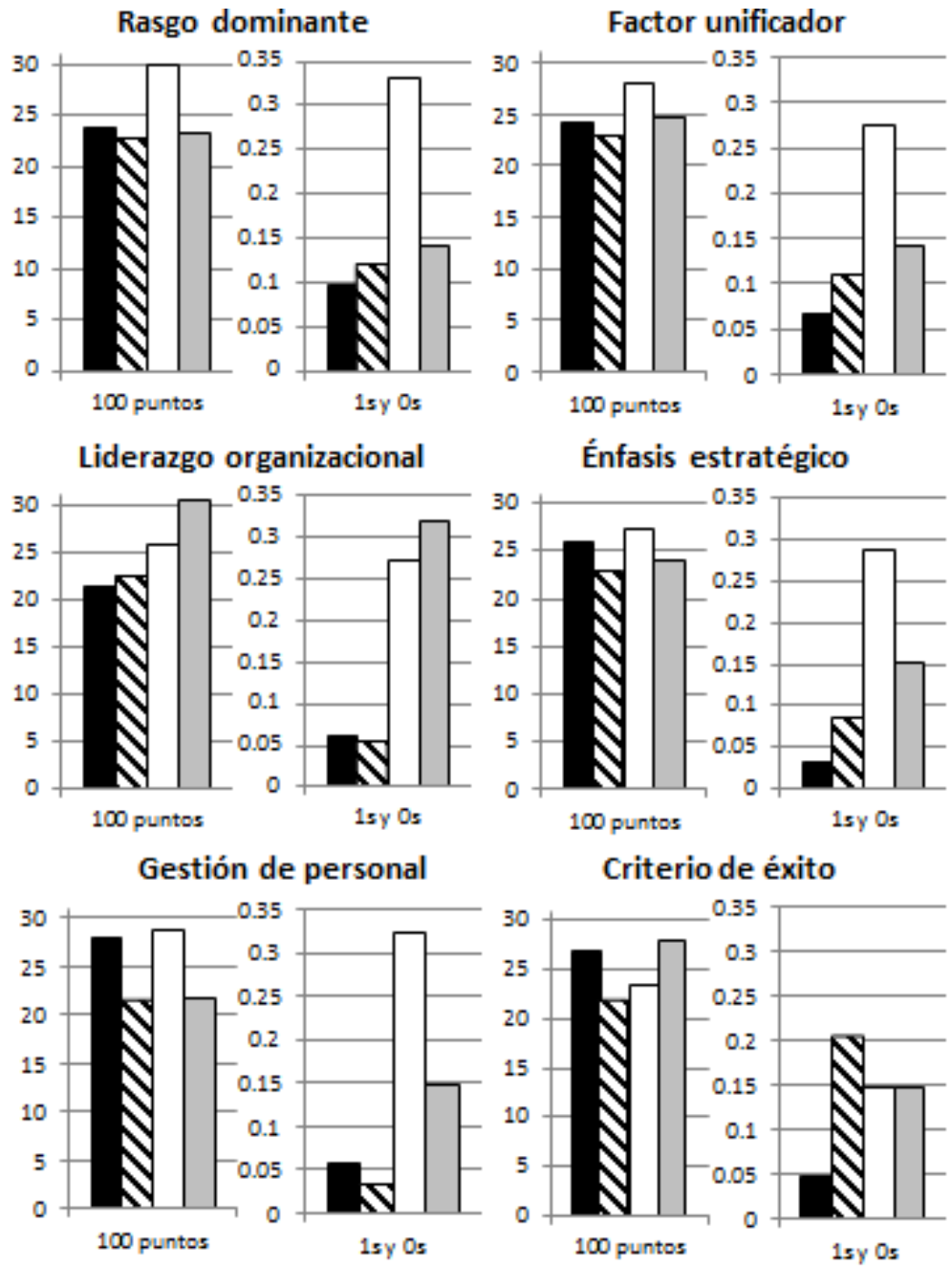

100 puntos

1sy 0 s

\section{Criterio de éxito}

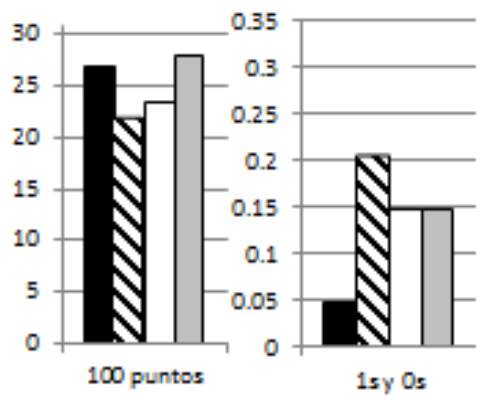

Figura 2. Valores para cada cultura en cada ítem según tipo de puntuación 
Exceptuando Criterio de éxito y Liderazgo organizacional, en todos los ítems Competición emergió claramente diferenciado como el valor prevalente. En el otro extremo, Cooperación redujo sustancialmente su prevalencia en cada uno de los ítems. Similar fue el caso de Creación, aunque emergió como el primer valor respecto a Criterio de éxito. Control mantuvo su primer lugar en Liderazgo organizacional y, en general, se colocó como el segundo en importancia.

La presentación final de resultados al cliente solo consideró aquellos basados en la conversión de puntajes a is y os. La cultura organizacional fue descrita por los consultores como una guiada por un criterio de profesionalismo y orientada a resultados competitivos y un grado importante de control que ha puesto poco énfasis en la cooperación entre áreas funcionales y en la creación de un clima de cooperación. Por consiguiente, se recomendó el fortalecimiento del área de recursos humanos y el desarrollo de líneas de carrera. El área de recursos humanos es una parte menor de la administrativa, la cual, a su vez, es considerada una función de segundo orden en la ORG. Allí recursos humanos se encarga básicamente de tareas rutinarias y quien está a cargo no es hombre, ni ingeniero, ni gerente; es decir, carece totalmente de poder dentro de la ORG.

La alta dirección de la organización reconoció como válida la descripción y la explicó tomando en cuenta que, en sus primeros años, el liderazgo organizacional orientó los esfuerzos del personal a tareas de supervisión y fiscalización que eran valoradas en sí mismas pero después fueron fijadas metas en términos de impactos en el sector que pusieron mayor énfasis aún en resultados cuantificables. De allí el fuerte énfasis actual en competición.

\section{Discusión}

La declaración de la gerencia representa una validación del reporte, es decir, de los resultados obtenidos con los is y os. Si los consultores hubiesen basado su informe en los resultados de la técnica de distribución de 100 puntos y hubiesen concluido que había tanta cooperación como competición en la empresa habrían causado pasmo en la ORG y habrían perdido credibilidad. En cambio, el diagnóstico de una cultura de competición largamente dominante en la ORG presentado por los consultores no fue cuestionado por ninguno de los 17 participantes de nivel gerencial que acudieron al taller de discusión de la evidencia. Sin embargo, siendo este un estudio de casos con metodología cualitativa, queda abierto a cuestionamientos metodológicos y requiere una replicación que incluya criterios de validez de mayor rigor.

\section{Estudio 2}

\section{Contexto y participantes}

El Estudio 2 es parte menor de una tesis de licenciatura en psicología sobre la relación entre mecanismos de influencia social ejercidos por los jefes y bienestar emocional de los subordinados. Se realizó 
en una organización privada de servicios dedicada a vender seguros y dar asistencia y acompañamiento al turista en viajes nacionales e internacionales. De origen argentino, la oficina de Lima opera desde hace 20 años. La totalidad de su personal $(\mathrm{N}=149)$ fue invitado individualmente a responder a una encuesta cara-a-cara, obteniéndose respuestas de 110 empleados. La principal razón para la pérdida de casos fueque los momentos de recolección de datos (de 9 am a $5 \mathrm{pm}$ ) no coincidieron con los laborales del tercio del personal de operaciones en el turno de madrugada.

\section{Instrumentos y procedimientos}

Se empleó la traducción castellana del OCAI con referencia al área funcional del informante. Participaron en el estudio solo los subordinados. Al igual que en el Estudio 1, se solicitó la distribución de 100 puntos entre las cuatro opciones de respuesta, pero, dado el alto número de empates observados, las respuestas para cada ítem fueron convertidas luego a 35 (para el tipo de cultura indicada como la prevaleciente según el puntaje asignado en casos sin empate), 2s (para el empate de dos tipos de cultura en el primer lugar), 1s (si hay empate de tres), y o.5 (si hay empate de cuatro). Los restantes puntajes fueron convertidos a os. Se puede interpretar la alta tasa de empates como un resultado de la recolección de datos cara-a-cara, donde la promesa de anonimato es menos creíble por el informante.

Además, se pidió a los jefes $(\mathrm{N}=13)$ que calificaran mediante una escala Likert la medida en que usaban con su personal varios mecanismos de influencia derivados de la conceptualización de French y Raven (1959), que identifica seis modalidades: información, recompensa, coerción, legitimidad, experticia, y referencia. Algunas de estas categorías fueron subdivididas en subcategorías siguiendo a Raven, Schwartzwald y Koslowsky (1998) y Raven (2008). Ellos definieron formas personales e impersonales de recompensa y coerción, y diferenciaron posición, reciprocidad, y equidad en el poder legítimo. Nuestro análisis diferenció mecanismos duros de influencia (reforzador impersonal, coerción, legitimidad por posición) y mecanismos blandos (reforzador personal, información, experticia, referencia, y legitimidad por equidad y reciprocidad).

Finalmente, se pidió a todos los subordinados que indicaran la frecuencia de cada uno de los 6o estados emocionales del Positive and Negative Affect Schedule ampliado o PANAS-X (Watson \& Clark, 1999) experimentados en el curso del último mes.

\section{Resultados}

Una vez descartados los casos donde la suma de puntajes distribuidos del OCAI excedía 100 o era menor que 10o, el tamaño de muestra se redujo a 86 casos. La consistencia interna del OCAI se evaluó separadamente para los puntajes referidos a cada tipo de cultura. Dado el bajo número de ítems (6), los alfas fueron moderados: cooperación $=.60$, creación $=.51$, control $=.70$, y competición $=.42$. Los paneles A y D de la Figura 3 se refieren a los puntajes 
correspondientes a los departamentos de administración y recursos humanos combinados en un solo grupo $(\mathrm{N}=16)$, los paneles B y E a los del departamento de comercialización $(\mathrm{N}=30)$, y los paneles $\mathrm{C}$ y $\mathrm{F}$ a los del departamento de operaciones $(\mathrm{N}=40)$. En la hilera alta están los puntajes distribuidos entre las cuatro culturas y en la hilera baja aparecen los resultados de su conversión a 3s, 2s, 1s, $0.5 \mathrm{~s}$, y os. Se puede notar fácilmente que, mientras el grupo de administración y recursos humanos mantiene el diagrama virtualmente inalterado, los otros dos grupos exhiben cambios importantes. Así, la diferenciación de los tres grupos resultó mínima en función de los puntajes distribuidos, pero muy nítida en el caso de los puntajes convertidos (D, E, y $\mathrm{F})$, que diferencian con claridad a administración/RRHH de comercialización tanto como de operaciones.
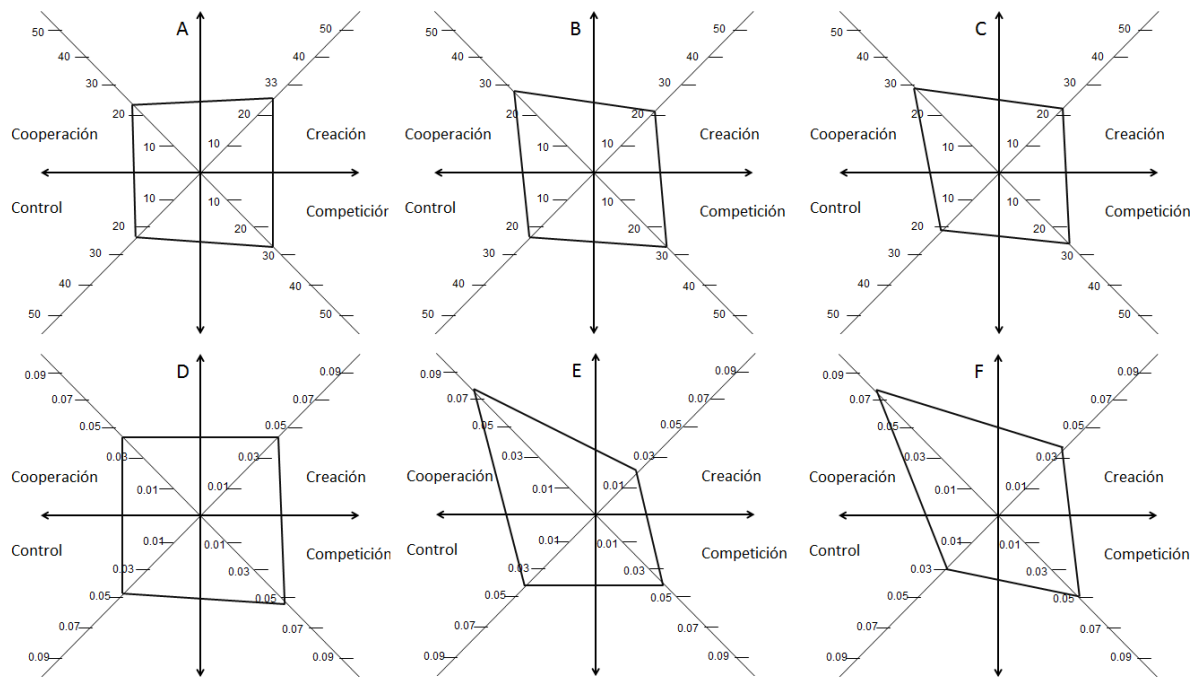

Figura 3. Diagramación de resultados de cultura para administración/RRHH (paneles A y D), comercialización (paneles B y E), y operaciones (paneles C y F), la hilera de arriba según distribución de 100 puntos y la hilera de abajo según conversión de los puntajes a 3s, 2s, 1s, 0.5s, y os

Los puntajes de influencia fueron bastante confiables para fines de investigación $(\alpha=.71$ para mecanismos duros $y .75$ para mecanismos blandos). La Figura 4 deja notar que, en paralelo con la diferenciación conseguida merced a la conversión de puntajes de cultura, administración y $\mathrm{RRHH}(\mathrm{N}=4$ gerentes $y$ jefes) se diferencia espacialmente de comercialización ( $\mathrm{N}=6$ ) y operaciones $(\mathrm{N}=3)$ en el uso de mecanismos de influencia duros y blandos al formar los últimos grupos un conjunto distante del primero. Los resultados sugieren que en administración/RRHH se ejerce más liderazgo de los dos tipos que en las otras gerencias. 


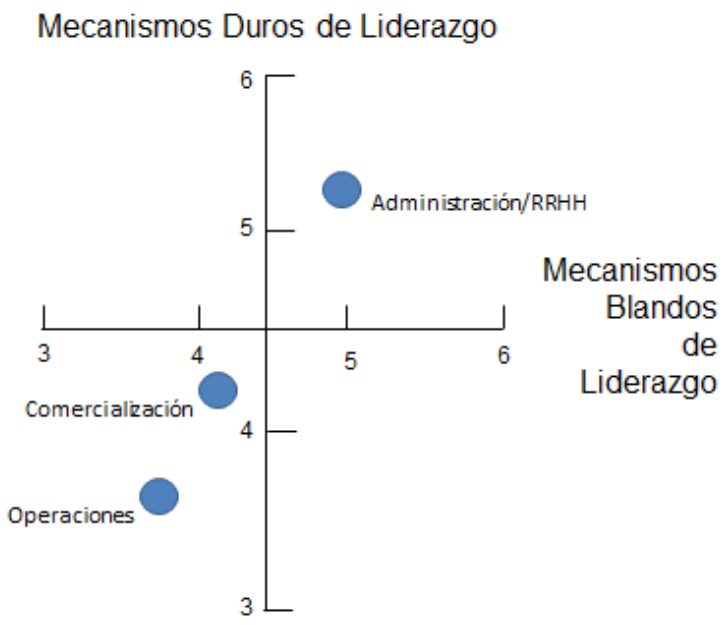

Figura 4. Promedios de liderazgo duro y liderazgo blando para cada gerencia

Luego de eliminar los casos de sujetos que no habían respondido a todos los ítems del PANAS-X, el número de casos se redujo a 104. Un análisis de componentes principales con rotación varimax en busca de los dos primeros componentes confirmó los supuestos del PANAS, pues los ejes resultantes fueron claramente definibles como emociones negativas (Factor 1) y emociones positivas (Factor 2). Consecuentemente, construimos una escala de emociones negativas con los 24 ítems con cargas en el Factor 1 superiores a .40 y una de emociones positivas con los 18 ítems con cargas igualmente fuertes en el Factor 2. Los $\alpha$ de Cronbach fueron, respectivamente, .90 y .89. Los promedios de emociones positivas en administración/RRHH $(\mathrm{N}=11)$ y el grupo combinado de comercialización y operaciones $(\mathrm{N}=74)$ fueron, respectivamente, 39.36 y 46.o8; es decir, el segundo grupo presentó más emociones positivas. La Tabla 1 presenta los niveles de significación estadística para las diversas variables; las mujeres presentaron significativamente más emociones positivas que los hombres. Los promedios de emociones negativas - 45.09 y 42.95no difirieron significativamente entre los dos grupos $(\mathrm{F}=0.267, p<.61)$. 
Tabla 1. Modelo Linear General para la Suma de Emociones Positivas según el Grupo de Pertenencia, Controlando por Nivel Jerárquico, Sexo, y Tiempo en la Empresa del Informante

\begin{tabular}{|lccccc|}
\hline \multicolumn{1}{|c}{ Origen } & Suma de Cuadrados & $\begin{array}{c}\text { Grados } \\
\text { de Libertad }\end{array}$ & $\begin{array}{c}\text { Media } \\
\text { Cuadrática }\end{array}$ & F & P \\
\hline Modelo corregido & 1034.41 & 4 & 258.60 & 2.57 & .044 \\
Intersección & 1730.08 & 1 & 1730.08 & 17.20 & .000 \\
Nivel jerárquico & 4.00 & 1 & 4.00 & 0.04 & .843 \\
Sexo & 421.18 & 1 & 421.18 & 4.19 & .044 \\
Tiempo en la empresa & 219.58 & 1 & 219.58 & 2.18 & .143 \\
Grupo & 347.13 & 1 & 347.13 & 3.45 & .067 \\
Error & 8047.78 & 80 & 101.00 & & \\
Total & 182831.00 & 85 & & & \\
Total corregido & 9082.19 & 84 & & & \\
\hline
\end{tabular}

Nota: Grupo es una variable dicotómica (administración/RRHH versus comercialización/operaciones). $R_{2}=.114 . ~ R 2$ corregido $=.070$.

\section{Discusión}

Según la medición de la cultura organizacional basada en la distribución de 100 puntos, administración/RRHH no se diferenciaría de comercialización u operaciones. La conversión de los puntajes, en cambio, produjo una clara diferenciación. Las evaluaciones del liderazgo fueron consistentes con esta diferenciación al mostrar que el liderazgo se ejercía de manera distinta en administración/RRHH que en comercialización y operaciones, aunque los pequeños números de casos impidieron evaluar la consistencia estadística. Sin embargo, respecto al bienestar emocional fue posible evaluar rigurosamente la consistencia de los hallazgos. Tal como se esperaría de una cultura tendiente a la cooperación o cultura tipo Clan, los niveles de bienestar emocional por el lado positivo fueron mayores en comercialización/operaciones que en administración/ RRHH y la diferencia bordeó la significación estadística $(p<.07)$. Es probable que con un mayor número de casos en administración/RRHH se hubiera conseguido significación de mantenerse la tendencia.

La impresión que dejan los hallazgos es que la cultura de la empresa está fuertemente orientada a la cooperación, pero una parte pequeña y secundaria de ella (administración/RRHH) no está comprendida dentro de ese espíritu y presenta mayor necesidad de supervisión y menor felicidad. Esta conclusión, sin embargo, hubiese escapado al diagnóstico de haberse basado el estudio en la distribución de 100 puntos. 


\section{Discusión General}

Evidentemente, los estudios 1 y 2 deben ser considerados solo los primeros pasos de varios requeridos para lograr un OCAI capaz de producir descripciones más nítidas y válidas de la cultura organizacional. Habiendo sido la conversión a is y os una solución de emergencia en el curso de una consultoría que fue conveniente replicar constructivamente en la segunda investigación, los estudios estuvieron limitados a una simulación estadística cuando el ideal hubiese sido un tratamiento experimental. Futuros estudios deben comparar los resultados de solicitar la distribución de 100 puntos a un grupo del personal seleccionado aleatoriamente y la asignación de is y os (o un esquema parecido) a un grupo equivalente, es decir, seleccionado al azar del mismo universo. El verse el informante forzado a optar podría traer consecuencias no necesariamente idénticas a las conseguidas aquí mediante la simulación estadística. Pero la congruencia de nuestro informe sobre cultura con la visión de los cuadros gerenciales de la ORG del
Estudio 1 y con los estilos de liderazgo y bienestar emocional en el Estudio 2 sugiere que los hallazgos deben tomarse en cuenta. Por consiguiente, vale la pena ir reflexionando sobre sus implicancias prácticas.

Una es la duda que levantan sobre la validez de las evaluaciones de clima organizacional, que son mucho más frecuentes que las de cultura organizacional en el Perú. Considérese el siguiente ítem de un cuestionario ampliamente utilizado por la firma líder del mercado peruano de estudios de clima, "Los jefes me mantienen informado acerca de temas y cambios importantes", a ser respondido mediante una escala Likert. Muy poca validez tendrán las respuestas si el personal que responde a un cuestionario de clima organizacional con preguntas de este tipo lo hace de la manera sesgada como lo hizo el de los dos estudios presentados aquí al distribuir 100 puntos entre las opciones de respuesta. La recomendación que sigue, entonces, es la de continuar haciendo esfuerzos por despejar las dudas tanto en el área de la cultura organizacional como en la del clima organizacional. 


\section{Referencias}

Borjas de Xena, L. (2010). Cultura y liderazgo en una empresa de servicios venezolana. Anales de la Universidad Metropolitana, 10, 139-162.

Cameron, K. S., \& Quinn, R. E. (1999). An introduction to changing organizational culture. Diagnosing and Changing Organizational Culture: based on the Competing Values Framework. San Francisco, CA: Jossey-Bass.

Cameron, K. S., Quinn, R. E., DeGraff, J., \&Thakor, A. V. (2006). Diagnosing and Changing Organizational Culture: based on the Competing Values Framework. Northampton, MA: Elgar.

Choi, Y. S., Seo, M., Scott, D., \& Martin, J. J. (2010). Validation of the Organizational Culture Assessment Instrument: An application of the Korean version. Journal of Sport Management, 24, 169-189.

French, J. R. P. Jr., \& Raven, B. H. (1959). The bases of social power. En D. Cartwright (Ed.), Studies in social power (pp. 1-14). Ann Arbor, MI: Institute for Social Research.

Gálvez, E. J., \& García, D. (2011). Cultura organizacional y rendimiento de las Mipymes de mediana y alta tecnología: Un estudio empírico en Cali, Colombia. Cuadernos de Administración y Organización, 24, 125-145.

Hartnell, C. A., Yi Ou, A., \& Kinicki, A. (2011). Organizational culture and organizational effectiveness: A meta-analytic investigation of the Competing Values Framework's theoretical suppositions. Journal of Applied Psychology, 96, 677-694.

Martínez, P. J., Ollivier, J. O., \& Escobedo, J. C. (2013). Relación entre la cultura organizacional y el desempeño de la organización: Un estudio en empresas maquiladoras de la ciudad de Chihuahua. Revista de Estudios en Contaduría, Administración e Informática, 2, 77-100.

Nummelin, J. (2007). Measuring organizational culture in construction sector Finnish sample. Journal of Construction \& Management, 23, 215-225.

Pierce, J. G. (2010). Is the organizational culture of the United States Army congruent with the professional development of its senior level officer corps? Recuperado de http://www.Strategic Studies Institute.army.mil el 22 de octubre de 2013.

Quinn, R. E., \& Rohrbaugh, J. (1983). A spatial model of effectiveness criteria: Towards a 
competing values approach to organizational analysis. Management Science, 29, 363-377.

Quinn, R. E., \& Spreitzer, G. M. (1991). The psychometrics of the Competing Values Culture Instrument and an analysis of the impact of organizational culture on the quality of life. En R. W. Woodman \& W. A. Pasmore (Eds), Research in organizational change and development, Vol. 5. Greenwich, CON: JAI Press.

Raven, B. H. (2008). The bases of power and the power/interaction model of interpersonal influence. Analyses of Social Issues and Public Policy, 8, 1-22.

Raven, B. H., Schwartzwald, J., \& Koslowsky, M. (1998). Conceptualizing and measuring a power/interaction model of interpersonal influence. Journal of Applied Social Psychology, 28, 307-332.

Schein, E. H. (2010). Organizational culture and leadership. Vol. 2. New York: Wiley.

Schneider, B., Ehrhart, M. G., \& Macey, W. H. (2013). Organizational climate and culture. Annual Review of Psychology, 64, 361-388.

Watson, D., \& Clark, L. A. (1999). The PANAS-X: Manual for the Positive and Negative Affect Schedule, Expanded Form. Obtenido del University of Iowa Institutional Repository.

Recibido: 22 de abril de 2019

Aceptado: 24 de setiembre de 2019 



\title{
CLIMA AFECTIVO PARA EL TRABAJO COOPERATIVO DE DOCENTES DE LIMA
}

\author{
AFFECTIVE CLIMATE FOR THE COOPERATIVE WORK \\ OF TEACHERS IN LIMA
}

\section{Doris Elida Fuster-Guillén}

Doctora en Educación. Asesora en investigaciones con metodologías cualitativas y cuantitativas. Docente dedicada a la enseñanza y la investigación en la Universidad Nacional Mayor de San Marcos, Lima, Perú.

(iD https://orcid.org/oooo-00o2-7889-2243

\section{Liliana Hilda Aldazábal Melgar}

Licenciada en Educación y Magister en Administración de la Educación. Se encuentra realizando estudios de Doctorado en Educación. Ha desempeñado el cargo de coordinación de normas educativas y tiene a su cargo la dirección de una escuela de educación básica regular. Es docente en la Universidad César Vallejo, Lima, Perú.

(iD https://orcid.org/oooo-ooo3-2481-882X

Sara Ynes Tello Cabello

Abogada de profesión. Magíster en Docencia e Investigación Universitaria en la Universidad San Martín de Porres. Docente en la Facultad de Administración y Derecho de la Universidad San Martín de Porres, Lima, Perú.

(iD https://orcid.org/oooo-0oo3-4864-1221 


\section{Patricia Edith Guillén Aparicio}

Doctora en Ciencias de la Educación. Autora del libro "La Enseñanza/Aprendizaje

de la Matemática en Instituciones Públicas de Bellavista” y coautora

de diferentes artículos científicos sobre competencias digitales y educación.

Ponente internacional del RELME. Actualmente trabaja como docente universitaria y es directora del Área de Matemática (AIBDE) en la Universidad San Martín de Porres, Lima, Perú.

(iD) https://orcid.org/oooo-0oo2-8143-3646

\section{Ronald M. Hernández}

Licenciado en Psicología y Candidato a Magíster en Educación. Especialista en Problemas de Aprendizaje, Formación de Capacitadores, Recursos Humanos, Calidad Académica, Estrategias de enseñanza-aprendizaje y TICs.

Coordinador de Producción Científica y Capacitación en la Universidad San Ignacio de Loyola, Lima, Perú.

iD https://orcid.org/oooo-0oo3-1263-2454

Correspondencia: Ronald M. Hernández

Vicerrectorado de Investigación

Universidad San Ignacio de Loyola

Av. La Fontana 750, La Molina, Lima, Perú.

Correo electrónico: rhernandezv@usil.edu.pe 
Rev. Psicol. (Arequipa. Univ. Catól. San Pablo) / Año 2019 / Vol 9 / № 3 / pp. 75-9o

ISSN 2306-0565 versión impresa / ISSN 2311-7397 versión on line

(c) $(9)$

Esta obra está bajo una Licencia Creative Commons

Atribución 4.o Internacional (BY-NC-ND)

\title{
CLIMA AFECTIVO PARA EL TRABAJO COOPERATIVO DE DOCENTES DE LIMA
}

\section{AFFECTIVE CLIMATE FOR THE COOPERATIVE WORK OF TEACHERS IN LIMA}

Doris Elida Fuster-Guillén', Liliana Hilda Aldazábal Melgar², Sara Ynes Tello Cabello3, Patricia Edith Guillén Aparicio3, Ronald M. Hernández ${ }^{4}$

1. Universidad Nacional Mayor de San Marcos, Lima, Perú

2. Universidad César Vallejo, Lima, Perú

3. Universidad San Martín de Porres, Lima, Perú

4. Universidad San Ignacio de Loyola, Lima, Perú

\begin{abstract}
Resumen
La investigación clima afectivo para el trabajo cooperativo de los docentes nace tras la inquietud que aqueja a las instituciones educativas respecto a las responsabilidades de los agentes educativos, cuyo propósito fue determinar la influencia del clima afectivo en el trabajo cooperativo que realizan los docentes en el quehacer académico y administrativo. El estudio se desarrolló con el enfoque cuantitativo y con un diseño no experimental de corte transversal y correlacional. La muestra conformada por 6o docentes entre niveles de primaria y secundaria. Se utilizó instrumentos estandarizados y para los resultados inferenciales se utilizó la prueba de Pearson con la que se demuestra que hay influencia entre variables, pero no es significativa. Se concluye que el trabajo cooperativo puede estar influenciado por otros factores no necesariamente por el clima afectivo.
\end{abstract}

Palabras clave: Clima afectivo, trabajo cooperativo, docentes, instituciones educativas. 


\begin{abstract}
This affective climate research, focused on the cooperative work of teachers, resulted from the concerns of educational institutions with respect to the responsibilities of their educational agents. The institutions were interested in determining the influence of the affective climate on the cooperative work of teachers as they completed their academic and administrative tasks. This study applied a quantitative approach and a non-experimental cross-sectional and correlational research design. The sample consisted of 60 teachers across primary and secondary levels. Standardized instruments were used and for the inferential results the Pearson test was used; when there was influence between variables, although the correlations were not significant. Cooperative work may be influenced by factors other than the affective climate.
\end{abstract}

Key words: Affective climate, cooperative work, teachers, educational institutions.

\section{Introducción}

Uno de los resultados más sobresalientes del cambio ha sido fomentar en los equipos de trabajo una estructura primordial de realización y gestión laboral (Peiró y Munduate, 1999). Las bases tradicionales, con respecto al concepto de puesto, son cambiadas por estructuras descentralizadas, horizontales y en forma de red, cuyos nódulos gozan de un grado elevado de autonomía y se encuentran interconectados; ya que un 80\% de los trabajadores son autónomos por la confianza y el clima que se practica en la institución y ello genera un trabajo de equipo en cada uno de sus miembros, que colabora en pro de los objetivos institucionales. En el actual contexto organizacional, los equipos de trabajo obtienen un estatus diferenciado en la competencia organizacional y se establecen como unidad básica de la institución.

Por otro lado, la teoría e investigación multinivel indaga acerca de las consecuencias del afecto en las organizaciones, postulando que este se manifiesta en cinco niveles diferenciados, a nivel intrapersonal, interpersonal, interaccional, grupal y organizacional (Ashkanasy, 2002). Agregado a ello, se destaca la importancia de las experiencias afectivas de los integrantes del equipo, que acoplados, desencadenan un estado afectivo masivo que influiría en cada uno de sus miembros (De Dreu, West, Fischer y MacCurtain, 2001). Así, cada uno de sus miembros colabora y coopera con entusiasmo y agrado a la institución. Par el caso de las instituciones educativas, los educadores y los directivos se relacionan en torno al factor organizacional. Este tipo de conexiones se encuentran estructuradas y unidas a alguna clase de regulación, que es identificada y admitida por ambos, con el objetivo de desarrollar el aprendizaje dentro de un clima socio emocional efectivo.

A partir de los años ochenta, se ha platicado mucho acerca de enseñanza 
estratégica, modelamiento, tutoreo, etc. Además, en paralelo a lo cognitivo, en la última década, se ha incrementado la tendencia de los profesores acerca del impacto que poseen las dimensiones afectivas en el desempeño docente. Éstas se clasifican en: 1) habilidad para percibir emociones y sentimientos en uno y en terceros, y 2) habilidad para emitirlos de modo apropiado y autorregulado en la interacción con los educandos. Las anteriores habilidades son las que Howard Gardner conoce como inteligencia intra e interpersonal y que subsiguientemente fueron denominadas por Goleman (1995) como inteligencia emocional, la cual es considerada esencial para propagar climas sociales propicios para el aprendizaje.

Determinar los indicadores de ocurrencia del clima afectivo en la institución educativa, en la cual los directivos deben ser los conductores hacia los docentes y trabajadores de la institución que conduzca a responsabilidad, respeto y armonía; creando un clima afectivo conformado por diversos factores, que interactúan entre sí, principalmente relacionados con factores afectivos y emocionales; de modo que el director o administrador es el encargado de patrocinar un atractivo clima afectivo, caracterizado por ser ameno, libre, sin perjuicios y tolerante. Al lograr ello en las instituciones, estamos seguros que los trabajadores, en esta oportunidad docentes, realizarán su trabajo con empeño, haciendo que se involucren en los trabajos en equipo.

Esta investigación tuvo como propósito establecer si existe relación entre el clima afectivo y el trabajo cooperativo de los docentes de una institución educativa, en la que se identificó que la comunicación que se recibe y reproduce entre los agentes educativos no es la correcta. Asimismo la integración es muy pobre, sobre todo si nos referimos a la totalidad de sus integrantes, donde los docentes demuestran inseguridad en sus acciones; no se encuentran predispuestos a realizar actividades, lo que puede tener relación con la conducción o dirección de la institución, ya que está dirigida por personas que no se preocupan por la institución. La mayor parte de las decisiones son pensadas en intereses personales más no institucionales, encontrando desacuerdos entre sus miembros, y esto genera desconcierto en el personal, ya que con dichas acciones crea un ambiente de desconfianza. A ello sumamos la falta compromiso del director, quien se ausenta de la institución, delega funciones a los coordinadores y no muestra interés en el trabajo en equipo.

\section{Empleando un enfoque colectivo al estudio del afecto}

Dentro de análisis psicosocial en el espacio laboralista y organizacional, se ha focalizado el estudio de los fenómenos a nivel individual, donde se considera que un individuo recopila y procesa datos formando experiencias afectivas personales sin correspondencia con los estados afectivos del grupo; proporcionando información acerca del funcionamiento de los individuos, las organizaciones y el trabajo. A pesar de ello, no explica dequé manera se llevan a cabo los afectosy otras experiencias de equipo de las 
áreas de trabajo. Relacionar a las personas, las organizaciones y el trabajo es complejo, y más aún si le sumamos los afectos individualesy colectivos en el desempeño laboral, y su relación con el trabajo cooperativo, que es materia de investigación en la actualidad porque permite ver el lado humano en el desarrollo de una organización.

Actualmente, los estudios psicosociales y organizacionales están interesados por comprender y valuar fenómenos de equipo de trabajo (González-Romá, Peiróy Tordera, 2002), las manifestaciones personales que se dan lugar en el área de trabajo y que, a su vez, dan origen a fenómenos a nivel colectivo. Si bien es cierto que la conducta humana se estructura socialmente, ésta también se caracteriza por la regularización social. Incluso la conducta, las percepciones y las experiencias de sujetos aislados están influidas por conceptos, valores e ideas que emergen del medio social y que se comparten, con otros individuos (Kozlowski y Klein, 200o). Así, la interacción humana dentro de una organización laboral comprende comportamientos, percepciones y vivencias individuales y colectivas que surgen del entorno en el cual se desenvuelve. En las investigaciones que abarcan el afecto dentro de lugares de trabajo, se tiende a considerarlo como una pertenencia colectiva de las áreas de labor. La investigación que se lleva cabo, enfoca desde una aproximación colectiva, el análisis del afecto de los colaboradores que laboran en equipos de trabajo dentro de la organización, aspectos que son importantes debido a su utilidad para entender la vida y el desarrollo del trabajo en las empresas.

\section{Modelo multinivel de las experiencias afectivas en la organización}

El modelo multinivel del estudio del afecto toma en cuenta todas las manifestaciones posibles de las personas en relación con la organización y funciones que desempeña. Ashkanasy (2003) refiere que este modelo está conformado por niveles: el nivel intrapersonal incorpora los procesos neurofisiológicos, conteniendo las manifestaciones fisiológicas de las emociones y los estados de ánimo. Estos estados afectivos son abordados desde la teoría de los sucesos afectivos (Weiss y Cropanzano, 1996), la cual considera que las experiencias afectivas en el centro laboral están definidas, tanto por las disposiciones afectivas personales y los sucesos laborales discretos que percibimos por experiencia en nuestra actividad laboral. Cada uno de estos sucesos ocasiona reacciones afectivas determinadas, las cuales intervienen en el comportamiento de los colaboradores. La diversidad de estos estados traerá como efectos, múltiples resultados en el centro laboral. Según esta teoría, nuestras conductas y actitudes se ven afectadas por las experiencias y vivencias que experimentamos dentro del lugar de trabajo.

En el nivel interpersonal, se tiene en cuenta las diferencias personales, y se sitúa aquí los rasgos afectivos, la satisfacción, el burnout, el compromiso afectivo y la inteligencia emocional. Dichos factores de carácter afectivo provienen de las manifestaciones intrapersonales y se mostrarían como efectos particulares. En este nivel, es importante tener claro el nivel intrapersonal, y conocer bien 
nuestras emociones y reacciones, para poder interrelacionarse con los demás.

El nivel interaccional, considera a la percepción y comunicación de las experiencias afectivas de dos personas. Waldrom (2000) remarca que este nivel es el núcleo afectivo en los centros de trabajo, debido a su importancia como enlace entre los niveles uno y dos, por una parte, y los niveles cuatro y cinco, por otra. Este nivel es el que permite conectar con los demás niveles incluyendo la percepción y comunicación de las experiencias de tipo afectivo.

El nivel de equipo, identifica a los grupos laborales como una "incubadora afectiva”. En donde los equipos experimentan afectos combinables entre sí y generan un estado afectivo colectivo que actuará en cada uno de los integrantes. Kelly y Barsade (2001) mencionan que los grupos de trabajo tienen una específica composición afectiva (o estado de ánimo), que influencia en las particularidades afectivas de los integrantes. Desde ese momento, este tipo de afecto se lleva a cabo por medio de diversos procesos grupales. En este nivel nace el intercambio afectivo de equipos, dando lugar al concepto de inteligencia emocional grupal que se forma en base a las características afectivas del equipo con los aportes de cada miembro.

El nivel organizacional, es de carácter cualitativo, pues en los niveles anteriores los valores y políticas de la organización eran analizados por los colaboradores en relaciones directas con sus pares y sus superiores. A este nivel, el escenario es poco claro y las interacciones de los colaboradores con los demás integrantes de la organización son cortas y menos frecuentes, pues aquí se manejan conceptos de "clima afectivo" o el de "cultura afectiva". El primero de ellos hace referencia al estado de ánimo colectivo relacionado al entorno laboral, la organización y su administración; siendo considerado un fenómeno afectivo. De otro lado la cultura está enfocada en las creencias y valores. Este nivel organizacional no solo involucra el estado de ánimo en relación del entorno laboral sino también considera las creencias y valores que poseen los miembros de la organización.

Cooper y Williams (1994) manejan el concepto de "organización saludable", dentro de este nivel, la cual es definida como la organización que prioriza la comodidad de los colaboradores y la conservación de efectos positivos en la organización. Cuando hacemos referencia al clima organizacional debemos tener en cuenta que existen dentro de las organizaciones sub climas (climas diferentes), y utilizamos el concepto de clima afectivo por asociarlo con el trabajo, la organización y la gestión dentro de un ambiente laboral.

Para la presente investigación nos ubicaremos en el cuarto nivel del modelo de Ashkanasy (2003) y emplearemos el equipo de trabajo como foco de estudio de los climas afectivos. 


\section{Definiciones de clima afectivo}

De Rivera (1992) lo conceptualiza como un fenómeno grupal que puede ser percibido he interpretado de modo objetivo. Este concepto podría utilizarse de modo ventajoso para investigar el afecto en los equipos y en las organizaciones, nos permite entender cómo las emociones pueden intervenir en nuestro desenvolvimiento, dentro de un grupo social.

Para Franco (1998), el clima afectivo implica "instaurar fiscalizadores de orden emocional que nos permitan revelar formas de aceptación social para expresar sus emociones" (p. 141). Pues al conocer el carácter de los individuos, ello nos lleva a conocer sus emociones, y por ende a mejorar su modo de actuar frente a su entorno; permite además, controlar las emociones, para así descubrir las formas de expresarlas de manera aceptable y que a su vez ayuda a desarrollar y mejorar la personalidad.

Para el estudio las experiencias afectivas colectivas serán conocidas como "clima afectivo". Este concepto es un constructo perteneciente al área organizacional y se utiliza para referirse a las percepciones que comparten los colaboradores de una organización. Por ende, el "clima emocional" y el "clima afectivo" cobran fuerza e la actualidad, pues presentan gran importancia dentro del ambiente organizacional (De Rivera, 1992).

Pirola-Merlo et al. (2002) destacan que el tono afectivo y clima afectivo, son cotejables debido a que explican las experiencias afectivas que poseen en común los integrantes de una unidad. González-Romá, Peiró, Tordera y Belmonte (200o) hacen referencia a "afecto" como un concepto más amplio que incluye nociones afectivas: estados de ánimo, emociones, sentimientos, disposición afectiva, etc., conceptualizándolo como un estado de sentimiento subjetivo que comprende estados de ánimo poco claros hasta emociones intensas (Ashforth y Humphrey, 1995). Así, utilizar el término afecto dentro de una organización incluye conocer estados de ánimo, emociones, sentimientos, etc., de las personas que forman parte de la misma. El concepto de clima afectivo se refiere a "los estados de ánimo compartidos por integrantes de un equipo de trabajo" (Gamero, 2008, p. 58), de modo que el clima afectivo permite que los miembros de un equipo de trabajo aprendan a compartir sus estados de ánimo y emociones.

\section{Componentes del clima afectivo}

Según Gamero (2008) tenemos dos dimensiones del clima afectivo: la intensidad y la homogeneidad.

\section{Intensidad del clima afectivo}

Comprendida como los estándares de los estados de ánimo de los miembros de un equipo, que miden la fuerza o energía con que se realiza una actividad, un sentimiento o una emoción. Asimismo, la intensidad del clima afectivo se puede ver afectada por dos tipos de conflicto, el relacional y el conflicto de tarea. 


\section{Conflicto relacional}

Gamero (2008) cita a Jehn (1994) al referirse a esta dimensión, que inserta elementos personales y afectivos como fricción, tensión y aversión que se da en los integrantes del equipo. Así pues, dentro de un conflicto relacional intervienen aspectos personales y afectivos que componen el grupo. Cuando en el entorno se observa un conflicto relacional, la información acerca de políticas, prácticas y procedimientos que vienen a ser premiadas, respaldadas y esperadas por la empresa, afectarán el desarrollo del clima afectivo (De Dreu y van Viannen, 2001).

\section{Conflicto de tarea}

Para Gamero (2008) quien cita a Jehn (1994), este conflicto implica discrepancias en ciertos aspectos y opiniones referentes a la tarea y funciones. Este se manifiesta dentro de un grupo o equipo cuando no existe acuerdos entre los colaboradores con respecto a las labores realizadas. Hay que considerar que ante el desarrollo de una tarea siempre se presentan diferencias, porque no todos percibimos las cosas de igual forma, aunque lo ideal es coordinar para una buena realización de la tarea destinada.

\section{Homogeneidad del clima afectivo}

Gamero (2008) la define como el grado de convergencia o semejanza de los estados deánimo de los miembros de un equipo, y dependen de los siguientes aspectos:

\section{Interacción entre los miembros del equipo}

Es la relación recíproca por medio de la cual gran parte de los integrantes articulan su comportamiento con respecto a la la transmisión de mensajes o informaciones. Estos podrían llevarse a cabo a través de medios personalizados. Los miembros de un equipo deben interactuar acoplando sus conductas de acuerdo al entorno y transmitir mensajes e informaciones entre ellos.

Normas de regulación afectiva

Se refiere a la graduación del comportamiento. Este ajuste de control y modulación de respuestas afectivas se ha investigado con mayor impacto en la primera infancia (Goleman, 1995); sin embargo, la regulación afectiva se manifiesta en el transcurso del desarrollo humano, debido a que concierne con el adecuado contacto con uno mismo, con el entorno y con la capacidad de simbolización. Regular lo afectivo involucra saber controlar el comportamiento y las respuestas afectivas, aprendizajes que se dan a lo largo de nuestro desarrollo personal y la relación con nuestro entorno.

\section{Comparación afectiva}

Abarca las reacciones emocionales personales en el entorno laboral comparándola con las reacciones emocionales de otros integrantes del equipo, y mediante este proceso se forma parte del equipo al cual pertenecemos. 


\section{Rendimiento del equipo}

En el último decenio, los estudios ejecutados en el área de la psicología organizacional se vienen desarrollando desde un aspecto "micro" para analizar el comportamiento del individuo (Peiró, 2009). A pesar de ello, la dinámica organizacional es compleja y por ende se han desarrollado enfoques, teorías, modelos, conceptos e indagaciones que abarcan niveles de análisis diferenciados.

Gamero (2008) se refiere al rendimiento del equipo como la autogestión de los equipos de trabajo para desarrollar estrategias innovadoras y alcanzar resultados diferenciados, y con ello, estándares elevados de rendimiento que los que se consigue por medio de los procedimientos tradicionales. En ese sentido, la convicción del equipo es muy importante para obtener niveles elevados en el rendimiento del mismo.

\section{Fundamentos teóricos del trabajo cooperativo}

El trabajo cooperativo ha posibilitado el intercambio de interdependencias y conocimientos, la socialización de procesos, experiencias y los resultados adquiridos; que traen como consecuencia el desarrollo integral del ser humano, siendo lo que le ha permitido avanzar el ser un ser social por naturaleza, modificando su entorno de manera social e individual. En ese sentido, todo conocimiento adquirido por el ser humano es elaborado socialmente a través de la interacción entre individuos con su medio, dependiendo de su contexto histórico;y transmitido de una generación a otra a través de la incorporación de las futuras generaciones dentro de la sociedad, siendo la educación fundamental para esto. Los antecedentes de aprendizaje cooperativo forman parte de la historia de la pedagogía y la humanidad. Así pues, tanto Piaget (1981) como Vigotsky (1987) dicen que los individuos cooperan cuando surge un conflicto socio-cognitivo que genera un desequilibrio cognitivo que, al mismo tiempo, estimula el desarrollo del conocimiento y la habilidad de adoptar diferentes puntos de vista.

\section{Trabajo cooperativo}

Según Ovejero (1999) es "una técnica educativa que busca la mejora del rendimiento y potenciar las capacidades intelectuales y sociales de los educandos" (p. 46). Es también una estrategia de gestión que beneficia la organización de los alumnos en grupos heterogéneos para llevar a cabo funciones y actividades de aprendizaje, y que involucra agrupar a los estudiantes en pequeños equipos con el objetivo de potenciar el desarrollo de sus miembros. Así, el trabajo cooperativo permite extraer el potencial de cada miembro y fortalecer el objetivo del trabajo a realizar.

Es por ello, que Ferreiro y Calderón (2001), señalan que el aprendizaje cooperativo:

Acrecienta la relación entre los miembros del equipo, con el docente y los otros equipos, de modo que cada uno aprende el contenido asignado y a su vez, el grupo también, formulando una 
manera diferente de relacionarse maestro y alumno en el proceso de enseñar y aprender. (p. 31)

El trabajo cooperativo es además, un valor incorporado en el currículo de formación, necesario para la mediación educativa en el aula y como ingrediente esencial de la organización de la comunidad educativa (Klein, Kuh, Chun, Hamilton y Shavelson, 2015). Por ello, el trabajo cooperativo es un valor importante en la labor educativa que requiere compromiso de los integrantes de la comunidad educativa.

El trabajo cooperativo demanda de una planificación minuciosa y exhaustiva de la intervención para lograr las condiciones competentes que necesita esta metodología (Cabrera, Colbeck y Terenzini, 2001). Aplicar el trabajo cooperativo necesita de una preparación que permita lograr los objetivos planteados. Este tipo de aprendizaje supone la "utilización didáctica de equipos reducidos en los que los estudiantes trabajan para potencializar su propio aprendizaje y el de los otros" (Johnson, Johnson y Holubec, 1999); y así, este método busca optimizar el aprendizaje de cada miembro que compone el grupo.

Pújolas (2008) subraya que los integrantes del equipo poseen una doble responsabilidad: aprender la enseñanza del docente y contribuir a que lo aprendan su equipo. Los docentes usan este tipo de aprendizaje para lograr que los estudiantes aprendan los contenidos de la disciplina y para que aprendan a trabajar en equipo como competencia profesional. Es decir "cooperar para aprender y aprender a cooperar". Además, el aprendizaje cooperativo no solo busca aprender los conocimientos que se reciben, sino también compartir lo que se aprenda con los otros miembros del equipo. Así, la cooperación es compartir actividades entre los integrantes para la consecución de una meta en común. El aprendizaje personal se logra si todos y cada uno de los integrantes lo han logrado también. Cooperar es interactuar entre los miembros del equipo para alcanzar el logro de la meta trazada.

Para Rué (1994) es “una herramienta de enseñanza que tiene su origen en la distribución de la clase en pequeños equipos mixtos en la cual se trabaja conjunta y coordinadamente entre sí para dar solución a actividades académicas y profundizar en su propio aprendizaje" (p. 120). Para Jonhson et al. (1999) son métodos de instrucción para grupos pequeños, de entrenamiento y desarrollo de habilidades diferenciadas (aprendizaje y desarrollo personal social), en la cual cada integrante es responsable de su aprendizaje y de los miembros de su equipo. Así, existe una responsabilidad entre el aprendizaje personal y el aprendizaje grupal que permite el desarrollo de habilidades mixtas. Por ello, este tipo de trabajo se elabora teniendo en cuenta la interacción de los miembros y también el trabajo individual que cada uno realiza.

Según Giraldo (2007), el aprendizaje cooperativo tiene su fundamento básico en la valoración del potencial educativo y la interacción grupal, y tiene en cuenta los valores de socialización e integración 
para el aumento del rendimiento escolar. Este autor nos hace percibir que el aprendizaje cooperativo gira entorno a las relaciones interpersonales de los miembros del grupo, las cuales si son eficaces permiten que se obtenga buenos resultados. En un trabajo cooperativo hay diversos grados de coordinación, planificación e interacción entre los individuos que cooperan, por ello se deben tomar en cuenta estos aspectos.

\section{Generalidades sobre el trabajo de grupo}

García, González y Mérida (2012) indican que este tipo de actividad es importante para el desarrollo cognitivo, social y académico; y permite potenciar las relaciones humanas y el aprendizaje autónomo. Así, el trabajo en grupo nos ayuda al desarrollo cognitivo, social y académico, así como también a potenciar las interacciones sociales

\section{Organización del trabajo en grupo}

Para García, González y Mérida (2012) es la planificación de los detalles en los grupos por parte del educador. Esta nos permite identificar el punto de vista que poseen los estudiantes en referencia a lo ejecutado por el docente. Objetivamente se analiza si la cantidad, dificultad, planificación y seguimiento de todo lo propuesto tiene concordancia con la consecución de aprendizajes. En consecuencia, la formación del trabajo cooperativo debe estar sustentado en una buena planificación, que pueda tomar en consideración la opinión de los participantes, y debe contar además, con normas claras.

\section{Funcionamiento de los grupos de trabajo}

Aquí se incorporan cuestiones que tienen relación con una serie de acciones ejecutadas en el transcurso del trabajo grupal. Se pone interés por las actividades que realiza el alumno antes de la preparación del resultado, y se agregan cuestiones que hacen referencia a la ponderación del trabajo en grupo con respecto a la evaluación final, información de criterios utilizados, la diferenciación en la valoración de las distintas aportaciones personales, autoevaluación de los alumnos y la valoración entre iguales. Así, en el funcionamiento de los grupos de trabajo no solo se ve el desarrollo, la ejecución y los resultados sino también la evaluación general y autoevaluación y la evaluación entre pares.

\section{Metodología}

Esta investigación se desarrolló según una metodología cuantitativa y se aplicó un diseño no experimental, de corte transversal correlacional, porque el estudio está centrado en identificar la relación del clima afectivo y el trabajo cooperativo en instituciones educativas.

\section{Muestra}

La muestra de estudio estuvo conformada por 6o docentes de una institución educativa de distrito del Rímac, tanto de nivel primario como secundario. Para la delimitación de los docentes integrantes de la muestra se utilizó el criterio de inclusión constituido por 
docentes nombrados con 10 años de experiencia mínima en instituciones educativas, porque son ellos quienes se rehúsan a trabajar en equipo.

\section{Instrumentos}

Para el recojo de información se utilizaron dos instrumentos: la Escala del Clima afectivo de Gamero (2008), que cuenta con 40 ítems distribuidos en dos dimensiones. La primera denominada intensidad del clima afectivo y la segunda homogeneidad del clima afectivo, con índices y rango variados que a continuación detallamos: de la pregunta 1 al 12 las escalas son: Nada (1), Poco (2), Medio (3), Bastante (4) y Mucho (5). Asimismo, de la 13 al 30 las escalas son: Nunca (1), Pocas veces (2), Frecuencia media (3), Bastantes veces (4) y Muchas veces (5); mientras que del ítem 31 al 38 los rangos de respuesta son: Totalmente en desacuerdo (1), Bastante en desacuerdo (2), Algo en desacuerdo (3), Algo de acuerdo (4), Bastante de acuerdo (5) y Totalmente de acuerdo (6). Por último, del ítem 39 al 40 sus escalas son: Muy mal (1), Mal (2), Regular (3), Bien (4) y Muy bien (5).

El trabajo cooperativo fue evaluado por medio del Cuestionario ACOES de García, González y Mérida (2012), que está conformado por tres dimensiones: la primera nombrada Generalidades sobre el trabajo en grupo, la segunda referida a la Organización del trabajo en grupo, y la tercera es el Funcionamiento de los grupos de trabajo. Tiene a una escala ordinal de respuesta, cuyos valores para la interpretación son: $1=$ Totalmente en desacuerdo, $2=$ En desacuerdo, $3=$ Medianamente de acuerdo, 4= De acuerdo y $5=$ Totalmente de acuerdo.

Los instrumentos han demostrado validez y confiabilidad en varios estudios como el de Aguilar y De la Cruz (2017), Medina (2016) y Rengifo (2015) para el clima afectivo, así como de Díaz (2014) y Nuria (2007) para el trabajo cooperativo. En esta investigación la validez de contenido fue realizadas a través del juicio de expertos y la fiabilidad del clima afectivo fue de .741 y la del trabajo cooperativo de .926 .

\section{Procedimientos}

En el proceso para recolectar la información se diálogo con las autoridades de la institución educativa para solicitar la autorización pertinente y poder realizar la recolección. Para el análisis de los datos de utilizó el paquete estadístico SPSS versión 24. Para la prueba de la normalidad se empleó el estadístico Kolmogorov-Smirnov y para la contrastación de hipótesis se utilizó la correlación de Pearson.

\section{Resultados}

Posteriormente del trabajo de campo llegamos a resultados descriptivos e inferenciales de las variables estudiadas que a continuación detallamos. 
Tabla 1. Clima afectivo y trabajo cooperativo en docentes de las instituciones educativas del Rímac

\begin{tabular}{|c|c|c|c|c|c|c|c|c|}
\hline \multirow{3}{*}{ Clima afectivo } & \multicolumn{6}{|c|}{ Trabajo cooperativo } & \multirow{2}{*}{\multicolumn{2}{|c|}{ Total }} \\
\hline & \multicolumn{2}{|c|}{ Bajo } & \multicolumn{2}{|c|}{ Moderado } & \multicolumn{2}{|c|}{ Alto } & & \\
\hline & $\mathbf{n}$ & $\%$ & $\mathbf{n}$ & $\%$ & $\mathbf{n}$ & $\%$ & $\mathbf{n}$ & $\%$ \\
\hline Bajo & $\mathrm{O}$ & $0 \%$ & o & o\% & 6 & $10 \%$ & 6 & $10 \%$ \\
\hline Moderado & o & o\% & 15 & $25 \%$ & 39 & $65 \%$ & 54 & $90 \%$ \\
\hline Alto & o & o\% & o & o\% & o & o\% & o & о\% \\
\hline Total & $\mathbf{o}$ & о\% & 15 & $25 \%$ & 45 & $75 \%$ & 60 & $100 \%$ \\
\hline
\end{tabular}

En la tabla 1, se observa que el $65 \%$ de los docentes presentan un nivel moderado de clima efectivo y a la vez presentan un nivel alto de trabajo cooperativo, por lo que podemos afirmar que mientras haya clima afectivo mejor se presenta el trabajo cooperativo.

Tabla 2. Coeficiente de correlación entre clima afectivo y el trabajo cooperativo de los docentes de las instituciones educativas del Rímac

\begin{tabular}{|cccc|}
\hline & Clima afectivo & $\begin{array}{c}\text { Trabajo } \\
\text { cooperativo }\end{array}$ \\
\hline $\begin{array}{c}\text { Clima } \\
\text { afectivo }\end{array}$ & Correlación de Pearson & 1 & .079 \\
& Sig. (bilateral) & & .550 \\
Nrabajo & Correlación de Pearson & .079 & 60 \\
cooperativo & Sig. (bilateral) & .550 & 1 \\
& $\mathrm{~N}$ & 60 & 60 \\
\hline
\end{tabular}

Los resultados de la Prueba de correlación de Pearson, arrojaron un coeficiente de correlación de $\mathrm{r}=.079$, lo que indica una correlación positiva despreciable. Además, el valor de significación observada $\mathrm{p}=.550$ es mayor al valor de significación teórica $\mathrm{p}=.05$. En consecuencia, la relación no es significativa al $95 \%$ y no se rechaza la hipótesis nula (Ho) asumiendo que existe relación directa pero no significativa entre el clima afectivo y el trabajo cooperativo de los docentes de las instituciones educativas del Rímac.

\section{Discusión}

Los resultados de nuestra investigación muestran que la relación entre el clima afectivo y el trabajo cooperativo de los profesores evaluados no es significativa, por lo tanto, se rechaza la hipótesis de investigación; en contraposición a lo mencionado por Díaz (2014) quien 
concluye que existe relación entre ambas variables. Rengifo (2015) por su parte, también concluyó que el clima afectivo de profesores universitarios de Iquitos, está relacionado significativamente con la motivación al logro profesional.

Los resultados de la investigación también muestran que el 90\% de los docentes tienen un nivel moderado de clima afectivo, y en concordancia a lo referido Medina (2016), se considera que para desarrollar el clima afectivo es necesario instaurar controles emocionales en las personas que les permitan descubrir formas aceptables de regulación que les ayuden a expresar sus emociones e interactuar con otros individuos.

De Rivera (1992) refiere que las experiencias afectivas son importantes en una institución, y siempre son un elemento fundamental en el área organizacional. Es por ello que, en esta investigación, las percepciones de unos u otros docentes, varían respecto a la intensidad del clima afectivo. Si bien en general hay un clima afectivo aceptable debido a la realización de los trabajos en común, el $40 \%$ de los docentes no percibe el clima afectivo como una prioridad para el cumplimiento de sus funciones.

Asimismo, en lo que respecta a los resultados descriptivos el $75 \%$ de los docentes perciben que en la institución educativa presenta un alto nivel de trabajo cooperativo, y en concordancia a ello Ovejero (1999), se concluye que la imagen de la escuela o institución educativa se ve reflejada según el contexto social. En consecuencia, en la institución educativa se presentan dificultades para conseguir una satisfactoria cohesión grupal, con las implicaciones que ello tiene tanto para el trabajo escolar. Si tenemos en cuenta que el trabajo cooperativo es fundamental para el logro de los objetivos institucionales, éste podría ser un valor añadido al currículo formativo, y un elemento imprescindible tanto para la intervención educativa en un aula como para la labor docente como miembro de una comunidad educativa con la que debe estar comprometido (Klein, Kuh, Chun, Hamilton y Shavelson, 2015).

En el estudio se observa finalmente, que el $87 \%$ de los docentes presentan un nivel alto de concepción del trabajo en grupo puesto que los docentes consideran que es necesario planificar y organizarse para la distribución equitativa de las funciones; y asimismo, mantener una comunicación clara y oportuna para el éxito de las actividades. En respaldo a ello, Ovejero (1999), hace mención que el trabajo cooperativo demanda de una planificación minuciosa y rigurosa de la intervención para lograr las condiciones idóneas que precisa esta metodología, condiciones que en la institución educativa, no siempre tienen lugar ya que se conforman los grupos no por afinidad más bien por necesidad; y sin tomar en cuenta aspectos de perfil idóneo en múltiples responsabilidades. A pesar de ello, el 58\% de los docentes perciben que la organización del trabajo en grupo es aceptable. 


\section{Referencias}

Aguilar. R., \& De la cruz, J. (2017). Clima afectivo en los docentes de la Facultad de Trabajo Social de la Universidad Nacional del Centro del Perú. (Tesis profesional). Universidad Nacional del Centro del Perú, Huancayo, Perú.

Ashforth, B., \& Humphrey, R. (1995). Emotion in the workplace: A reappraisal. Human Relations, 48, 97-125.

Ashkanasy, N. (2002). Studies of cognition and emotion in organizations: Attribution, affective events, emotional intelligence and perception of emotion. Australian Journal of Management, 27, 11-20.

Ashkanasy, N. (2003). Emotions in organizations: A multi-level perspective. En F. Dansereau y F. U. Yammarino (Eds.), Research in Multi-level Issues, Vol. 2: Multilevel Issues in Organizational Behavior and Strategy (pp. 9-54). Amsterdam: Elsevier Science.

Cabrera, A., Colbeck, C., \& Terenzini, P. V. (2001). Developing performance indicators for assesing classroom teaching practices and student learning. Research in Higher Education, 42(3), 327-352.

Cooper, C. L., \& Williams, S. (1994). Creating Healthy Work Organizations. Chichester, UK: Wiley.

De Dreu, C. K. W., \& Van Vianen, A. E. M. (2001). Managing relationship conflict and the effectiveness of organizational teams. Journal of Organizational Behavior, 22, 309-328.

De Rivera, J. (1992). Emotional climate: Social structures and emotional dynamics. International Review of Studies on Emotions, 2, 197-218.

Díaz, S. (2014). Comunicación Organizacional y Trabajo Cooperativo en Trabajadores de una Universidad de la Ciudad de Quetzaltenango. (Tesis profesional). Universidad Rafael Landívar, Quetzaltenango, Guatemala.

Ferreiro, G. R., \& Calderón, E. M. (20o1). El ABC del Aprendizaje Cooperativo. Trabajo en equipo para enseñar y aprender. México. Editorial Trillas.

Franco, T. (1998). Vida afectiva y educación infantil. España: Narcea, S.A. 
Gamero, N. (2008). El clima afectivo en equipos de trabajo: antecedentes y consecuencias. España: Universidad de Valencia.

García, M., González, I., \& Mérida, R. (2012). Validación del cuestionario de evaluación ACOES. Análisis del trabajo cooperativo en educación superior. Revista de Investigación Educativa, 3o(1), 87-109.

Giraldo, C. (2007). ¿Protección o desprotección social? Bogotá: Universidad Nacional de Colombia.

Goleman, D. (1995). Inteligencia Emocional. Barcelona: Kairós.

González-Romá, V., Peiró, J. M., Tordera, N., \& Belmonte, J. (200o). Emotional climates at work. Determinants of the formation processes of collective emotions. Trabajo presentado en el XXVII International Congress of Psychology, Estocolmo, Suecia.

González-Romá, V., Peiró, J. M., \& Tordera, N. (2002). An examination of the antecedents and moderator influences of climate strength. Journal of Applied Psychology, 87, 465-473.

Johnson, D. W., Johnson, R. T., \& Holubec, E. J. (1999). El aprendizaje cooperativo en el aula. Buenos Aires: Paidós.

Kelly, J.R., y Barsade, S.G. (2001). Mood and emotion in small groups and workteams. Organizational Behavior and Human Decision Processes, 86, 99-130.

Klein, S. P., Kuh, G., Chun, M., Hamilton, L., \& Shavelson, R. (2005). An Approach to Measuring Cognitive Outcomes across Higher Education Institutions. Higher Education, 46(3), 251-276.

Kozlowski, S. W., \& Klein, K. J. (200o). A multilevel approach to theory and research in organizations: Contextual, temporal, and emergent processes. En K.J. Klein y S.W. Kozlowski (Eds.), A Multilevel Theory, Research, and Methods in Organizations. Foundations, Extensions and New Directions (pp. 3-9o). San Francisco: Jossey-Bass.

Medina, C. (2016). Relación entre el Clima Afectivo y la Satisfacción Laboral de Profesores de un Centro Educativo Adventista de la Región de Junín (Tesis profesional). Universidad Peruana Unión, Junín, Perú.

Nuria, V. (2007). Clima afectivo y equipos de trabajo: antecedentes y consecuencias (Tesis doctoral). Universidad de Valencia, Valencia, España. 
Ovejero, A. (1999). El Aprendizaje Cooperativo: Una alternativa eficaz a la enseñanza tradicional. Barcelona: PPU.

Peiró, J. M., \& Munduate, L. (2001). Research developments on Workand Organizational Psychology in Spain: An overview. Revista de Psicología Social Aplicada, 11, 31-48.

Peiró, S. (2009). Valores educativos y convivencia. Ecuador: Club Universitario.

Piaget, J. (1981). La teoría de Piaget. Infancia y Aprendizaje, 4(2), 13-54.

Pirola-Merlo, A., Härtel, C., Mann, L., \& Hirst, G. (2002). How leaders influence the impact of affective events on team climate and performance in $\mathrm{R} \& \mathrm{D}$ teams. The Leadership Quarterly, 13, 561-581.

Pújolas, P. (2008). Nueve ideas clave del aprendizaje cooperativo. Barcelona: Grao.

Rengifo, A. (2015). Clima afectivo y la motivación al logro profesional docente en la Facultad de Ciencias Biológicas. (Tesis de Maestría). Universidad Nacional de la Amazonía Peruana, Iquitos, Perú.

Rue, J. (2010). El trabajo Cooperativo. (Documento en formato html). Descargado el 5 de julio de 2018 de: .Giac.upc.es/pag/giac_cas/giac_que_es.htm.

Vigotsky, L. (1987). El desarrollo de los procesos psicológicos superiores. México: Editorial Grijalbo.

Waldrom, V. R. (200o). Relational experiences and emotion at work. En S. Fineman (Ed.), Emotion in Organizations (pp. 64-82). London: Sage Publishing.

Weiss, H. M., \& Cropanzano, R. (1996). Affective events story: A theoretical discussion of the structure, causes and consequences of affective experiences at work. En B. M Staw, y L. L. Cummings (Eds.), Research in Organizational Behavior, vol. 18 (pp. 1-74). Greenwinch, CT: JSI Press.

Recibido: 22 de abril de 2019

Aceptado: 15 de octubre de 2019 


\section{ARTÍCULOS DE REVISIÓN}

Construcción DEL SENTIDO DESDE LAS NARRATIVAS

DE LOS MIEMBROS DE UNA ORGANIZACIÓN

Eduardo Escalante, Ignacio Fernández y Pía Cordero

¿QUÉ HACE A UNA DECISIÓN BUENA? CRITERIOS DE TOMA DE DECISIONES EN EL MANAGEMENT CIBERNÉTICO

Gonzalo Flores-Castro Lingán 



\title{
CONSTRUCCIÓN DEL SENTIDO DESDE LAS NARRATIVAS DE LOS MIEMBROS DE UNA ORGANIZACIÓN
}

\author{
CONSTRUCTION OF IN MEANING FROM NARRATIVES OF MEMBERS \\ OF AN ORGANIZATION
}

\begin{abstract}
Eduardo Escalante
Licenciado en Lingüística y Literatura. Licenciado en Educación. Magíster en Ciencias Sociales y Director del Instituto de Investigaciones Psicológicas de la Universidad del Aconcagua (Mendoza, Argentina). Actualmente es Docente de la Universidad Juan Agustín Maza, Mendoza, Argentina.

\section{Ignacio Fernández}

Psicólogo por la Pontificia Universidad Católica de Chile y Magíster en Dirección de Recursos Humanos por la Universidad Adolfo Ibáñez. Premiado como Psicólogo Organizacional del año 2011 por el Colegio de Psicólogos de Chile. Director de LEAD Institute, Chile.
\end{abstract}

\section{Pía Cordero}

Psicóloga y Magíster en Psicología Organizacional por la Universidad Adolfo Ibáñez. Coach en LEAD Institute, Chile.

Correspondencia: Eduardo Escalante Universidad Juan Agustín Maza

Lateral Sur del Acceso Este 2245

M5519, Mendoza, Argentina.

Correo electrónico: ed.escalante@gmail.com 

Rev. Psicol. (Arequipa. Univ. Catól. San Pablo) / Año 2019 / Vol 9 / № 3 / pp. 95-103

ISSN 2306-0565 versión impresa / ISSN 2311-7397 versión on line

(c) $\left(\begin{array}{l}(1) \\ \text { Esta obra está bajo una Licencia Creative Commons } \\ \text { Atribución 4.o Internacional (BY-NC-ND) }\end{array}\right.$

\title{
CONSTRUCCIÓN DEL SENTIDO DESDE LAS NARRATIVAS DE LOS MIEMBROS DE UNA ORGANIZACIÓN
}

\section{CONSTRUCTION OF IN MEANING FROM NARRATIVES OF MEMBERS OF AN ORGANIZATION}

\author{
Eduardo Escalante', Ignacio Fernández y Pía Cordero ${ }^{2}$ \\ 1. Universidad Juan Agustín Maza, Mendoza, Argentina \\ 2. LEAD Institute, Santiago, Chile
}

\begin{abstract}
Resumen
En este artículo, se describe la construcción de significado en las prácticas organizativas utilizando el paradigma de la construcción naturalista del sentido creado por Kurtz y Snowden (2003) como una forma de examinar los acontecimientos de una organización lejos de los procesos naturales de control y la opinión de expertos. Las narrativas, las historias, las interacciones son elementos fundamentales de las acciones colectivas culturales en una organización. De este modo, sus acontecimientos se tratan más allá de un enfoque positivista. Se postula una metodología para construir el sentido (narrative sensemaking). Este método sugiere escuchar las diferentes historias de los diferentes actores de la organización y clasificarlas. Díadas o tríadas se utilizan términos distintivos, que permiten a los actores contar sus historias y sus percepciones en un marco cualitativo y cuantitativo en lo posible, lo que depende de herramientas computacionales. Este proceso permite a una combinación única de un análisis estadístico (objetividad de los números) con el contexto rico proporcionada por la evidencia anecdótica. Una vez recogidas las distintas narrativas, se organiza un taller de interpretación. En esta etapa, los consultores ayudan a encontrar patrones de captura que emerge del número de señales de historias. Las señales débiles pueden ayudar a anticipar las tendencias futuras y ayudar a tomar decisiones sobre futuras estrategias e intervenciones.
\end{abstract}

Palabras clave: Complejidad, construcción de sentido, narrativas, historias. 


\begin{abstract}
This paper describes the construction of meaning in organizational practices using the naturalistic construction of meaning paradigm created by Kurtz and Snowden (2003) as a method of examining organizational events apart from the natural processes of control and expert opinion. Narratives, the stories and interactions, are fundamental elements of the cultural collective actions of an organization. Thus, organizational events are addressed beyond a positivist approach. A methodology for constructing meaning is proposed (narrative sensemaking). This method suggests listening to the different stories of the different actors in the organization and classifying them. Dyads or triads employ distinctive terms, allowing actors to tell their stories and describe their perceptions in a qualitative framework, and where possible a quantitative framework, depending on the computational tools to be used. This process allows a unique combination of statistical rigor (objectivity of numbers) along with the rich context provided by anecdotal evidence. Once the various narratives are collected, an interpretation workshop is organized. At this stage, consultants help to find emerging patterns captured from the number of story cues. Weak cues can help to anticipate future trends and help make decisions about future strategies and interventions.
\end{abstract}

Key words: Complexity, sensemaking, narratives, stories.

\section{Introducción}

Hace un tiempo venimos trabajando los conceptos de Kurtz y Snowden (2003), con respecto al análisis de la complejidad y el uso de las narrativas, que permiten analizar determinados procesos en una organización. Específicamente, los conceptos de historias y significantes. El término historia no denota algo bien construido y ejecutado, sino que representa la experiencia cruda vivida por un individuo, que correspondería a un GPS orientador para traducir la complejidad en gestión efectiva y hacerlo resiliente (propiedad emergente de los sistemas adaptativos complejos).

Nuestra existencia transcurre en un mundo enteramente delimitado. En éste, establecemos tanto límites naturales como artificiales. Al usar el concepto de "límite" se alude de uno u otro modo a una discontinuidad. Y eso ocurre en las organizaciones. En toda organización hay historias de fracasos y éxitos, nudos gordianos sin resolver, límites que superar. Es decir, siempre se está trazando líneas o límites para organizar su experiencia propia o ajena. Los límites ordenan la acción y le confieren sentido. Pero, así como hay una actitud delimitadora hay una actitud desdelimitadora: remover los límites. Más aún si nos movemos en dominios que no están ordenados y que son complejos. Las distinciones que hemos hecho no funcionan, no son efectivas, $y$, por ende, es preciso examinarlas y posiblemente modificarlas. Es por ello que se habla de la fenomenología 
del límite que nos ilumina también en los casos en que se extralimita, donde no se trata de suprimir un límite, sino de traspasarlo. El tema es indagar que impulsa a hacerlo o no hacerlo.

Ungran aportede la construcción de sentido narrativo en relación con las metodologías convencionales es la desintermediación. Esto significa que los expertos intervienen solamente para mediar el proceso de construcción de sentido, permitiendo que los miembros de la organización clasifiquen sus historias según categorías, o etiquetas quellamamos significantes. Se pueden usar díadas o tríadas de términos distintivos y también se puede partir de un problema o de datos estadísticos resultantes de la aplicación de una escala de medición.

\section{Modelo y metodología de análisis}

Antes de continuar con este proceso metodológico. Describiremos el modelo de análisis de la complejidad de Snowden (1999): dominios simple, complicado, complejo, y caótico. Este autor habla de la multiontología de la construcción del sentido. Es una especie de cartografía que es en realidad una "ontología epistemológica", porque lo que busca es hacer identificaciones y distinciones: orden/ desorden; conocido/desconocido. Y todo ello para poder definir lo que se podría ver como la antropología que ocurre en cada escenario o dominio; e indagar en el sentido de las distintas actuaciones reales y posibles o simplemente imposibles. Este autor explora lo que nos distingue y define en cada dominio (orden/desorden), agregaríamos lo que nos incumbe, nos importa, nos preocupa. En este proceso se nos va el sery el de los otros con los que interactuamos. Es decir, el transcurrir de la existencia humana y las diversas identidades que van surgiendo en cada dominio y en los límites de éstos. Un enfoque de esta índole permite darse cuenta que la identidad se va transformando con el tiempo y que por lo mismo no es sino una manifestación del ser de la plenitud, del ser que se individúa y fenomeniza en la organización, entre otros. El autor ofrece así, un conjunto de distinciones que permiten aproximarse a la gestión de sistemas humanos.

Snowden identifica cuatro escenarios, dominios o contextos para la toma de decisiones: conocido (simple), conocible (complicado), complejo y caótico. Los dos primeros corresponden a sistemas ordenados, en los que los patrones que se visualizan tienden a repetirse con pocos cambios. Las causas conducen a efectos confiables y observables y no se esperan mayores sorpresas. La diferencia entre el primeroy el segundo es lo que actualmente se conoce y lo que se puede hallar.

Los dominios complejo y caótico caen en el territorio de los sistemas sin orden, esto es, sus patrones no son predecibles, incluso si existe mucha información. Los patrones en un espacio complejo dependen de las interacciones entre entidades, incluyendo observadores. Los patrones complejos no se repiten, lo que hace difícil predecirlos. Sin embargo, hay patrones que aparecen y desaparecen. La diferencia entre la complejidad y el caos deriva del hecho que la primera genera patrones relativamente simples de una variedad grande de 
interacciones, en cambio el segundogenera patrones intrincados. Representa un orden de otro tipo: el no orden.

Hoy las organizaciones enfrentan complicaciones y complejidades del entornoy de sí mismas (las interacciones de los actores), el orden simple no es la tendencia necesariamente, hay demasiados elementos emergentes, cada uno generando sus principios, lógica y conocimiento. Esto hace interesante las elaboraciones de Snowden (2002) para hacer explícitos los supuestos de las personas y/o grupos ante un tema particular. En la figura 1, se puede observar que la dinámica organizacional, funciona con un orden determinado (si hubiera desorden, simplemente dejaría de existir). Como hemos señalado más arriba, en este orden, hay cuatro escenarios posibles: simple, complicado, complejo, y caótico. Cada tema de la organización se puede representar en algunos de estos espacios de la matriz, además de la intensidad (tamaño del círculo) y orientación que tengan (positiva/negativa).

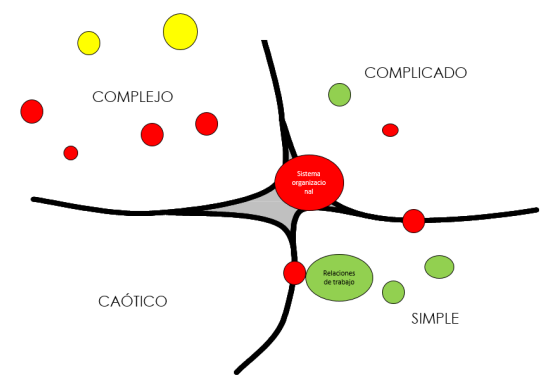

\section{Figura 1. Dominios de compeljidad}

La experiencia indica que una persona puede tener interpretaciones múltiples sobre un tópico en particular basado en el contexto en el que se experimenta ese tópico. Es el poder performativo de las palabras. Comprender que tenemos identidades múltiples es tan importante como comprender que tenemos realidades múltiples. Nuestras identidades no tienen supuestos que son siempre consistentes. Por ejemplo, uno puede ver el tópico de la disciplina de manera muy diferente como padre que como empleado de una organización. Además, las identidades múltiples requieren que se tome en cuenta la naturaleza del contexto histórico y local.

El esquema de la figura 1 no intenta proveer una visión fija de la realidad sino más bien un pantallazo en el tiempo que se puede comparar con otros pantallazos para explorar patrones y trazar movimientos. La utilidad de éste radica en la habilidad para apoyar a los individuos y/o grupos en la toma de decisiones que requieren tomar en cuenta diversos puntos de vista ante un determinado fenómeno. El foco se centra en la toma de decisiones (Kurtz \& Snowden, 2003). Esta noción de utilidad es consistente como lo que se denominada "construcción social de la realidad".

Tradicionalmente los enfoques positivistas para hacer indagaciones operan bajo el supuesto que las cosas existen en el mundo y pueden ser descubiertas y que podemos aprender sobre ella y comprender su naturaleza "verdadera". Es común preguntarse sobre el "rigor" de la información cuando se examina una investigación desde la perspectiva positivista. Esto es, se busca la validez del estudio. Pero, ¿rigor con respecto a qué? ¿en qué se basa? 
Se asume que el conocimiento es fijo y tiene propiedades indiferentemente de nuestra comprensión de esas propiedades. Si cambiamos nuestra orientación desde un mundo que existe fuera de nosotros a una orientación donde el mundo es una combinación de interacciones, en constante co-evolución el mundo mismo, entonces se puede traspasar muchos de los obstáculos filosóficos paradójicos en el campo de las ciencias sociales. Se produce un desplazamiento y el valor de la información y el conocimiento ya no está en el rigor y validez, sino en su utilidad en un determinado momento local histórico. Además, el valor en la utilidad no es un valor fijo en el tiempo, dado que va emergiendo nueva información.

Desde nuestro punto de vista, se puede argumentar que la figura anterior se puede utilizar para maximizar la utilidad proveyendo a los participantes la oportunidad para externalizar sus supuestos acerca de un tópico particular. Esto permite lograr una comprensión compartida sobre un tema y se constituye en el primer paso en la consideración de las soluciones o toma de decisiones.

Se trabaja con el sentido como un suceso, una acción, pero también con el sentido en cuanto justificación (del suceso, de la acción), y finalmente con el sentido en tanto orientación, lo queda dirección. Además, se pueden descubrir los "focos del sin-sentido", esto es, fenómenos, sucesos, situaciones que revelarían pérdida de sentido: molestia, fastidio, cansancio, etc. Se puede detectar las fuentes ocasionales y persistentes del sentido (que revelarían un determinado patrón o tendencia).

Seusa el término "comprensión compartida" en contraste con "consenso". Esto porque la meta no necesariamente es el alcanzar el consenso, puede ocurrir que a la espera del consenso se esté instalando el estatus-quo. Se denota que los participantes estén concientes de los puntos de vista múltiples ante un tema en particular incluso si no están de acuerdo.

Al final del día, la estructura de poder en el lugar puede tomar la decisión final, pero de esta manera la decisión se tomará a la luz de todos los participantes. Si hay un desequilibrio se destacará en este proceso. De este modo, la toma de decisiones se entenderá en un nivel más profundoy será más difícil descartara aquellos que podrían ser impactados negativamente. El consenso denota que todos los involucrados están de acuerdo con una decisión particular. Se sustenta en la noción de una verdad o solución particular.

Lo anterior permite convocar a la escena a Cynthia Kurtz que ofrece una variedad de métodos que incorporan la recopilación de información desde perspectivas múltiples. Kurtzy Snowden (2003) desarrollado herramientas computacionales para realizar el proceso. El primero ofrece SenseMaker que es muy apropiada para este tipo de análisis, pero bastante costosa; la segunda propone Narrafirma, herramienta también bastante poderosa que es gratuita.

Las historias narradas por las personas son filtros a través de los que 
toman decisiones (Snowden, 2005). Usan material fragmentado para dar sentido al mundo alrededor de ellas. Metodológicamente, la combinación de datos duros (estadísticos) con datos blandos (narrativas) se pueden construir en sentido cuando se abordan realidades complejas, en orden a destilar patrones y responder de manera oportuna. En el caso de las organizaciones, revela el mundo a través de los ojos de sus actores (Oliver \& Snowden, 2005).

El punto de partida puede ser una pregunta (por ejemplo, cuáles son las creencias sobre algo que no funciona), una imagen, una situación, un dato estadístico (un promedio de las respuestas ante un reactivo). Estos elementos desencadenan una "experiencia vivida" que le da significado al acontecer, lo importante es que ahora se recurre a la interpretación dada por otros (al diálogo apreciativo). Esto permite detectar patrones en las historias, discutirlos y construir conglomerados (clusters), para finalmente, actuar sobre esos patrones. Se pueden simular patrones beneficiosos y desechar los no deseables. Se puede usar una tríada (tres aspectos de un dominio de interés). El uso de formas triangulares permite la tensión creada entre tres puntos equidistantes como alternativas; los participantes se ven forzados a considerar detenidamente su elección reduciendo el prejuicio de la conformidad (esto es, la tendencia a seleccionar lo mejor, fácil o la respuesta esperada en una escala mono-dimensional.

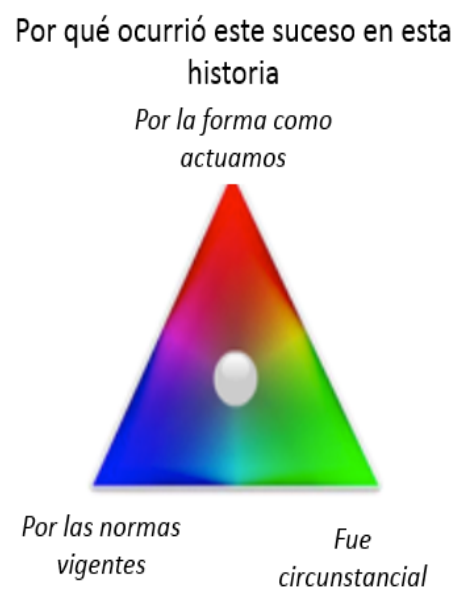

\section{Figura 2. Ejemplo 1 de Tríada}

Algunas tríadas pueden permitir observar la diversidad de la ética humana y determinar el sentido del locus moral de la responsabilidad. Como un dominio amplio, que involucra temas de conciencia, obligación, deber, culpa y la estructura de la experiencia moral. La tríada no focaliza lo que debería ser, sino que pone el énfasis en lo que es. La tríada de la responsabilidad moral enfatiza lo personal más que lo social (ver figura 2).

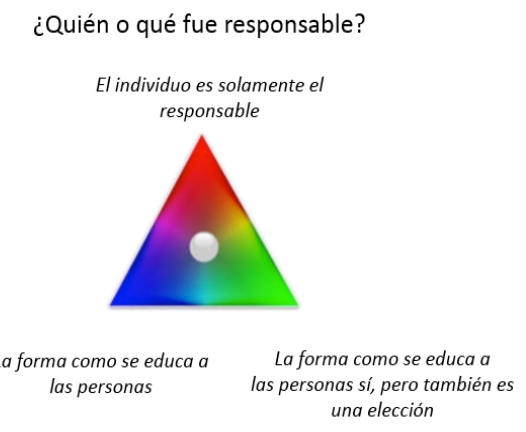

Figura 3. Ejemplo 2 de Tríada 


\section{(2) Observador/es}

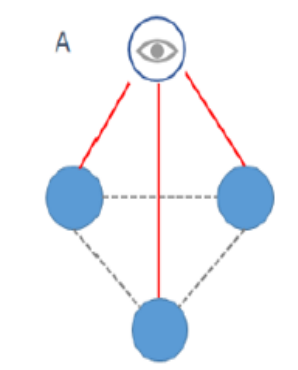

Conexiones centrales fuertes Interacciones distribuidas débiles

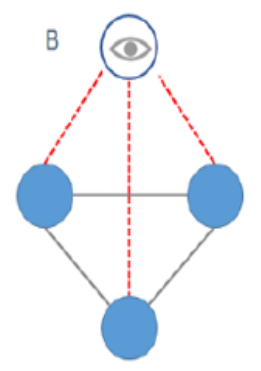

Débil conexiones centrales Interacciones distribuidas débiles

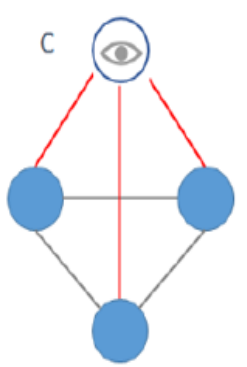

Conexión

débil

Conexión

fuerte

\section{Figura 4. Tipos de conexiones}

Los actores de la organización (observadores) podrán identificar a través de sus narrativas los vínculos que existen en un determinado momento entre sus diferentes estructuras. Aquí, es preciso aclarar que en este enfoque quien trabaja con las historias no dice o interpreta o cambia o selecciona las historias, nunca. Todos estos procesos los realizan solamente las personas en un grupo de interés. La mediación permite pensar, hablar, compartir e identificar patrones, pero se respeta la integridad de la historia como materia prima en bruto.

Se trata de la identidad colectiva de la resiliencia de una organización, o su habilidad para gestionar las múltiples identidades sin quiebres (mantener la suficiente diversidad de aquellas identidades) que es poyada por la identidad de resiliencia de sus empleados.

El análisis de datos cuantitativos y cualitativos de una historia y las formas de significación revelan un número de tendencias o temas que son representados en la matriz de la figura 1. Algunos temas residen en un dominio específico. Otros se posicionan en los límites de dos escenarios entre dominios adyacentes para indicar la presencia contemporánea de características típicas de diferentes dominios (por ejemplo, un tema muestra características de un sistema complicado y complejo). El color del tema puede indicar positivo, neutral, o negativo. Para cada tema el tamaño del círculo es proporcional a la recurrencia de este tema en las historias (esto es, temas que aparecen en muchas historias se representan en círculos más grandes que los temas que aparecen en pocas historias). Cuando un tema es muy recurrentey la solución se ve compleja, entonces se requiere que un experto loaborde usando sus conocimientos y capacidades. En especial, cuando hay más de una solución posible y solamente se puede optar después de una cuidadosa evaluación de los diferentes criterios. 


\section{Conclusiones}

La ontología epistemológica de diferentes dominios propuesta por Snowden (1999): dominio simple, complicado, completo y caótico, es un ordenamiento interesanteque permite a su vez identificar comportamientos antropológicos en las organizaciones a través del estudio de las narrativas de sus actores. Este tipo de enfoque permite que los sistemas complejos de una organización estén alertas a las señales de formación de patrones. La cognición está distribuida de manera diferente según ciertos umbrales numéricos: las organizaciones trabajan con 50 menos individuos, 15 o menos, 150 o menos. Snowden describequince como el "límite de confianza" y cinco como el límite de la memoria de corto plazo.

La investigación de las historias y el compaginarlas en la matriz de Snowden, permitiría construir el sentido en las organizaciones empleando procesos mixtos: cuantitativos y cualitativos. De este modo, muchos temas que no se visualizan con métodos tradicionales podrán emerger con toda la riqueza de su poder descriptivo. Los temas que caigan en el dominio simple serán de fácil solución, más trabajo se requerirá en el dominio complicado y las narrativas de los actores permitirán con el conocimiento experto identificar soluciones a partir de los patrones identificados y analizados. Si se trata de un tema que cae en el borde o dentro del dominio complejo, se requerirá experimentación como vía para aprender y comprender sus patrones, indudablemente se requerirá paciencia para lograr una solución práctica y aceptable. Aplicar un enfoque de decisiones impropias puede ocasionar efectos contraproducentes. 


\section{Referencias}

Kurtz, C., \& D. Snowden. (2003). The New Dynamics of Strategy: sense making in a complex complicated world. IBM Systems Journal 42(3), 462-483.

Oliver, G. R., \& Snowden, D. J. (2005). Patterns of narrative in organizational knowledge sharing: Refolding the envelope of art-Luddism and techno-fabulism. En G. Schreyögg, \& J. Koch (Eds.), Knowledge management and narratives: organizational effectiveness through storytelling (pp. 15-72). Berlin: Erich Schmidt Verlag.

Snowden, D. J. (1999). The Paradox of Story: Simplicity and Complexity in Strategy, Scenario and Strategy Planning, 1(5), 16-20.

Snowden, D. J. (2002). Complex acts of knowing: Paradox and descriptive self awareness. Journal of Knowledge Management, 6(2), 100-111.

Snowden, D. (2005). Stories from the Frontier. E:CO Issue, 7(304), 155-165.

Snowden, D. J., \& Boone, M. E. (2007). A Leader's Framework for Decision Making. Harvard Business Review, November, 69-76.

Recibido: 25 de agosto de 2017

Modificado: 14 de octubre de 2018

Aceptado: 19 de marzo de 2019 



\title{
¿QUÉ HACE A UNA DECISIÓN BUENA? \\ CRITERIOS DE TOMA DE DECISIONES \\ DESDE EL MANAGEMENT CIBERNÉTICO
}

\author{
WHAT MAKES A GOOD DECISION? CRITERIA TO THE MAKING \\ DECISIONS FORM THE CYBERNETIC MANAGEMENT
}

\section{Gonzalo Flores-Castro Lingán}

Licenciado en Administración de Negocios por la Universidad Católica

San Pablo. Magíster en Filosofía por la Universidad de Piura.

Con estudios en Doctrina Social de la Iglesia para Profesionales

por la Catholic Univerity of America en Pensamiento Tomista por la Universidad

Fasta (Argentina), en Educación Católica por Faith and Reason Institute (EE.UU.).

Becario Austral-Templeton para el Doctorado en Filosofía con orientación en Fundamentos de las Ciencias Naturales y Cognitivas

en la Universidad Austral (Argentina). Docente de la Escuela Profesional de Administración de Negocios de la Universidad Católica San Pablo, Arequipa, Perú.

(iD https://orcid.org/oooo-0oo1-8820-7580

Correspondencia: Gonzalo Flores-Castro Lingán

Departamento de Administración de Negocios

Universidad Católica San Pablo

Urb. Campiña Paisajista s/n Quinta Vivanco

Barrio de San Lázaro, Arequipa, Perú.

Correo electrónico: gonzalofcl_1@hotmail.com 



\title{
¿QUÉ HACE A UNA DECISIÓN BUENA? CRITERIOS DE TOMA DE DECISIONES DESDE EL MANAGEMENT CIBERNÉTICO
}

\section{WHAT MAKES A GOOD DECISION? CRITERIA TO THE MAKING DECISIONS FORM THE CYBERNETIC MANAGEMENT}

\author{
Gonzalo Flores-Castro Lingán \\ Universidad Católica San Pablo, Arequipa, Perú
}

\begin{abstract}
Resumen
El presente artículo intenta analizar la buena toma de decisiones bajo el paradigma del management cibernético, valiéndonos de la teoría de la acción de Juan Antonio Pérez López. Se exponen, en la introducción, algunos problemas sobre los criterios para considerar buena una decisión. Se desarrolla el moldeo perezlopiano para analizar todos los posibles resultados de una acción y encontrar los criterios de decisión a tomar en cuenta en una buena decisión. Al final se introducen las variables éticas implícitas en el modelo, que permiten tener una mirada holística de la buena decisión.
\end{abstract}

Palabras clave: Acción, toma de decisiones, ética, management, Juan Antonio Pérez López.

\footnotetext{
Abstract

This article attempts to analyze what constitutes good decision-making under the cybernetics management paradigm, using the action theory ofJuan Antonio Pérez López. Some problems with the criteria for identifying a decision as good are presented in the introduction. Perez López's theory was developed in order to analyze all possible results of human action and describe the decision criteria to be considered in determining whether a decision is good. In the conclusion, the ethical variables implicit in the model are introduced, which allow a holistic view of good decision-making.
} 
Key words: Action, decision-making, ethics, management, Juan Antonio Pérez López.

\section{Introducción}

En marzo 2001 Neal Paterson, consejero delegado de la Cerner Corporation, observó que el estacionamiento de la compañía tenía cada vez menos autos estacionados en horarios de oficina. Ante la sospecha que sus colaboradores trabajaban menos de las cuarenta horas establecidas, envió un e-mail a sus directivos en los siguientes términos: «Un gran número de nuestros empleados está trabajando menos de 40 horas. Como directivos, o no saben o no les importa lo que están haciendo sus colaboradores. En cualquier caso, hay un problema que o resuelven o los reemplazaré. Son responsables de lo que pasa. Tienen dos semanas». Los directivos de Cerner consiguieron que todo el mundo estuviera trabajando desde las ocho de la mañana hasta las cinco de la tarde. Lo que no anticipó Neal Patterson es que el autoritario e-mail fuese filtrado y colgado en Internet. El mensaje fue leído por analistas e inversores que quedaron sorprendidos por el lenguaje usado. El resultado: el precio de la acción de la compañía bajo un $22 \%$ en tres días. Toda la prensa económica de EE. UU. se hizo eco de este hecho, de modo queal negativo impacto económico hubo que añadirle la vergüenza personal para el consejero delegado (Ariño, 2005).

Esta decisión parece que estuvo mal por varias razones. Entre las cuales podemos encontrar razones económicas (la baja en el precio la acción), así como de imagen empresarial (prensa económica) e incluso de ambiente laboral (maltrato, uso injusto de poder, "traición" de un directivo, etc.). Sin embargo, de haber obtenido mayores beneficios económicos, por ejemplo, un incremento del $2 \%$ en las acciones, $i$ se habría considerado la acción de Paterson como buena? En términos económicos la respuesta quizás sea afirmativa. De hecho, en su famoso artículo del New York Times Magazine en 1970, titulado «The social responsibility of business is to increase its profits», Friedman defendía la tesis de que las empresas no deben tener otra responsabilidad que la de maximizar sus beneficios. En otros términos, independientemente de las otras funciones que cumpla una empresa, el criterio máximo de actuación empresarial es la maximización de beneficios económicos y a ella debe de subordinarse la toma de decisiones empresariales. Así, una buena decisión empresarial es aquella que genere mayores beneficios económicos ${ }^{1}$.

Sin embargo, intuitivamente sabemos que esto no es así. El criterio económico no puede ser el único criterio para que una decisión sea calificada de buena. De hecho, los efectos de considerar la maximización de beneficios como criterio dominante los hemos sufrido en las crisis de la última década (Argandoña, 2010). Existen, pues, otras razones por las cuales consideramos una decisión como buena, pero resulta difícil explicitarlas. Como dice Higgins, «todos nos vemos motivados a tomar buenas decisiones... pero ¿qué hace que una decisión sea buena?» (Higgins, 
2000, p. 1218), es decir, ¿qué criterios tenemos para calificar a una decisión como buena? El asunto es peliagudo pues, para empezar, resulta difícil la definición del término "bueno". ¿A qué nos referimos con que una decisión es buena? ¿a que obtuvo beneficios económicos? ¿a que fue una decisión ética? ¿a que los involucrados salieron satisfechos emocionalmente? Los escolásticos dirían que "bueno" es un término análogo, por lo que se puede decir de muchas maneras (Feser, 2014), lo cual no nos dice mucho, porque bueno puede ser un resultado económico, así como puede existir una bondad ética.

No es el único problema. Por ejemplo, Melé (2009), quien toma a los escolásticos como base de su análisis (Melé, 2014), explica que existen tres tipos de bienes: aquellos llamados bienes útiles (por ejemplo, dinero), placenteros (por ejemplo, buen ambiente laboral) y humanos o morales (aquellos que nos perfeccionan como humanos, como la confianza en las personas o la buena reputación). Pues bien, ¿estos bienes están separados?, ¿es posible hablar de una decisión buena en un aspecto (útil) y mala en otro (moral)?, y si es así, ¿sería una decisión globalmente buena o mala? Aquí entramos en el problema de la integración de la bondad ética en la toma de decisiones (Argandoña, 2007; Flores Castro, 2018). La mayoría de las teorías dentro de la dirección de empresas no toma en cuenta aspectos éticos en sus decisiones (Torres, 2001; Rosanas, 2007a), tienen diversos problemas en sus supuestos teóricos y filosóficos (Ghoshal, 2005; Rosanas, 2009; Alcázar, 2010) en especial los antropológicos y éticos (Mitroff, 2004; Melé \& González, 2015).

Por otra parte, tenemos problemas epistemológicos para encontrar qué cosa hace a una decisión buena. Por ejemplo, abordar el asunto desde una perspectiva post hoc, haciendo revista a todas y cada una de las decisiones que fueron exitosas y obteniendo de ellas los principios por los cuales son exitosas, es un absurdo metodológico. Hacerlo así presupone los criterios por los cuales se califica a una decisión de "buena": escoger entre buenas y malas decisiones en una muestra presupone un criterio por el cual afirmamos "estas decisiones son buenas y por tanto podemos obtener criterios de decisión de ellas"; al escoger las buenas para saber por qué son buenas ya hemos usado un criterio para decir "son buenas", cayendo en una petición de principio.

Además, abordar el problema desde la perspectiva post hoc, es acercarse a la cuestión de manera descriptiva. Esto es problemático para la ciencia del management que, en general, está preocupada con resolver problemas prácticos, es decir, está preocupada de aquellas verdades útiles, aquellas que le permitan resolver sus problemas específicos (Rosanas, 2012)2. La lógica científica toma en cuenta proposiciones del tipo «Si Ax entonces By», en donde Ax explica causalmente a By y permite predecir su evento. Por ejemplo, si se bajan las tasas de interés, habrá más consumo; si se suben los precios de los productos habrá menos clientes, etc. Tendríamos que fabricar un "archivo» de todas las afirmaciones verdaderas «Si 
Ax entonces By» que sean consideradas buenas. Esto, desde el punto de vista práctico o de la acción, no tiene sentido, resulta poco práctico (e inaplicable en ciertas circunstancias) para cualquier directivo profesional (Pérez López, 1991). Es, en cualquier caso, preferible conseguir una serie de criterios formales, que prescindan del contenido real de la decisión, para poder ser usados como criterios universales de decisión.

Por todo esto, el presente artículo pretende exponer, de manera lógica, los criterios a priori que debe tener en cuenta un decisor para asegurar, al menos formalmente, que su decisión es una buena decisión. Para ello, nos basaremos en la teoría de la acción de Juan Antonio Pérez López (1991, 2014), que es relativamente poco conocida (Argandoña, 2007). Su trabajo es lo que él llama una lógica de la acción, que se enmarca en el paradigma del management cibernetics
(Melé, Chinchilla, \& López-Jurado, 2018). Además, el modelo de Pérez López integra diversos tipos de resultados de la acción, incluyendo los resultados éticos, de manera que puede considerarse una abstracción completa, es decir, un tipo de teoría que permite evaluar una acción de manera global: si puede ser considerada una buena decisión en todos los aspectos y no solo en uno (Rosanas, 2007b). Nuestro objetivo es exponer el moldeo mínimo para considerar a una decisión como buena, así como brindar razones suficientes para considerar los criterios que aquí expondremos. Así mismo, utilizaremos datos de diferentes ciencias para ir construyendo el modelo.

\section{Evaluación de una buena decisión}

El esquema mínimo para conceptualizar la interacción (acción-reacción) entre dos personas puede graficarse de la siguiente manera:

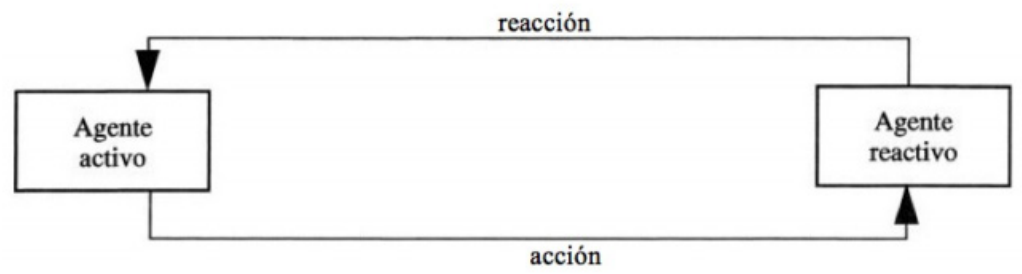

Figura 1. Modelo básico de sistema.

Fuente: Original de Teoría de la acción en las organizaciones: la acción personal de Pérez López (1991, p. 25)

Cuando el agente activo tiene un problema, es decir, se percata que «existe una situación que no es del todo agradable para una persona [el mismo u otra], o cuando se sospecha que existen situaciones más agradables que las actuales» (Ariño, 2005, p. 19), y que no puede solucionar solo; ejecuta una acción con otro agente (reactivo), con la esperanza que la acción de dicho agente (la reacción) solucione su problema. Esta acción se basa en una decisión 
previa y que, si soluciona su problema - es eficaz- puede ser considerada como una buena decisión. De hecho, la respuesta tradicional que se ha dado a la pregunta sobre si una decisión es una buena decisión es en términos de resultados, «en pocas palabras, una buena decisión es aquella que produce resultados positivos» (Higgins, 200o). Ahora bien, ¿qué se debe tomar en cuenta para conseguir esos "resultados positivos"? ¿qué criterios, evaluaciones o condiciones se deben tomar en cuenta?

Si realizamos un rápido análisis de esta interacción caemos en cuenta que tenemos, al menos, tres evaluaciones que debemos realizar para tratar de conocer $a$ priori la eficacia de la decisión del agente activo. En primer lugar, se debe analizar la proposición, o plan de acción, la díada «acción-reacción»; esto es, evaluar la validez de la proposición, que no es otra cosa que «la medida en que la acción y la reacción realmente resuelven el problema que se pretendía resolver» (Ariño, 2005, p. 30). En segundo lugar, debemos evaluar si el estado interno del agente activo es tal que le permite ejecutar el plan de acción; es decir, si le es factible u operativo ejecutar el plan de acción. Por último, hemos de evaluar si el estado interno del agente reactivo está en condiciones de realizar la reacción; o sea, si es operativo o instrumental (operatividad del agente reactivo) para dicho agente ejecutar su acción (la reacción).

En el ejemplo de Paterson, el problema parece haber sido que "las personas no están cumpliendo su horario de trabajo". En este caso, el plan de acción de Paterson era válido, porque la acción tomada, enviar el e-mail, ha resultado en la reacción por parte de los directivos, dar una orden a los subordinados para que estén cumplan cabalmente un horario de trabajo. Fue operativo, porque Paterson tenía el poder necesario para dar ese tipo de orden —un ultimátum-. Y fue instrumental porque los directivos subordinados a Paterson tenían también el poder necesario de dar la orden a sus empleados para que cumplan un determinado horario de oficina. Diferente hubiese sido el caso de otro directivo que sea inferior en la cadena de mando, pues no hubiese sido operativo para él pedirles a los otros directivos del mismo nivel utilizando un e-amil con un ultimátum.

Hasta aquí, podemos ver que fue una buena decisión. Esta evaluación de una acción concreta es lo que podemos llamar una evaluación estática. Sin embargo, en las organizaciones se requieren múltiples interacciones entre diversos agentes en distintos momentos, sea entre directivos y colaboradores, colaboradores con otros colaboradores, vendedores con clientes, etc. ¿Qué pasaría si los estados internos de los agentes cambian debido a las interacciones pasadas? La pregunta es clave para realizar un análisis completo. De hecho, la experiencia muestra que ese cambio existe y que influye en las futuras interacciones, incluso a nivel neuronal (Sapolsky, 2017). No tomar en cuenta el cambio de los estados internos de los agentes para la evaluación de una acción sería una abstracción incompleta. En 
ese sentido, al cambio producido en el agente activo luego de una interacción le llamaremos eficiencia - operatividad futura-, y al cambio producido en el agente reactivo le llamaremos consistencia -instrumentalidad futura-.

Ahora bien, el cambio al que nos referimos no es cualquier tipo de cambio, sino aquel «cambio que ocurra en los agentes como consecuencia de la ejecución del proceso de interacción, siempre que dicho cambio sea significativo para la explicación de las futuras interacciones» (Pérez, López, 1991). Para distinguirlo, utilizaremos el término aprendizaje, que es mucho más preciso. Dicho aprendizaje puede ser positivo, es decir, permite que las interacciones puedan continuar produciéndose en el futuro (o incluso facilitar las interacciones futuras); o negativo, esto es, un aprendizaje que dificulte o incluso imposibilite las futuras interacciones. Así, tenemos la evaluación mínima y completa de una interacción: un análisis estático - eficacia del plan de accióny un análisis dinámico -eficiencia y consistencia de un plan de acción-.

En el caso propuesto, parece ser que Paterson sólo realizó una evaluación estática de su decisión. Pues era eficaz (válida, operativa e instrumental), pero generó diversos aprendizajes en los agentes reactivos. Recibir un ultimátum no es algo que sea del todo agradable para algunos, y el no pensar en lo que podría haberles sucedido a sus directivos le pasó factura. De hecho, podría decirse que la decisión fue buena en su momento (resolvió el problema de los horarios, fue eficaz), pero la forma en que se hizo puso en riesgo la eficacia futura de la organización. Dicha decisión fue inconsistente, no se pensó en el aprendizaje de los directivos y ocasionó otro problema futuro. Pérez López (1992a) lo ejemplificaba con la fábula del pastorcillo mentiroso: un pastorcillo tenía un problema, estaba aburrido, y opto por un plan de acción para divertirse, iba a la taberna y gritaba "lobo, lobo"; viendo cómo los otros pastores corrían en respuesta a su falso pedido de auxilio, él se reía y divertía mucho; repitió esta fórmula dos o tres veces, y a la siguiente —cuando en verdad los lobos llegaronlos pastores ya no le creyeron y simplemente no fueron. Podría decirse que su forma de divertirse, aunque eficaz, era profundamente inconsistente, y por tanto una mala decisión, igual que la de Paterson.

\section{Evaluación dinámica:algunos ejemplos}

Cuenta Esopo que un día, un granjero, descubrió que su ganso había puesto un huevo de oro. Aunque escéptico al principio, pudo comprobar que era auténtico. El granjero estaba feliz de la buena suerte que había tenido, más aún cuando se repitió la extraña experiencia. Todos los días veía como su ganso ponía otro huevo de oro, llegando a ser muy rico. Pero, junto con su creciente fortuna crecieron la impaciencia y la codicia. Incapaz de esperar, el granjero decidió matar al ganso para obtener todo el oro de una vez. Pero al abrir el ave, la encontró vacía. Allí no había huevos de oro, y ya no había modo 
de conseguir ninguno más. El granjero había matado al ganso que los producía.

¿Fue una buena decisión la del granjero? Sencillamente no, pero ¿por qué? Porque no solo no fue eficaz (el ganso carecía de la instrumentalidad necesaria para dar los huevos de oro ante el corte fatal del granjero); sino, sobre todo, porque fue inconsistente. Dicha decisión afectó a aquello que podía solucionarle sus problemas económicos no solo ahora, sino también a futuro. De hecho, el granjero podría haber intentado reproducir al ganso, o realizar un tipo de análisis veterinario externo para verificar que hubiese huevos de oro, o realizar una operación quirúrgica experta sin dañar al ganso. Todas estas opciones podrían haber sido eficaces (o no), pero hubiesen respetado la eficacia futura (la consistencia). El pobre granjero pronto se encontró sin los medios que producen los huevos. Ahora bien, ¿qué pasaría si fuesen personas? Es el caso de Paterson, que obtuvo los huevos de oro (las personas estaban en su lugar de trabajo) a costa de la vida del ganso (el malestar de los directivos). Algo parecido puede pasar en otros tipos de contextos, pero peor.

Por ejemplo, un operario trabaja en una empresa que está creciendo rápidamente. Ve una oportunidad magnífica de ascenso dentro de la organización (problema). Ella está a cargo de una máquina y está ansiosa por causar una buena impresión en sus superiores. Produce en niveles óptimos: ningún tiempo muerto, nada de mantenimiento. La máquina trabaja día y noche, la producción es extraordinaria, los costos bajan, etc. (huevos de oro, eficacia)
Al cabo de un tiempo, dicha persona obtiene su ascenso. Pero, el sucesor del puesto hereda una máquina deteriorada que empieza a fallar. Tiene que realizar mantenimiento, los costos se disparan y la utilidad cae en picado. ¿A quién se culpará por la pérdida de la empresa? Al sucesor. Su predecesor destruyó la máquina, pero ni se ha enterado que ha sido su culpa. No se dará cuenta de lo mala que fue la decisión de sobre exigir la máquina sin tomar en cuenta que es lo que le pasaría a futuro, es decir, sin tomar el criterio de consistencia en la decisión?

De hecho, el ejemplo anterior oculta el criterio de eficiencia. La primera persona que usó la máquina y que ascendió, aprendió algo: que puede obtener un resultados - un ascenso- usando una máquina hasta el extremo. El problema es que, al fallar el reemplazo, no se enterará de que fue por su mala decisión; o, dicho de otra manera, no se enterará de que de que su decisión fue ineficiente. Esto es una de las peores cosas que le puede pasar a una persona, que su decisión sea eficaz e inconsistente, pero que no sepa que es inconsistente, pues es el peligro de un aprendizaje negativo, algo que la persona pensaba que era una buena decisión en el fondo era una decisión mala (Pérez López, 1991). Al menos Paterson se enteró gracias a la mala fama de la prensa norteamericana.

Hasta aquí tenemos los criterios claves para la buena toma de decisiones: debe de ser eficaz, eficiente y consistente. Eficaz porque una buena decisión debe resolver un problema; eficiente, porque 
una buena decisión busca que el decisor esté en mejores condiciones para poder resolver mejor los problemas futuros (un aprendizaje positivo en el agente activo); y consistente, porque una buena decisión aspira a que, a futuro, las personas con las que se interactúa estén en una mejor disposición para resolver los problemas del agente activo. Si a un futuro no se puede resolver el problema debido a la decisión, fue una mala decisión, especialmente en un contexto organizacional en el que las decisiones suelen repetirse constantemente con los mismos agentes. Como dice Pérez López, «si la decisión es de un solo uso, piénselo dos veces antes de usarla» (Pérez López, 1992b).

\section{Resultados y motivos de la acción:}

Teniendo en cuenta la Figura 1 y el análisis realizado, podemos afirmar que por cada decisión se pueden esperar tres tipos de consecuencias o resultados de la acción (Pérez López, 2014): resultados extrínsecos, o la misma acción del agente activo y la reacción del agente reactivo (lo que ambos hacen, la propia interacción) ${ }^{4}$; resultados intrínsecos, el aprendizaje del agente activo fruto de la decisión tomada; y resultados trascendentes, o el aprendizaje del agente reactivo fruto de la interacción. Estos resultados son «irreducibles entre sí» (Alcázar, 2010, p. 105), además de ser a posteriori, mientras que la evaluación del plan de acción por parte del agente activo es $a$ priori.

Distinguir entre ambos, resultados y criterios deevaluación, resulta útil para el análisis pues una cosa es la eficacia, eficiencia y consistencia a priori y otra a posteriori. Una decisión puede ser una buena decisión $a$ priori y no a posteriori. Y, como dijimos, una buena decisión es aquella que produce resultados positivos, es decir, a posteriori. He allí una dificultad teórica para saber qué es una buena decisión. Porque, como hemos visto, una decisión puede ser eficaz (resultado extrínseco positivo), pero haber tenido aprendizajes negativos por parte de ambos agentes, como el caso del pastorcillo: losagentes reactivos cada vez estaban menos dispuestos a colaborar con él (inconsistencia) y el pastorcillo no se enteró de que su decisión fue la que causó el deterioro de la "máquina" - comoen el casodel operario(ineficiencia). Hemos de afirmar que, entre ambas, lo fundamental es que la decisión sea buena a priori (a nivel de criterios), pues que la decisión sea buena a posteriori (a nivel de resultados) puede no estar bajo control del agente activo. Esto debido a las circunstancias que no siempre son la mismas (no se cumple el criterio ceteris paribus en la vida real), y porque el agente reactivo es libre, su reacción depende de su querer más que de la acción del agente activo5. Por otra parte, evaluar que una decisión sea buena a posteriori puede llevarnos a los problemas epistemológicos quevimos en la introducción.

Una buena decisión, por tanto, no es aquella que produzca resultados positivos a posteriori en todos los aspectos necesariamente - pues existe el factor suerte (Ariño \& Maella, 2009)—. Una buena decisión es aquella en la que se evalúa $a$ priori todos los posibles resultados de la acción, eligiendo los positivos en todos los aspectos. Al hacerlo pueden ocurrir dos 
cosas: tener suerte, no solo solucionando el problema, sino siendo consistente; en ese caso, la decisión es una buena decisión y habrá aprendido positivamente, sabrá que debe hacer e interiorizará los criterios de decisión - es eficiente, sabe por qué fue una buena decisión-; o no tener suerte, la acción fue ineficaz a posteriori, en estecaso, al menos no caerá en aprendizaje negativo, sabrá que no debe realizar algún plan de acción, pero al menos habrá considerado todos los posibles resultados - no fue inconsistente o, al menos, la inconsistencia de la acción no se debió al agente activo de manera intencionada-.

Por otra parte, la consideración de los resultados de la acción nos lleva a la valoración de estos para la decisión. En otras palabras, «el logro de cualquiera de aquellos tres tipos de resultados, o de todos simultáneamente, puede llegar a ser motivo de las decisiones de una persona, es decir, puede ser un logro intentado en sus decisiones» ${ }^{6}$ (Pérez, López, 2014, p. 55). Este sencillo esquema lógico nos muestra que los agentes pueden tener distintos motivos para la acción. Al respecto, Pérez López (2014, p. 55) afirma que «[los] aprendizajes pueden tener un gran valor para el agente activo... [No siendo] nada extraño que la consecución de dichos aprendizajes pueda ser un objetivo explícitamente buscado por las decisiones de una persona», pero añade inmediatamente que «también puede ocurrir que ambos aprendizajes no solo no sean buscados, sino que sean, por el contrario, ignorados a la hora de tomar las decisiones» (Pérez López, 2014, p. 55). De hecho, nada nos impide pensar que, en toda lógica, el agente activo tenga que actuar por todos los motivos al mismo tiempo; sin embargo, «en una acción intervienen ordinariamente los tres motivos, aunque con mayor intensidad unos que otros» (Ferreiro \& Alcázar, 2012, p. 65).

Tenemos por tanto tres motivos de la acción para agente: motivos extrínsecos o aquellos que buscan los resultados extrínsecos, es decir, el logro de satisfacciones - la resolución del problema que producen las interacciones-; motivos intrínsecos o la valoración de los resultados intrínsecos, a saber, la búsqueda del propio aprendizaje del agente activo; y los motivos trascendentes oaquellos que buscan resultados trascendentes, o sea, el aprendizaje del agente reactivo ${ }^{7}$. Cabe notar que, al realizar una acción, el agente activo puede tener un motivo ignorando otros, pero los resultados se dan con independencia de las intenciones del decisor. Por otra parte, no necesariamente se debe preferirun resultado a otro: si bien se deben tener en cuenta todos los resultados de la acción para que sea una buena decisión, no necesariamente debe de motivarnos uno másqueotro. En otras palabras, la condición de una buena toma de decisiones es esta: se deben tomar decisiones eficaces, eficientes y consistentes sea por el motivo que sea.

\section{Relación estructural, relación operativa: tipos de aprendizaje y ética}

Dado el análisis anterior, podemos deducir que se encuentran dos tipos de relaciones entre los agentes, una subyacente y necesaria para la otra. Por una parte, podríamos hablar de las condiciones de posibilidad de la interacción (acción-reacción): el estado interno de los agentes 
- operacionalidad e instrumentalidaddebe ser tal (debe haber un mínimo necesario) que permita la interacción; de no ser así, no hay interacción posible. A esta relación subyacente le llamaremos relación estructural, esto es, «los grados de confianza que puedan existir entre ambas personas» (Pérez López, 2014, p. 156). Supuesto esta relación estructural (entre otras cosas, un mínimo de confianza), la relación toma otro cariz, el de la relación operativa o aquellas acciones y reacciones que de hecho solucionan los problemas del agente activo y del reactivo. Nótese que tanto la relación estructural como la relación operativa son solo abstracciones de la relación real (u organización real). Si la organización, la relación real, desea seguir en el tiempo, se ha de tomar decisiones tomando en cuenta los criterios de eficiencia y consistencia, es decir, velando por que los estados internos de los agentes tomen en cuenta los resultados intrínsecos y trascendentes de las acciones (como condición de posibilidad de cualquier interacción actual y futura), y que mejoren en la calidad de sus interacciones, a saber, que las acciones y reacciones solucionen cada vez mejor los problemas.

Ahora bien, dado que los motivos de la acción pueden lógicamente distintos, pueden existir al menos dos tipos de aprendizaje. Si me mueven a actuar los motivos extrínsecos estoy buscando mejorar la relación operativa (¿qué tipo de acción generará la reacción que busco?, ¿cómo puedo mejorar la eficacia de mis acciones para generar mejores reacciones?), tendré un resultado intrínseco (buscado o no) que es un aprendizaje operativo, "adquisición de un conocimiento o habilidad "técnica": aprender un idioma, manejar un auto, dominar una técnica financiera... etc.» (Ferreiro \& Alcázar, 2012, p. 61). Por otra parte, si me mueve a actuar motivos trascendentes estoy buscando la mejora en la relación estructural (¿el otro querrá seguir colaborando conmigo a futuro?, ¿lo que estoy haciendo está fortaleciendo nuestra relación, ¿le estoy tomando en cuenta?, ¿le ayudo a tomarme en cuenta en su decisión?), tendré un resultado intrínseco (querido o no) que es un aprendizaje estructural, se aprende «a tomar conciencia del impacto de... [la] acción sobre otras personas» (Ferreiro \& Alcázar, 2012, p. 62).

Esta distinción entre aprendizajes operativos y estructurales nos abre la puerta al criterio ético en la toma de decisiones. En primer lugar, tomar decisiones consistentes implica tener un mínimo de motivos trascendentes en nuestra toma de decisiones (aunque no sea el motivo principal). Esto quiere decir que estoy pensando en el posible resultado trascendente, ¿qué le pasará al otro cuando ejecute este plan de acción? Como no lo sabemos con toda certeza, podemos realizar una simulación: si el agente reactivo pusiera en práctica conmigo el mismo plan de acción que yo pretendo poner en práctica con él y con las mismas intenciones que me mueven a mí, ¿querría colaborar con él? (Ariño, 2005). Esta formulación no es otra que «la regla de oro», el conocido principio ético de valor universal ${ }^{8}$, por lo que puede afirmarse que la evaluación incluye una valoración ética en sus supuestos. 
Pero el asunto va más allá. Valorar lo que le sucederá a otra persona en la interacción, es decir, tener motivos trascendentes - sobre todo trascendentes-, es precisamente no utilizarlo simplemente como un medio sin, a su vez, también como un fin en sí mismo. La fórmula de conducta que acaba de expresarse no es otra que la del segundo imperativo categórico de Kant, y «es el principio [moral] más importante para regir las relaciones de la persona en la empresa como comunidad de persona que es» (Llano, 1997, p. 98). Este principio, también llamado «principio personalista» (citado por Wojtila, 2013, p. 41), puede ser formulado de manera positiva de la siguiente manera: «las personas deben ser tratadas no solo con respeto, sino con benevolencia y cuidado» (Melé, 2009, p. 81). Lo cual confirma la integración de la bondad ética en los criterios decisionales que estamos analizando.

Debe tomarse en cuanta que tanto «(a) prendizaje operativo y estructural son los dos tipos de resultados internos que se producen en la persona por el solo hecho de haber actuado, con independencia de lo que venga del exterior o de lo que les ocurra a las personas con las que interactúa» (Ferreiro \& Alcázar, 2012, p. 62); además, ambos pueden ser tanto positivos como negativos. La noción de aprendizaje nos permite introducir otro rasgo de la buena toma de decisiones ética de tradición aristotélica: la noción de virtud. Es el camino que redescubrió Alasdair MacIntyre (2010) en su proyecto
«Tras la Virtud» y que Pérez López reconoce explícitamente: «Hablar de ética sin mencionar las virtudes morales es como hablar de mecánica sin mencionar la gravitación: se estaría haciendo un discurso más o menos poético, pero nada que pueda parecerse a un análisis riguroso» (Pérez López, 1998, p. 28).

\section{Conclusiones}

Una decisión no puede considerarse buena solamente por haber conseguido resultados económicos. Siendo "bueno" un término que tiene muchos sentidos, podemos concluir que una buena decisión es aquella que toma en cuenta, a priori, todos los resultados posibles de la acción, es decir, es una que considera los criterios de eficacia, eficiencia y consistencia. Si una decisión es buena en todos esos sentidos, podemos decir que es una buena decisión, con independencia del resultado a posteriori de la decisión. La valoración moral o bondad ética de la acción está íntimamente integrada en estos criterios de toma de decisiones graciasa la noción deaprendizaje operativo y estructural contenidos en los criterios deeficienciay consistencia. Se toma en cuenta desde la regla de oro universal, pasando por el segundo imperativo kantiano o principio personalista, hasta llegar a la noción de virtud aristotélica, dependiendo del tipo de motivos por los que se tome una decisión. Por tanto, los criterios vistos hasta ahora pueden servir al decisor para valorar sus decisiones de tal manera que sepa, al menos formalmente, que su decisión es una buena decisión. 


\section{Referencias}

Alcázar, M. (2010). Las decisiones directivas: Una aproximación antropológica al logro de efiacia y de aprendizajes positivios en las organizaciones. (Tesis Doctoral). Universidad de Navarra, Pamplona, España.

Ariño, M. A. (2005). Toma de decisiones y gobierno de organizaciones. Barcelona: Deusto.

Ariño, M. Á., \& Maella, P. (2009). Iceberg a la vista. zera Edición. Barcelona: Empresa Activa.

Argandoña, A. (2006). Milton Friedman (1912-2006). CaixaBank Chair of Corporate Social Responsibility, OP-07-9.

Argandoña, A. (2007). Integrating Ethics into action theory and organizational theory. Journal of Business Ethics, 78, 435-446.

Argandoña, A. (2010). La dimensión ética de la crisis financiera. Mediterráneo Económico, 18, 183-198.

Covey, S. R. (1993). The seven habits of highly effective people. USA: Simon \& Schuster.

Ferreiro, P., \& Alcázar, M. (2012). Gobierno de personas en la empresa. 6ta. Edición. Lima: Planeta.

Feser, E. (2014). Scholastic Metaphysics. Germany: Editiones Schlasticae.

Flores-Castro, G. (2018). Integración de la ética en la toma de decisiones. Ilustro, 9, 53-80.

Fuster, J. M. (2016). Cerebro y libertad. Los cimientos cerebrales de nuestra capacidad para elegir. Barcelona: Ariel.

Ghoshal, S. (2005). Bad management theories are destroying good management practices. Academy of Management Learning E Education, 4(1), 75-91.

Higgins, E. T. (2000). Making a good decision: Value from fit. American Psychologist, 55(11), 1217-1230. 
Llano, C. (1997). Dilemas éticos de la empresa contemporánea. México D.F.: Fondo de Cultura Económica.

MacIntyre, A. (2010). After virtue. zera. Edición. Indiana: University of Notre Dame Press.

Melé, D. (2009). Business Ethics in Action. Seeking Human Excelence in Organizations. Londres: Palgrave Macmillan.

Melé, D. (2014). Re-thinking capitalism: What we can learn from Scholasticism. Journal of Business Ethics, 133(2), 293-304.

Melé, D., Chinchilla, M. N., \& López-Jurado, M. (2018). The "Freely Adaptive System". Application of this Cybernetic Model to an Organization Formed by Two Dynamic Human Systems. Philosophy of Management. doi: 10.1007 / s40926-018-0098-x

Melé, D., \& González, C. (2015). Fundamentos antropológicos de la dirección de empresas. Pamplona: EUNSA - Astrolabio.

Mitroff, I. I. (2004). An open letter to the Deans and Faculties of American Business Schools. Journal of Business Ethics, 54, 185-189.

Pérez López, J. A. (1991). Teoría de la acción humana en las organizaciones. La acción personal. Madrid, España: Rialp.

Pérez López, J. A. (1992a). Apuntes sobre la teoría de la acción humana en las organizaciones. Bogotá: Universidad de la Sabana.

Pérez López, J. A. (1992b). Cómo generar confianza. Buenos Aires, Argentina. Obtenido de: https://www.youtube.com/watch?v=VRTM3XsVGyo

Pérez López, J. A. (1998). Liderazgo y ética en la dirección de empresas. Bilbao: Deusto.

Pérez López, J. A. (2014). Fundamentos de Dirección de Empresas. 6ta. Edición. Madrid: Rialp.

Rosanas, J. M. (2007a). Beyond economic criteria: A huministic approach to organizational survival. IESE Business School, 654, 1-22.

Rosanas, J. M. (2007b). On the methodology of Management Research. IESE Business School, 692. doi: http://dx.doi.org/10.2139/ssrn.1026241 
Rosanas, J. M. (2009). Pero, ¿Qué es el management? Revista de Antiguos Alumnos del IEEM, 12(1), 31-36.

Rosanas, J. M. (2012). Methodology and research in Management. International Journal of Management and Economics, 36, 8-19.

Sapolsky, R. (2017). Behave. The biology of humans at our best and worst. New York: Penguin Press.

Torres, M. B. (2001). Character and Decision-Making. (Tesis Doctoral). Universidad de Navarra, Pamplona, España.

Wojtyla, K. (2013). Amor y Responsabilidad. Madrid: Palabra. 


\section{Notas}

1 En honor al famoso economista, añadimos lo siguiente: «La tesis de Friedman (...) no es arbitraria ni, como se ha dicho en ocasiones, una muestra de capitalismo salvaje. Es una consecuencia lógica de los supuestos que sustentan su modelo. Friedman llevó a cabo un formidable trabajo explotando las consecuencias de esos supuestos, con lógica e inventiva...» (Argandoña, 2006, p. 7).

2 Nótese que esto no es un utilitarismo epistemológico. No afirmamos que el criterio de verdad sea la utilidad, es decir "es verdadero porque es útil"; afirmamos algo distinto, "de lo verdadero, lo útil". Es decir, se usan abstracciones de realidades con ciertos fines utilitarios; pero siguen partiendo de la realidad y se ajusta a ella, tomando todas las variables relevantes al problema (Rosanas, 2012).

3 Los ejemplos los tomo de Covey (1993).

4 Nótese que la operacionalidad e instrumentalidad actuales no son resultado de la interacción, sino sus condiciones de posibilidad.

5 La libertad es un supuesto de todo el sistema de Pérez López (Alcázar, 2010), el cual cuenta con sólidos fundamentos filosóficos (Mele, 2011, 2014) y científicos (Fuster, 2016). Según Melé, Chinchilla y López-Jurado (2018), «Pérez López did not debate the so-called problem of free will (is free will real or a mere illusion?), but his implicit assumption-like Aristotle-is that free will is not an illusion and we are not fully determined by external or biological factors». El tema es discutible, pero afirmamos junto con Fuster que «...es precisamente en el crisol de probabilidades e incertidumbres del cerebro humano donde cobra vida la libertad. La capacidad para escoger entre posibilidades proviene literalmente de la varianza y los grados de libertad de innumerables variables que subyacen a la acción humana futura. Como pasa con la evolución, el determinismo y la causalidad directa se disuelven en la probabilidad y, al hacerlo, ceden ante un factor teleológico: la finalidad, el objetivo» (Fuster, 2016, p. 17).

6 Motivo es la realidad en cuanto se prevé que resolverá el problema del agente, siendo por tanto valorada. En ese sentido, motivo y valor son lo mismo (Ferreiro \& Alcázar, 2012).

7 La búsqueda del aprendizaje del agente activo (resultado intrínseco) es un motivo intrínseco y produce el resultado intrínseco, mientras que la búsqueda del resultado trascendente es un motivo trascendente que produce un resultado intrínseco no buscado directamente (un aprendizaje en el agente activo que le 
facilita la consideración de resultados trascendentes), no produce el resultado trascendente (esto depende también del agente reactivo).

8 Se encuentra en distintas tradiciones sapienciales y religiosas, aunque con algunas variaciones. Estas tradiciones incluyen al Antiguo Egipto, el Zoroastrismo, la Filosofía Griega (Pítaco, Diógenes, Sexto Empírico, Isócrates y Epicteto), Judaísmo, Cristianismo, Islamismo, Sufismo, Hinduismo, Jansenismo, Sijismo, Confucianismo, Taoísmo, Budismo, Shintoismo, Humanismo Secular, Espiritualidad de los Nativos Americanos, Proverbios Africanos, entre otros (Melé, 2009).

Recibido: 11 de noviembre de 2019

Aceptado: 20 de diciembre de 2019 


\section{RESEÑA}

¿QUÉ SABEMOS ACERCA DE LA INVESTIGACIÓN LATINOAMERICANA EN PSICOLOGÍA ORGANIZACIONAL?

Tomás Caycho-Rodríguez 



\section{¿QUÉ SABEMOS ACERCA DE LA INVESTIGACIÓN LATINOAMERICANA EN PSICOLOGÍA ORGANIZACIONAL?}

Tomás Caycho-Rodríguez

Universidad Privada del Norte, Lima, Perú 

Rev. Psicol. (Arequipa. Univ. Catól. San Pablo) / Año 2019 / Vol 9 / N 3 / pp. 127-130 ISSN 2306-0565 versión impresa / ISSN 2311-7397 versión on line (c) $\left(\begin{array}{l}\text { (C) } \\ \text { Esta obra está bajo una Licencia Creative Commons } \\ \text { Atribución 4.o Internacional (BY-NC-ND) }\end{array}\right.$

\title{
¿QUÉ SABEMOS ACERCA DE LA INVESTIGACIÓN LATINOAMERICANA EN PSICOLOGÍA ORGANIZACIONAL?
}

\author{
WHAT DO WE KNOW ABOUT LATIN AMERICAN RESEARCH \\ IN ORGANIZATIONAL PSYCHOLOGY? \\ Tomás Caycho-Rodríguez \\ Universidad Privada del Norte, Lima, Perú
}

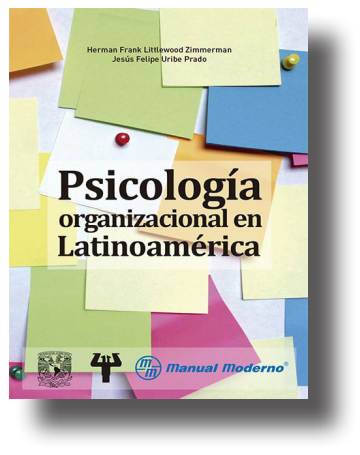

Han aparecido en libro, y con el título de Psicología Organizacional en Latinoamérica, un conjunto de investigaciones compiladas por Herman Frank Littlewood Zimmerman y Jesús Felipe Uribe Prado sobre esta importante área de la psicología. La edición corresponde a Manual Moderno, y se convierte en una referencia obligada para cualquier investigador de la psicología organizacional. Forman el libro 19 estudios, entre empíricos y revisiones, escritos por 35 investigadores de diversos países latinoamericanos.
Littlewood, H. F. y Uribe, L. F. (Eds.). (2018). Psicología organizacional en Latinoamérica. México: Manual Moderno.

ISBN 978-607-448-709-1, págs. $35^{2}$
El primer capítulo, escrito por Luis Fernando Arias Galicia, brinda un panorama acerca del uso de las pruebas psicométricas en México. Específicamente se hace referencia al inadecuado manejo que se tiene de los instrumentos en el ámbito de la selección de personal. El contenido de este capítulo parece no solo ser útil en México sino en otros países, como el Perú, donde no encontramos una adecuada regulación para la identificación y uso de esta clase de instrumentos. Arias Galicia termina el capítulo 
brindando sugerencia para un adecuado análisis de la validez, confiabilidad y estandarización de los instrumentos psicométricos, así como de otras técnicas como la entrevista. En el segundo capítulo, Héctor Macías Díaz, analiza el proceso de capacitación y brinda un conjunto de sugerencias para hacerlo más efectivo y se convierta así, en una estrategia importante de las organizaciones. El capítulo tres, de Sergio Madero Gómez, analiza el sistema de compensaciones como parte fundamental del esquema de pagos de las empresas. Específicamente, se analiza el diseño de las compensaciones desde una perspectiva estratégica, su papel como factor de atracción y retención de los trabajadores, así como los diferentes sistemas de incentivos que existen.

En el cuarto capítulo, Ignacio Mendoza Martínez, describe y analiza en profundidad la teoría de liderazgo transformacional. Adicionalmente, se presenta la adaptación del Multifactor Leadership Questionnaire y los resultados de un estudio descriptivo sobre el liderazgo transformacional en México. En sintonía con lo anterior, el quinto capítulo de Carlos Andújar y Mónica Pérez, presenta una propuesta para el desarrollo de líderes emocionalmente inteligentes, la cual se basa en una perspectiva estratégica y un enfoque de desarrollo organizacional basado en el cambio cultural. Victoria Barrón Cruz y colaboradores, en el capítulo 6, brindan los resultados de un estudio que tiene como objetivo identificar y describir las competencias de comunicación intercultural de trabajadores chinos y mexicanos. Para esto, los autores parten de un riguroso análisis teórico sobre este tipo de competencias. El estudio concluye que competencias como, dominio de un segundo idioma, habilidades interpersonales, empatía cultural, efectividad en el equipo e incertidumbre cultural; resultan las más importantes en este contexto. El capítulo 7, cuya autoría corresponde a Arturo Juárez García, tiene como objetivo realizar un repaso general del desarrollo de las investigaciones centradas en los factores psicosociales en México. A partir de ello, el autor propone un modelo conceptual y taxonómico sobre el tema.

El estrés como un antecedente del desgaste ocupacional, y sus relaciones con la salud y el bienestar ocupacional es el tema central del capítulo 8, de Carmen Camacho Cristiá. El capítulo 9, de Jesús Felipe Uribe y colaboradores, analiza también el problema del estrés y su relación con los estilos de afrontamiento. En este sentido, los autores realizaron dos estudios, a partir de los cuales, se creó un instrumento para medir los estilos de afrontamiento a partir de 171 pares de frases. Se propone aquí, que existen cuatro estilos de afrontamiento: 1) desesperanza cognitiva, 2) evitación conductual, 3) solución real cognitiva y 4) conductas de acción y control. Siguiendo con la línea psicométrica, Leonor Delgadillo y colaboradores, diseñan un instrumento para medir la violencia laboral, denominado Evila-AD, conformado por 37 
ítems, los cuales se agrupan en cinco dimensiones (violencia sexual, hostilidad-desvalorización, coerción-discriminación, estabilidad laboral y desarrollo laboral). Aquí, si bien se saluda la iniciativa, parece existir una serie de limitaciones derivadas de la evaluación de la estructura del instrumento, ya que se utilizan procedimientos como componentes principales y rotación varimax que son totalmente inadecuados para la determinación de la estructura factorial de un instrumento de medida.

A partir de aquí encontramos capítulos referidos a problemas no tradicionales en la investigación organizacional en Latinoamérica. Así, el mobbing es el tema del capítulo 11 escrito por Mara Trujillo y colaboradores. Los autores presentan los resultados de un estudio descriptivo, donde las principales conclusiones señalan que las mujeres reportan más casos de mobbing y que, una empresa con estructura de trabajo débil con políticas internas frágiles fomentan la aparición de este problema. Alicia Omar, en el capítulo 12, analiza el tema de justicia organizacional, su importancia, tipos, instrumentos de medición, su relación con variables personales y contextuales así como los mecanismos de desarrollo. La autora combina lo reportado por la literatura internacional y sus propios aportes científicos. En el capítulo 13, Norma Betanzos y colaboradores, revisan los diferentes modelos teóricos sobre el compromiso organizacional y su importancia en la productividad, así como su estudio en el contexto mexicano. Esto le permite proponer un modelo teórico que tome en consideración las características particulares del trabajador mexicano. Juan Diego Vaamonde analiza el sexismo en el trabajo, enfatizando el modelo de Peter Glick y Susan Fiske. Asimismo, propone estrategias de prevención y tratamiento del sexismo en el contexto organizacional de los países latinoamericanos. El cinismo organizacional es un problema analizado en el capítulo 15 escrito por Solana Salessi. La autora analiza conceptualmente el cinismo en las organizaciones, así como sus relaciones empíricas con otros constructos, dando énfasis en los aportes latinoamericanos. El capítulo 16 de Littlewood se centra en el análisis conceptual y empírico de la renuncia psicológica. Para esto, el autor no se basa solo en lo publicado en artículos de investigación, sino también en tesis y actas de congresos.

Fany Eisenberg, en el capítulo 17 propone un método de diagnóstico estructural organizacional basado en la teoría general de sistemas y la teoría de sistemas sociales. Este método se basa en seis reglas: jerarquía, límites, alianzas, triangulaciones, territorio y geografía. Imke Hindrichs y colaboradores, en el capítulo 18, analizan histórica y epistemológicamente el concepto de empowement en diferentes niveles y contextos. En base a esto, los autores debaten las intervenciones de empowerment desde la mirada de la psicología social organizacional, aplicada al contexto latinoamericano. Finalmente, Fernando Toro, analiza 
el papel central de la coherencia en la administradores y otros profesionaadecuada gestión del clima y cambio les afines, quienes encontrarán en el organizacional. libro, elementos importantes para su actividad. No es descabellado pensar

Este es un libro que llena un vacío en en una traducción al inglés de esta la literatura latinoamericana sobre la obra que haga accesible también su psicología organizacional. Sin embargo, contenido a los lectores que no son esta obra debe ser no solo de interés hispanoparlantes.

de los psicólogos, sino también de los 
HISTORIAS DE LA PSICOLOGÍA

COMENTARIO:

SinTÉTiCa historia de LA PSicología organizacional EN El Perú

Arturo Orbegoso Galarza 



\section{COMENTARIO}

\section{SINTÉTICA HISTORIA DE LA PSICOLOGÍA ORGANIZACIONAL EN EL PERÚ}

Arturo Orbegoso Galarza

Universidad César Vallejo, Trujillo, Perú 

Rev. Psicol. (Arequipa. Univ. Catól. San Pablo) / Año 2019 / Vol 9 / N 3 / pp. 135-138

ISSN 2306-0565 versión impresa / ISSN 2311-7397 versión on line (c) $\left(\begin{array}{l}(1) \\ \text { Esta obra está bajo una Licencia Creative Commons } \\ \text { Atribución 4.o Internacional (BY-NC-ND) }\end{array}\right.$

\author{
COMENTARIO
}

\title{
SINTÉTICA HISTORIA DE LA PSICOLOGÍA ORGANIZACIONAL EN EL PERÚ
}

\section{HISTORICAL SYNTHESIS OF ORGANIZATIONAL PSYCHOLOGY IN PERU}

\author{
Arturo Orbegoso Galarza \\ Universidad César Vallejo, Trujillo, Perú
}

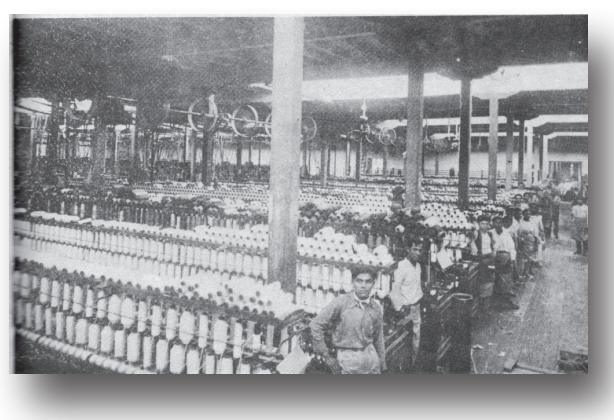

La psicología organizacional en el Perú, como es imaginable, tiene un pasado previo a la creación de la psicología como carrera universitaria y vinculado a diferentes coyunturas económicas, ya sea de expansión o de recesión. Los primeros difusores o propagandistas de la salud laboral fueron médicos, abogados y educadores entre la segunda y tercera décadas del siglo XX.
En lo que sigue se proponen épocas o períodos quea juicio del autor constituyen momentos significativos que contribuyeron a delinear la psicología organizacional peruana.

Cabe aclarar que con el vocablo organizacional se busca abarcar los esfuerzos de psicólogos y otros profesionales en entidades laborales o de lucro, públicas y privadas, en los ámbitos de la salud laboral y la gestión del talento humano en el Perú entre 1900 y la actualidad.

\section{Industrialización, salud obrera y extensión del estado}

Superada la Guerra del Pacífico, las últimas décadas del siglo XIX fueron de 
reconstrucción nacional, proceso que implicó la irrupción de capitales extranjeros y empresas transnacionales que generaron una primera industrialización incipiente pero con importantes consecuencias (Cotler, 2016). Esta penetración se redujo a zonas o reductos específicos, llamados enclaves, en los que se combinaron formas de producción modernas y tradicionales (Cotler, 2016). A los centros agro-exportadores y mineros se sumó el crecimiento de algunas ciudades, la capital Lima en primer lugar. La urbanización y la difusión de fábricas incrementaron la clase trabajadora.

Este inicial proletariado, de crecimiento constante, plantea reclamos a la élite en el poder. Y una parte de esta última, pro-industrial, liberal y modernizadora, coincide en la necesidad de generar reformas que dinamicen el mercado de trabajo y transformen el país. Aquí aparece un primer contingente de profesionales preocupados por la salud obrera: médicos alarmados por barrios pobres e insalubres y abogados dispuestos a mejorar por ley condiciones de trabajo paupérrimas (Basadre, 2005). Algunos educadores predican que las pruebas de inteligencia permiten discriminar a los educandos y obreros hábiles de quienes no lo son (Orbegoso, 2016).

Las primeras décadas del siglo XX comportaron demandas y protestas obreras de variada intensidad que, mezcladas con el discurso de salubridad de algunos galenos y académicos, propiciaron ciertos progresos formales: ley de la jornada de ocho horas, ley sobre el trabajo de mujeres y niños, ley sobre accidentes de trabajo, ley sobre la higiene industrial y otras (Orbegoso, 2016, 2018). Obviamente, hubo sectores conservadores que opusieron una férrea resistencia a estas reformas.

Igualmente, las entidades del gobierno se multiplican y los procedimientos para seleccionar personal se perfeccionan a partir de los años '30. Ministerios, universidades públicas, policía, fuerzas armadas y escuelas de oficios emplean pruebas psicológicas todavía administradas por psiquiatras o educadores (Alarcon, 2000, Orbegoso, 2016).

\section{Expansión económica, relaciones de trabajo y migrantes}

Durante los años ' 50 , tiempo de dictadura militar y de crecimiento económico gracias al alza de las materias primas, se generó un interés por el estudio de la gente en las fábricas (Orbegoso, 2016). El discurso gubernamental manifestaba preocupación por las relaciones entre capital y trabajo. Naturalmente, tras esto estuvo el propósito de mediatizar la actuación de los sindicatos.

El estudio de la conducta industrial fue también fruto de la influencia de la sociología norteamericana sobre investigadores locales. Así se explican estudios aparecidos por entonces sobre relaciones laborales y las consecuencias del trabajo industrial en migrantes andinos (Orbegoso, 2016). 
Por esta época se instituyen los estudios superiores de psicología y en las universidades públicas de San Marcos y Villarreal aparecen los primeros cursos de psicología laboral e industrial (Orbegoso, 2016).

\section{Entre la comunidad laboral y el Estado}

A fines de los ' 60 una dictadura militar de corte nacionalista expropia compañías privadas y expande el aparato estatal al crear empresas ligadas a sectores como la minería, la pesca, el petróleo, las telecomunicaciones y otros (Zapata, 2018). A estas dependencias se incorporaron psicólogos de las primeras promociones universitarias (Uculmana, 1975, Ponce 1998).

Un interés central para el gobierno de facto fue reducir los conflictos entre el capital y el trabajo. Para ello se dispuso por ley, la participación de los trabajadores en la dirección y utilidades de las empresas, forma de gestión que recibió el nombre de comunidad industrial (Alberti, Santistevan \& Pasará, 1977).

Paralelamente, este mismo gobierno propiciaba la creación de empresas de propiedad social y cooperativas. Estos esfuerzos suscitaron trabajos de investigación entre psicólogos pertenecientes a dichas empresas y entre académicos (Alarcón, Bibolini, Infante, \& Ponce).

\section{Crisis, privatizaciones y auge de la especialidad}

Los '8o fueron una etapa de crisis económica, de violencia terrorista y de retroceso del Estado. Paradójicamente, la burocracia no se redujo y hasta se incrementó. Los psicólogos organizacionales, mayoritariamente empleados por el gobierno en variedad de empresas estatizadas en los '70, prosiguieron sus labores de selección de personal, evaluación de desempeño, capacitaciónyafines (Lazo \& Zanolo, 1996).

A principios de los ' 9 o un gobierno de credo liberal decidereducir radicalmenteel aparato estatal y aplica un programa de privatizaciones, lo que implicó prescindir de un gran contingentede empleados públicos y profesionales, psicólogos entre ellos. Se abrieron entonces dosvías para este segmento: migrar al sector privado o reciclarse en la docencia. La instalación de nuevas empresas, fruto de la apertura económicay la multiplicación de universidades hicieron esto posible.

A partir de entonces se extienden nuevas formas de relación entre empresa y trabajadores. Lospsicólogosorganizacionales deben adaptarse a varias formas de flexibilización laboral contribuyendoa su puesta en práctica e incluso siendo contratados temporal y no permanentemente como antaño.

Un último elemento a tener en cuenta es la extensión de adherentes a la psicología organizacional, en otras palabras, el crecimiento de estos especialistas debido sobre todo a la aparición de nuevas universidades que ofrecen tales estudios. Y he aquí otra paradoja: pese a la multiplicación de psicólogos empresariales, aún no hay una asociación que los identifique y represente. Asimismo, la participación de este colectivo en el ámbito de la investigación y las publicaciones académicas sigue siendo limitado. 


\section{Referencias}

Alarcón, R., Bibolini, A., Infante, J. \& Ponce, C. (Eds.). (1975). La investigación psicológica en el Perú. Memorias del Primer Congreso Peruano de Psicología. Lima: Sociedad Peruana de Psicología.

Alarcón, R. (2000). Historia de la psicología en el Perú. Lima: Universidad Ricardo Palma.

Alberti, G., Santistevan, J. \& Pásara, L. (1977). Estado y clase. La comunidad industrial en el Perú. Lima: Instituto de Estudios Peruanos.

Basadre, J. (2005). Historia de la República. Lima: El Comercio.

Cotler, J. (2016). Clases, estado y nación en el Perú. Lima: Instituto de Estudios Peruanos.

Lazo, J. \& Zanolo, B. (1996). Investigaciones y publicaciones psicológicas en el Perú. Lima: San Marcos.

Orbegoso, A. (2016). Psicología peruana. Los prejuicios detrás de la ciencia. Trujillo: Universidad César Vallejo.

Orbegoso, A. (2018). Orígenes sociales de la psicología y la psiquiatría en el Perú (1850-1930). Lima: Sociedad Peruana de Historia de la Psicología.

Ponce, C. (1998). La psicología durante el período del gobierno militar (1968-1980). Revista de Psicología (Universidad Nacional Mayor San Marcos), 2(1), 25-31.

Uculmana, C. (1975). Descripción y perspectivas de la psicología industrial en el Perú. En R. Alarcón, A. Bibolini, I. Infante, C. \& Ponce. La investigación psicológica en el Perú. Memorias del Primer Congreso Peruano de Psicología (pp. 490-497). Lima: Sociedad Peruana de Psicología.

Zapata, A. (2018). La caída de Velasco. Lima: Taurus. 
INSTRUCCIONES PARA LOS AUTORES 



\section{INSTRUCCIONES PARA LOS AUTORES}

La Revista de Psicología es editada por el Departamento de Psicología de la Universidad Católica San Pablo, con el objetivo de difundir la investigación científica que tiene lugar en su seno institucional, y de promover el intercambio de información científica con otras instituciones nacionales o extranjeras. Es una publicación abierta a la comunidad científica y académica nacional e internacional, la cual se edita dos veces al año, y que cubre diversas temáticas dentro del campo de la psicología.

Normas de presentación y envío de trabajos:

1. Los manuscritos deberán ser preparados y estructurados siguiendo las normas de publicación de la Asociación Psicológica Americana (APA, 2011), debe presentarse además, una carta en donde se consigne el nombre del autor principal y de los autores trasladando los derechos de autor a la Revista de Psicología de la Universidad Católica San Pablo; esta deberá incluir una declaración en donde se consigne que los hallazgos del manuscrito no han sido previamente publicados o no se encuentran en proceso de revisión por otra/s revistas de investigación.

2. Los manuscritos no deberán superar una extensión de 35 páginas a doble espacio, incluidas referencias, tablas y gráficos y deberá ser presentado en el tipo de letra Times New Roman número 12. Los gráficos no deben tener una resolución menor a 75 pixeles para ser incluidos en la revista.

3. Dirigir los artículos al Departamento de Psicología, Universidad Católica San Pablo, Quinta Vivanco s/n, San Lázaro; teléfono 051-54-608020 (anexo 362); e-mail:warias@ucsp.edu.pe

Tipos de publicación aceptados:

- Artículos empíricos

- Artículos de revisión

- Artículos teóricos

- Artículos metodológicos

- Entrevistas

- Estudios de casos

- Reseñas de libros

- Comentarios

- Necrologías 
Proceso de revisión (arbitraje) y criterios de evaluación

1. El comité editorial tiene como objetivo velar el proceso de aceptación de un manuscrito para publicación, para ello contamos además con un comité científico de revisores nacional e internacional. Los manuscritos se valoraran en base a:

- $\quad$ La concordancia con la política editorial de la revista

- La relevancia del tema tratado

- Calidad en el desarrollo del tema tratado

- $\quad$ El seguimiento a las normas de publicación (formato APA, 2011)

2. Una vez recibido el manuscrito y cumplidas los criterios de evaluación editorial el manuscrito pasa por las siguientes etapas:

- Carta de recepción del manuscrito al autor/es.

- $\quad$ Evaluación por dos especialistas (Comité de Revisores Nacional e Internacional).

- Información del comité editorial a los autores sobre la aceptación, aceptación con modificaciones o rechazo.

- Revisión de la corrección por el Comité Editorial.

- Una vez que el manuscrito es aprobado por el Comité Editorial se envía a imprenta.

- Las pruebas de imprenta son revisadas por el Comité Editorial y por el autor principal del manuscrito.

- Aprobadas las correcciones de imprenta son enviadas para su publicación.

Estructura general de los artículos

- $\quad$ Título (español e inglés).

- $\quad$ Nombre autor(es), e-mail y filiación institucional.

- Resumen en castellano (Máximo 250 palabras)

- $\quad$ Resumen en inglés (Abstract, máximo 250 palabras).

- $\quad$ Palabras claves en castellano e inglés (entre 3 y 6 palabras)

- Introducción: Breve definición del problema, investigaciones relevantes y perspectiva teórica.

- Método: Incluye sujetos, instrumentos, técnicas y procedimientos. En el caso de estudios clínicos de caso(s) puede incluirse en este acápite la descripción de caso.

- Resultadosy/o análisis del material: Presentación de los análisis cuantitativos y/o cualitativos (con gráficos y tablas, si se requiere).

- Discusión: Análisis teórico de los resultados.

- Referencias bibliográficas. 
Normas de citas bibliográficas (ejemplos)

Artículos

Sánchez, F.; Bardales, M. y Perales M. (1999). Percepción del clima organizacional en un grupo de trabajadores del Hospital Víctor Larco Herrera. Revista Peruana de Psicología, 4(8), 187-194.

Libros:

Delgado, H. (1962). Contribuciones a la psicología y la psicopatología. Lima: Editorial Peri-Psyches.

Capítulo de libro:

Spielberger, C. D., Reheiser, E. C., Owen, A. E. \& Sydeman, S. J. (2003). Measuring psychological vital signs of anxiety, anger, depression, and curiosity in treatment planning and outcome assessment. En M. Maruish (Ed.), The use of psychological testing for treatment, planning and outcomes assessment (3ra. Edición) (pp. 421-447). Hillsdale, NJ: Lawrence Erlbaum.

Artículos electrónicos con DOI (Digital Object Identifier)

Soto-Añari, M. \& Cáceres-Luna, G. (2012). Funciones ejecutivas en adultos mayores alfabetizados y no alfabetizados. Revista Chilena de Neuropsicología, 7(3), 127-133. doi: 10.5839 .0703 .06

Artículos electrónicos sin DOI

Muratori, M., Delfino, G. \& Zubieta, E. (2013). Percepción de anomia, confianza y bienestar: la mirada desde la psicología social. Revista de Psicología, 31(1), 129-150. Recuperado de: htpp://revistas.pucp.edu.pe/index.php/psicología/ article/view/6373/6427 
